San Jose State University

SJSU ScholarWorks

Master's Theses

Master's Theses and Graduate Research

Fall 2019

\title{
Observations of Fire Behavior on a Grass Slope During a Wind Reversal
}

Dianne Hall

San Jose State University

Follow this and additional works at: https://scholarworks.sjsu.edu/etd_theses

\section{Recommended Citation}

Hall, Dianne, "Observations of Fire Behavior on a Grass Slope During a Wind Reversal" (2019). Master's Theses. 5063.

DOI: https://doi.org/10.31979/etd.9g2s-fd75

https://scholarworks.sjsu.edu/etd_theses/5063

This Thesis is brought to you for free and open access by the Master's Theses and Graduate Research at SJSU ScholarWorks. It has been accepted for inclusion in Master's Theses by an authorized administrator of SJSU ScholarWorks. For more information, please contact scholarworks@sjsu.edu. 

REVERSAL

\author{
A Thesis \\ Presented to \\ The Faculty of the Department of Meteorology and Climate Science \\ San José State University \\ In Partial Fulfillment \\ of the Requirements for the Degree \\ Master of Science
}

by

Dianne Hall

December 2019 
(C) 2019

Dianne Hall

ALL RIGHTS RESERVED 
The Designated Thesis Committee Approves the Thesis Titled

OBSERVATIONS OF FIRE BEHAVIOR ON A GRASS SLOPE DURING A WIND REVERSAL

by

Dianne Hall

APPROVED FOR THE DEPARTMENT OF METEOROLOGY AND CLIMATE SCIENCE

SAN JOSÉ STATE UNIVERSITY

December 2019

Craig Clements, Ph.D. Department of Meteorology and Climate Science

Sen Chiao, Ph.D. Department of Meteorology and Climate Science

Alison Bridger, Ph.D. Department of Meteorology and Climate Science 
ABSTRACT

OBSERVATIONS OF FIRE BEHAVIOR ON A GRASS SLOPE DURING A WIND REVERSAL

by Dianne Hall

This experiment studied fire-atmospheric interactions and wildland fire behavior on a slope. A grass slope was instrumented with both in situ and remote instruments to record both meteorological conditions and the fire behavior. A headfire was lit and allowed to burn upslope through the instruments. The data collected were analyzed to determine the fire behavior, specifically fire spread (direction and rate) and flame characteristics (length, height, and angle). During the first several minutes of the experiment, fire behavior was as expected with an upslope rate of spread at $0.1 \mathrm{~m} \mathrm{~s}^{-1}$ and flame lengths between $1 \mathrm{~m}$ and $4 \mathrm{~m}$. However, the rest of the fire burned much more slowly than expected with an upslope rate of spread of $0.02 \mathrm{~m} \mathrm{~s}^{-1}$ and flame lengths of only between $0.25 \mathrm{~m}$ and $2 \mathrm{~m}$. Backing fire behavior was observed. Lidar analysis indicated that an upper level wind surfaced during the experiment and a wind reversal occurred. During the initial part of the fire the wind was $45^{\circ}$ from upslope, so the wind and slope were mostly in alignment. During the second part of the fire, the wind was downslope, so the wind and slope were in opposition. From this experiment, we can conclude that the wind speed and direction can overcome the influence of slope on fire behavior. 


\section{ACKNOWLEDGEMENTS}

I would like to thank my Thesis Advisor, Dr. Craig Clements for exposing me to the meteorological side of firefighting. I loved being a fire fighter and came to understand fire behavior even more after joining the Fire Weather Research Lab. Dr. Clements conceived of this experiment and I enjoyed working with the lab members on this and several other fire experiments. Without the help and hard work of the past and present members of the Fire Lab, this experiment would not

have occurred, and I am so grateful for the help and support. Fort Hunter Liggett supplied the location for the experiment and went above and beyond in ensuring our success.

I would like to thank my other Thesis Committee members, Dr. Sen Chiao and Dr. Alison Bridger, for their guidance over the years with both their class instruction and with this thesis. I have learned so much from you.

To my friends and family who supported over the years, I thank you, and especially to Dr. Helen Mamarchev, without whose encouragement, this thesis would not have been completed.

This research was made possible through a Fire Grant from National Institute of Standards and Technology (NIST) 60NANB11D189, grants from the National Science Foundation (NSF) Grants AGS-0960300, AGS-1151930 and the International Association of Wildland Fire (IAWF) 2012 Graduate Scholarship. 


\section{TABLE OF CONTENTS}

List of Tables ............................................................................... viii

List of Figures................................................................................. ix

CHAPTER 1 Wildland Fire Behavior Characteristics ................................ 1

1.1 Introduction ...................................................................

1.2 Wildland Fire Behavior Characteristics....................................... 2

1.2 .1 Intensity .................................................................. 2

1.2.2 Rate of Spread...............................................................

1.2.3 Direction of Spread .......................................................... 4

1.2.4 Flame Length........................................................... 5

1.2.5 Flame Height ........................................................... 5

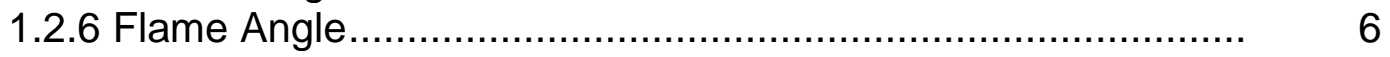

1.3 Wildland Fire Behavior Research ............................................... 6

1.3.1 Genesis of Wildland Fire Behavior Research ........................ 6

1.3.2 Fire Behavior Experiments.................................................. 7

1.3.2.1 Laboratory Studies ................................................. 7

1.3.2.2 Field Studies ............................................................

CHAPTER 2 Experimental Design, Data Collection, and Data Processing 9

2.1 Experimental Design .............................................................. 9

2.1.1 Topography................................................................... 9

2.1.2 Fuel..................................................................... 10

2.1.3 Weather .............................................................. 12

2.1.4 Fire Behavior ................................................................ 13

2.1.4.1 Fire Behavior Prediction .......................................... 13

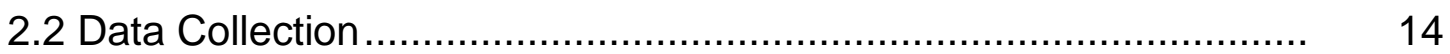

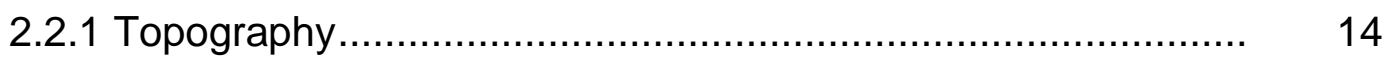

2.2.2 Fuel....................................................................... 16

2.2.2.1 Fuel Sample Collection............................................ 16

2.2.2.2 Fuel Moisture Sample Collection ................................... 17

2.2.3 Weather ......................................................................... 18

2.2.4 Fire Behavior .............................................................. 24

2.2.4.1 Ignition Line .................................................... 24

2.2.4.2 Determination of Ignition Time..................................... 25

2.2.4.3 Rate of Spread Markers ............................................. $\quad 25$

2.2.4.4 Still Photographic Sequences..................................... 26

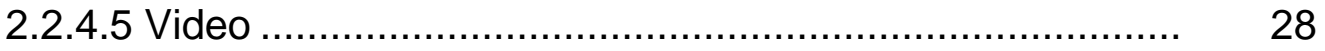

2.3 Data Processing Procedures.................................................... 29

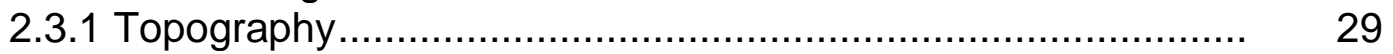

2.3.2 Fuel Analysis ........................................................... 29

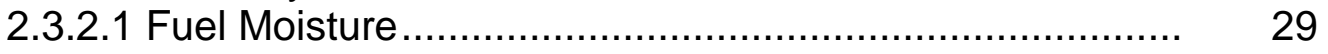




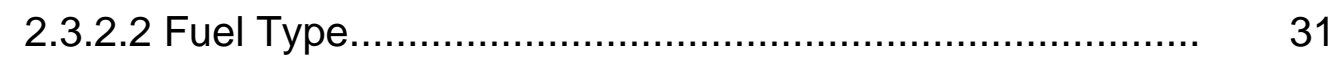

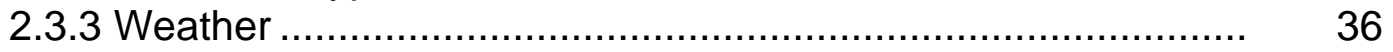

2.3.3.1 Synoptic Conditions ............................................ 36

2.3.3.2 Sounding ……..................................................... 38

2.3.3.3 Sodar ............................................................... 40

2.3.3.4 Lidar ................................................................... 40

2.3.3.5 AWS ............................................................ 42

2.3.3.6 Micromet Sonics ...................................................... 43

2.3.4 Fire Behavior ................................................................... 44

2.3.4.1 Fire Boundary Determination.................................... 44

2.3.4.2 Flame Height and Flame Length Determination ............. 51

2.3.4.3 Heat Flux .................................................................. 52

CHAPTER 3 Observed Fire Behavior..................................................... 53

3.1 Rate of Spread (ROS) ......................................................... 53

3.2 Direction of Spread ........................................................... 55

3.3 Flame Length, Flame Height, Flame Angle ................................. 57

3.4 Fire Perimeter and Fire Area ...................................................... 58

CHAPTER 4 Analysis of Fire Behavior ................................................. 61

4.1 Fire Behavior Prediction (BehavePlus) ........................................ 61

4.2 Observed vs. Predicted Fire Behavior ........................................... 63

CHAPTER 5 Summary, Conclusions, Limitations of Study, Further 65

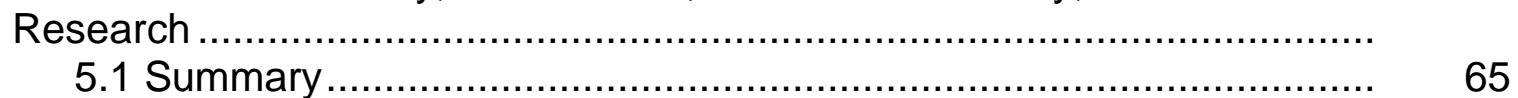

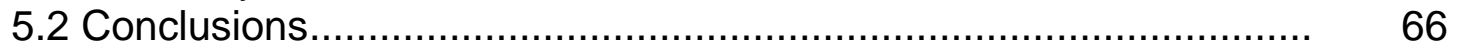

5.3 Limitations of the Study ....................................................... 67

5.4 Further Research / Next Steps ................................................... 68

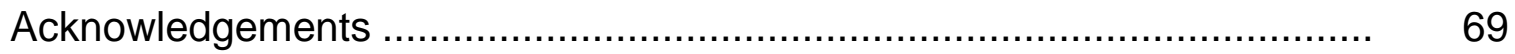

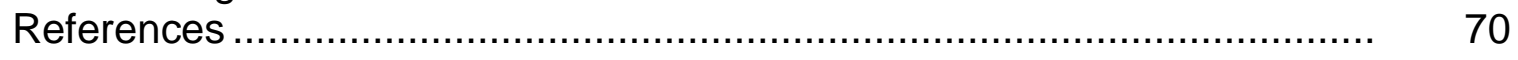

Appendices

Appendix A - Video Segment Metadata ......................................... $\quad 75$

Appendix B - Photograph / Georeferenced Photo / Fire Line Boundary 77

Appendix C - Georeference Points FHL Site 1 ................................... 89 


\section{LIST OF TABLES}

Table 1 - Geographic Instrument Selection and Data Collected ....................... 15

Table 2 - Fort Hunter Liggett Site 1 In Situ Tower Instruments......................... 22

Table 3 - Fort Hunter Liggett Site 1 Non-Tower In Situ Instruments .................. 23

Table 4 - Fort Hunter Liggett Site 1 Remote Sensing Instruments.................... 23

Table 5 - Fort Hunter Liggett Site 1 Rate of Spread (ROS) Markers .................. 25

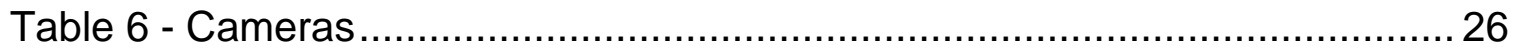

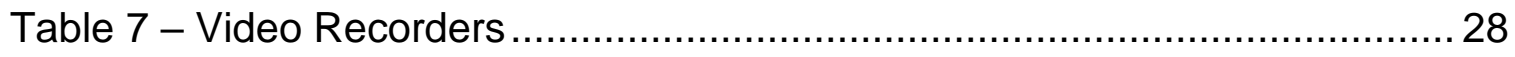

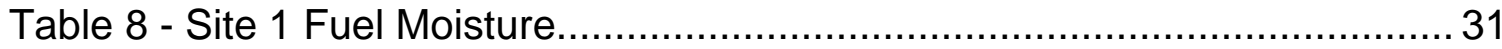

Table 9 - Biomass Fuel Loading Fort Hunter Liggett Site 1 ............................. 32

Table 10 - Video Segment Metatdata Summary …......................................... 45

Table 11 - Video Segment 1 Image Times ……….......................................... 46

Table 12 - ArcGIS Layer Definitions …........................................................ 47

Table 13 - Sample Georeference Points (Minute 4) .......................................... 49

Table 14 - Calculated Rate of Spread per minute.......................................... 54

Table 15 - Direction of Maximum Fire Spread (in degrees) …..........................56

Table 16 - Observed Flame Height, Length, and Angle at Each Minute ............ 58

Table 17 - Observed Fire Perimeter and Area at Each Minute ........................ 59

Table 18 - BehavePlus Fire Prediction for Ignition to Tower $1 \ldots \ldots \ldots \ldots \ldots \ldots \ldots \ldots \ldots . . .61$

Table 19 - BehavePlus Fire Prediction for Tower 1 to Tower 3 ........................ 62

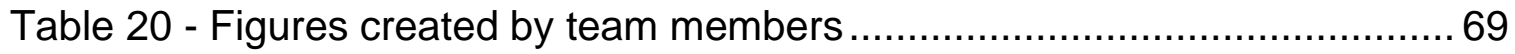




\section{LIST OF FIGURES}

Figure 1 - Fire rate of spread and direction of spread..................................... 4

Figure 2 - Flame characteristics .......................................................... 5

Figure 3 - Stony Valley experiment site ..................................................... 15

Figure 4 - Location of fuel samples site 1 ................................................ 16

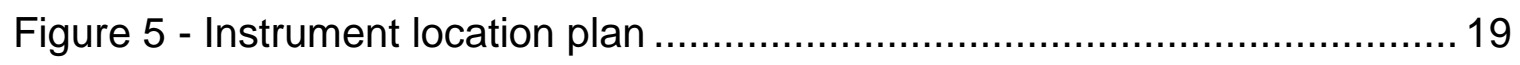

Figure 6 - Fort Hunter Liggett site 1 pre-ignition ............................................ 20

Figure 7 - Remote instrument layout Fort Hunter Liggett site 1 ....................... 20

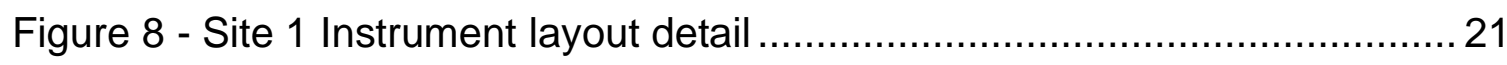

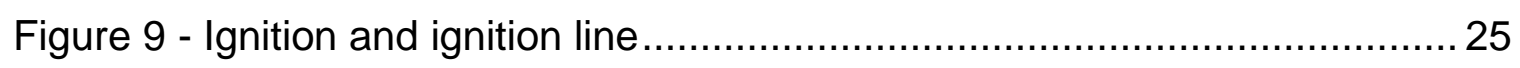

Figure 10 - Rate of spread marker stake (yellow dot) locations......................... 26

Figure 11 - Tripod \#1 perspective - north still camera ..................................... 27

Figure 12 - Tripod \#3 perspective - south still camera ................................... 27

Figure 13 - Fort Hunter Liggett site 1 tower line transect.................................29

Figure 14 - FHL site 1 fuel sample analysis................................................... 34

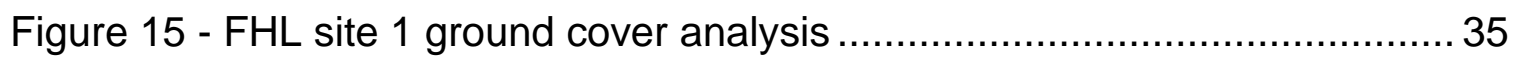

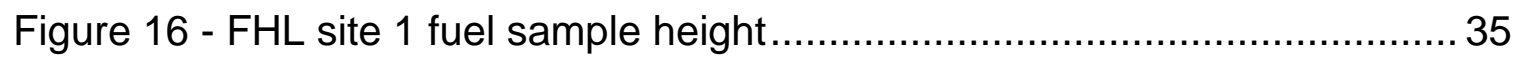

Figure 17 - $12 \mathrm{Z} 850 \mathrm{hPa}$ analysis 20 June 2012 (from NOAA)......................... 36

Figure 18 - $12 Z$ surface analysis 20 June 2012 (From NOAA) ......................... 37

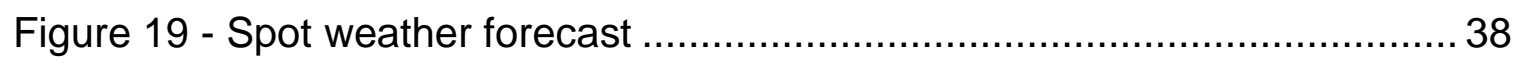

Figure 20 - Sounding wind speed (left) and direction (right) ............................. 39

Figure 21 - Sounding temperature and dew point........................................... 39 


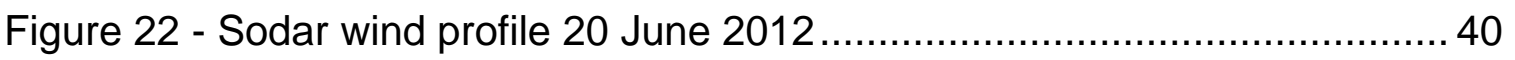

Figure 23 - Lidar RHI profile 08:32 PDT (1532 UTC) 20 June 2012 .................. 41

Figure 24 - Lidar at ignition 11:19 PDT (1919 UTC) 20 June 2012 .................. 41

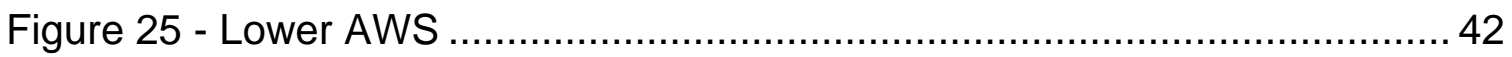

Figure $26-10 \mathrm{~m}$ wind speed and direction for the 3 towers ........................... 43

Figure 27 - Sample georeferenced image (minute 4) …................................ 49

Figure 28 - Fire boundary - shown as a black line for minute $4 \ldots \ldots \ldots \ldots \ldots \ldots \ldots \ldots . . . . . . . . . .50$

Figure 29 - FHL site 1 fire boundaries at each minute ................................... 51

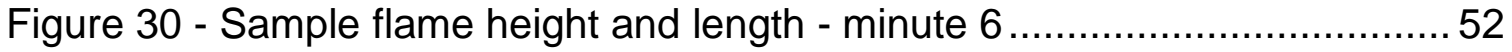

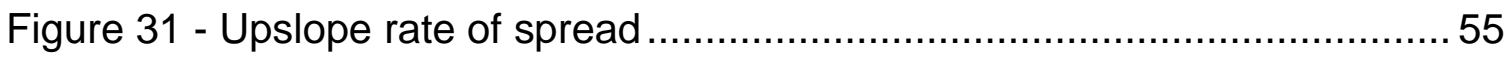

Figure 32 - Location of maximum fire rate of spread at each minute................. 57

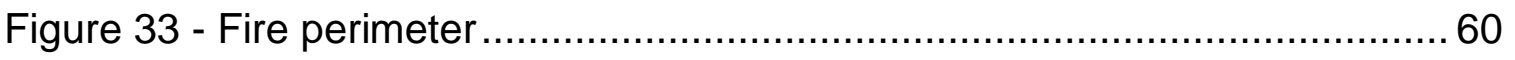

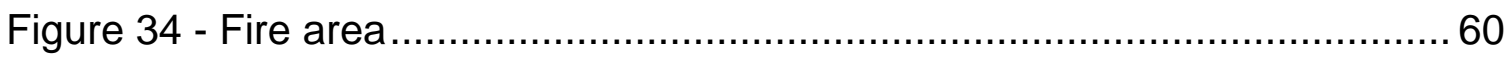




\section{CHAPTER 1 \\ Wildland Fire Behavior Characteristics}

\subsection{Introduction}

Fire is a complex chemical reaction involving rapid oxidation of fuel to generate heat and light. This relationship is often represented as a fire triangle consisting of heat, fuel and oxygen, or as the fire tetrahedron consisting of these three factors with the addition of the chemical chain reaction (IFSTA 2013). Wildland fire is a subset of fire that occurs in undeveloped areas (NWCG 1996). Wildland fire behavior results not only from complex reactions to create fire itself, but is also influenced by the interactions between fuels, topography, and weather. This relationship between fuels, topography and weather is referred to as the wildland fire triangle (NWCG 1996).

Fire behavior on sloped terrain differs from that on flat ground as both the intensity and the rate of spread (ROS) increase as the slope angle increases (McArthur 1967; Rothermel 1972; Linn 2010). While there have been both laboratory studies (Weise 1996, 1997) and field studies (Clements and Seto 2015) focused on fire behavior on slopes, there have been comparatively few field studies that have measured the fire's rate of spread simultaneously with micrometeorology of the near surface environment at the fire front. The FireFlux and FireFlux II experiments measured fire-atmosphere interactions of a head fire passage in grass fuels with no slope (Clements 2006, Clements 2007, Clements 2008, Clements et al. 2019). Additionally, most field studies have been conducted utilizing backing fires, i.e., fires that spread downslope or into the 
wind, rather than heading fires, i.e., fires that spread into the wind or upslope; thus, the data obtained do not represent the actual atmospheric environment of wildfires.

\subsection{Wildland Fire Behavior Characteristics}

Wildland fire behavior is generally described in terms of intensity, rate of spread, and direction of spread (Rothermel 1972). Other useful measures of wildland fire behavior are flame length, flame height, and flame angle.

\subsubsection{Intensity}

There has been a great deal of discussion on how to define and measure fire intensity, and this has resulted in some confusion about the meaning of the term. Fire intensity can be broadly thought of as the energy released during a fire. However, fire intensity, fireline intensity, reaction intensity, temperature, residence time and radiative energy are just a few of the metrics that have been to describe the energy released from a fire (Keeley 2009).

In physics, 'intensity' is defined as the time-averaged energy flux (Bird et al. 1960). Since flux is a measure of the flow rate per unit area, intensity becomes the time-averaged energy flow rate per unit area. This means that intensity describes the amount of energy transferred as the fire moves. This energy is transferred into the environment (released) as organic matter pyrolyzes and the resulting vapors combust. In an environment absent of wind, the energy transfer is through radiation and is measured as radiative flux. When wind occurs in the same direction as fire spread, convective energy transfer becomes a factor to 
consider and convective flux must be added to the fire behavior model (Frandsen 1971; Rothermel 1972). When the energy measured is restricted to the infrared spectrum, the energy transport can be described as radiative heat flux.

The closest alignment in fire behavior with the meaning of intensity as described in physics is Rothermel's term, 'reaction intensity' (Rothermel 1972) Reaction intensity is defined as the heat release rate per unit area $\left(\mathrm{W} \mathrm{m}^{-2}\right)$ at the fire front, and is the heat source for Rothermel's fire spread model.

Byram (1959) defines intensity as 'fireline intensity'. Fireline intensity is the rate of heat transfer per unit length of the fire line $\left(\mathrm{kW} \mathrm{m}^{-1}\right)$. Both conductive and radiative heat transfer are included in Byram's fireline intensity measure.

However, there are several fire effects that cannot be fully predicted using either Rothermel's or Byram's definitions of intensities. For example, neither of these measures alone is a predictor of how much total heat the vegetation will be exposed to during the fire front passage. The total heat exposure is necessary to understand the amount of vegetation that will be consumed or damaged as the fire front passes. Another concern with both of these definitions is that the resulting values are difficult to translate into visual indicators and thus do not serve as useful tools for assessing fire behavior by on-the-ground fire fighters at active fires.

\subsubsection{Rate of Spread}

Show (1919) proposed three different ways to measure the rate of spread of a fire: linear distance from the point of origin, area burned, and fire perimeter 
(Figure 1). Linear distance from the point of origin helps determine the rate of spread at the fire front and thus determines the type of firefighting resources (manpower, engines or aircraft) required. Fire perimeter is generally used to determine the number of firefighting resources required to manage the fire since the resources required are proportional to the perimeter (Potter 2012a). Area burned is useful for determining the total number of acres affected and thus the resources required to rehabilitate the fire area.

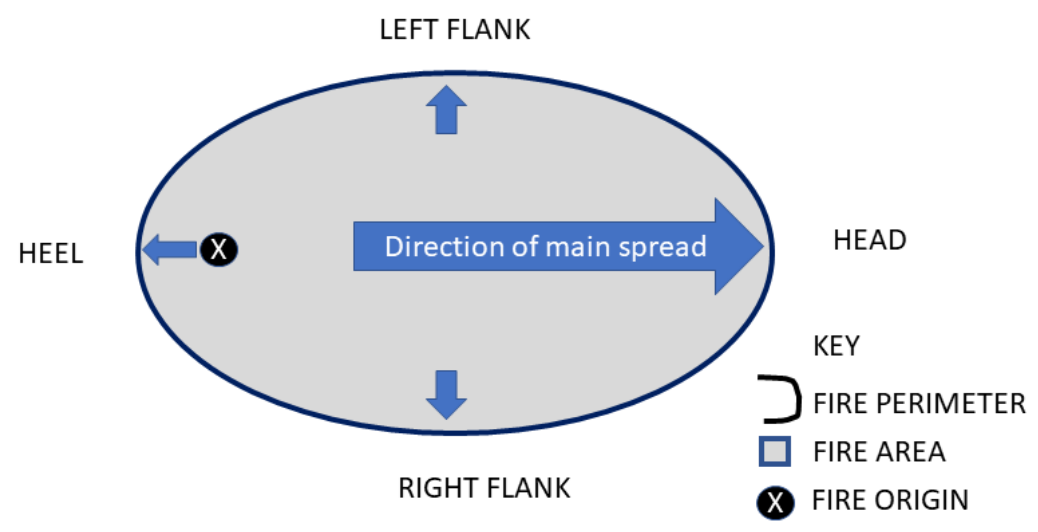

Figure 1 - Fire rate of spread and direction of spread

\subsubsection{Direction of Spread}

The direction of spread is measured on four flanks: head, left, right, and heel (Figure 1). The head of the fire is the main direction of spread and is generally the direction of most rapid fire spread. The head fire direction of spread is generally in the direction of the wind and upslope. The left flank and right flank are progressions that are perpendicular to the main fire spread. The heel of the fire proceeds in the opposite direction of the head fire, is slower, and generally 
exhibits backing fire behavior in that the fire progresses into the wind or downslope.

\subsubsection{Flame Length}

Flame length (Figure 2) is the distance of the flame from the base of the flame to the tip of the flame. If the flame is not influenced by wind, the flame will be vertical, and the flame length will be the vertical length of the flame. However, if the flame is influenced by wind, the flame is deflected from the vertical and the flame length will increase and become larger than the vertical distance. Flame length helps determine the heat transfer and thus the rate of spread of a fire (Weise 1996).

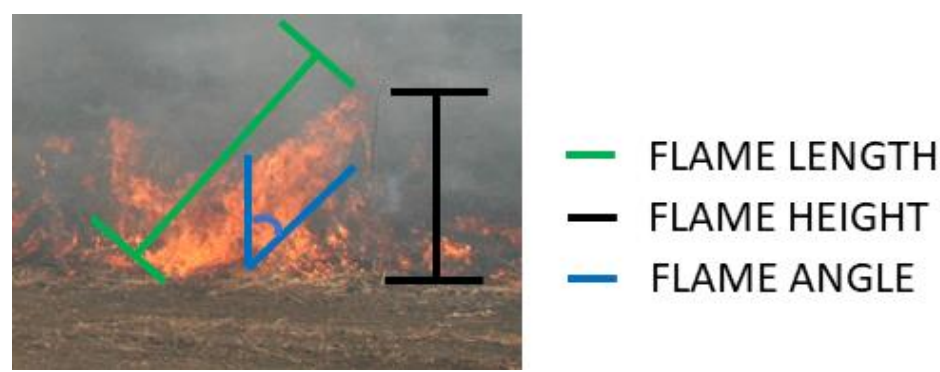

Figure 2 - Flame characteristics

\subsubsection{Flame Height}

Flame height (Figure 2) is the vertical distance from the base of the flame to the tip of the flame. Flame height and flame length will be the same if the fire is not influenced by wind; however, under the influence of wind, the flame will be deflected from the vertical and the flame length will increase while the flame height may stay the same. 


\subsubsection{Flame Angle}

When a flame is influenced by wind, the flame will be deflected from the vertical. Flame angle (Figure 2) is measured from a vertical line to the middle of the flame (Weise 1996). Flame angle is linked with flame length when determining the radiative heat transfer of fires to unburned fuels.

\subsection{Wildland Fire Behavior Research}

\subsubsection{Genesis of Wildland Fire Behavior Research}

The United States Forest Service (USFS) established the Priest River Forest Experiment Station to study forest fire behavior after the Big Burn of 1910 burned 3 million acres of forest in Northern Idaho, Western Montana, and Eastern Washington in the United States and Southeast British Columbia in Canada. 87 people were killed in this fire, including 78 fire fighters. The goal of the research was to predict the conditions for increased fire danger and thus serve as a warning system for the USFS. The National Fire Danger Rating System (NFDRS) was one of the results of this research (Hardy 1977). The NFDRS uses weather observations, fuel type, and fuel condition to predict the potential fire intensity in specific geographic areas in the USA (Schlobohm 2002).

The importance of understanding wildland fire behavior was reemphasized in 1949 after 13 firefighters died while trying to outrun a fire front that was accelerating up a slope in the Mann Gulch Fire in Montana, USA. The supervisor, Wagner Dodge, lit a fire around him. He survived as the main fire went around the burned-out area he had created. Two other firefighters survived 
because they were able to get to a rockslide on the other side of the ridge. All three survived because they were able to break the wildland fire triangle by removing the fuel (MacLean 1992). After this tragedy, the US Forest Service set up three additional research labs: Macon, Georgia in 1959; Missoula, Montana in 1960; and Riverside, California in 1962, to study fire behavior.

\subsubsection{Fire Behavior Experiments}

\subsubsection{Laboratory Studies}

Much fire behavior experimentation has been done in laboratories (Fons 1946; Anderson et al. 1966; Rothermel and Anderson 1966; Thomas 1971; Albini 1976; Nelson and Adkins 1988; Wolff 1991; Beer 1993; Weise 1996; Wu et al. 2000; Mendes-Lopes et al. 2003; Anderson et al. 2006; Dupuy et al. 2011). This research has contributed to understanding the behavior of fire in a laboratory environment but does not take into account fire-atmospheric interactions.

\subsubsection{Field Studies}

Collecting data sets for actual wildland fire is difficult due to the environmental and logistical constraints. Wildland fires generally occur in very complex terrain which increases the variability of the input conditions and further complicates the fire behavior analysis. It is difficult to collect the initial conditions at the time and location of the ignition since fires may go undetected for a period of time, so the initial conditions are often not known.

Show (1919) performed initial field experiments to document the effect of wind on fire spread. However, although the experiment sites had different 
slopes, he averaged the slopes of all the sites and used this average for his calculations, thus removing slope as a variable. Gray (1933) determined that fuel composition, fuel moisture, air movement, and topographic slope were independent variables affecting the rate of spread of a fire. Curry and Fons $(1938,1940)$ determined a curvilinear relationship between wind and slope. At low wind speeds, slope is a minor factor, but as the wind speed increases, slope increasingly becomes important. If the wind is in the direction of upslope, then the influence is maximized. McArthur $(1967,1969)$ studied several grassfires in Australia and observed relationships between weather and fire behavior. Thomas $(1967,1971)$ studied both laboratory and controlled burns in Australia and developed rate of spread predictions.

Several field experiments have been conducted more recently including: FireFlux, Houston, TX, 2006; FireFlux II, Houston TX, 2013; RxCADRE, Elgin Airforce Base, FL, 2008, 2011, 2012; Camp Parks, Dublin, CA, 2010, resulting in an increased understanding of fire-atmospheric interaction on fire behavior (Clements, 2007, 2014; Ottmar, et al., 2016; Clements and Seto, 2015). Of these experiments, all but the Camp Parks experiment were conducted on flat terrain, so slope had not been a factor until the Camp Parks experiment. The Camp Parks experiment was on a slope and was a test case to determine how to instrument a fire with in situ instruments. Many of the lessons learned in that experiment were used to improve the experimental design of the Fort Hunter Liggett (FHL) slope fire experiment, which is the topic of the current work. 


\section{CHAPTER 2 \\ Experimental Design, Data Collection, and Data Processing}

\subsection{Experimental Design}

The goal of this experiment was to observe fire behavior for a head fire on a slope, and to generate data sets for that fire. These data sets include

measurements of the three factors that dictate wildland fire behavior: topography, fuels, and weather. Additionally, the data sets include the measurements of the resulting fire behavior: rate of spread, flame height, flame length, flame angle, and fireline intensity. Since fire-atmospheric interactions were the focus of this experiment, the other variables influencing fire behavior were to be kept as constant as possible throughout the experiment.

\subsubsection{Topography}

The topography is the lay of the land and is the least variable factor in wildland fire behavior (NWCG 1996). Topography of an area is not generally thought of as variable because large influences such as earthquakes, slides, or mechanical grading are required to change it. Topographic features of interest are the slope angle and the aspect.

When fire changes from burning on flat land and starts burning up a slope, the rate of spread increases. When the slope reaches $10^{\circ}$, the rate of spread is approximately double that on flat land. The rate of spread doubles again on $20^{\circ}$ slopes (McArthur 1967). When the slope angle reaches $24^{\circ}$, more of the flame is in direct contact with the slope and the flame is considered attached to the slope. This increases the rate of heating of the fuels and fire behavior becomes 
explosive with dramatic increases in rate of spread upslope (Wu et al. 2000, Dold et al. 2009).

The aspect refers to the Cartesian direction the slope faces. In the northern hemisphere, south aspect slopes receive the most direct sunlight as compared with other aspects (NWCG 1996). This increased insolation causes southern and western aspect slopes to be drier, resulting in generally lighter fuel loads. The drier, lighter fuel load is more available to burn and can contribute to rapidly spreading fires (NWCG 1996).

A uniform slope was required to control for the variability of a change in slope on fire behavior. A hill with a $20^{\circ}$ slope was desired for the experiment to give a high rate of spread, but keep the fire behavior below the explosive level. A south or west aspect was desired to ensure a light and uniform fuel load.

\subsubsection{Fuel}

The fuel is the vegetation that will burn. Wildland vegetation types vary from light grasses to shrubs to forests (NWCG 1996). The intensity of the fire varies with both the amount of fuel, or fuel loading, and with the characteristics of the fuel (Rothermel and Anderson 1966). There are numerous characteristics, but those that seem to influence fire behavior the most are fuel moisture content, chemical properties such as oil content, and available surface area (Anderson 1982). The fuel is subject to seasonal variation as more fuels tend to be dryer and ready to burn, referred to as fuel availability, in the summer and fall than during winter and spring (Scott and Burgan 2005). The various types of fuels 
have been studied and similar characteristics were found. Fuels with similar characteristics were grouped together and classified as a fuel model since they would exhibit similar fire behavior. Thirteen (13) fuel models were originally developed (Anderson 1982) and then these models were further refined and expanded upon into the 42 Standard Fire Behavior Fuel Models (Scott and Burgan 2005).

Fuel is moderately variable as generally the same fuel will be found from year to year in the same geographic area, but the fuel moisture content will vary as the drying season progresses and thus change the availability of the fuel.

A uniform fuel bed was desired to control for fuel variability. Grass is a very common fuel and it is easy to see its underlying topography. Grass fires are easy to ignite, burn quickly, and are relatively easy to control once lit, so a grass fuel bed was desired. Samples of grass from the experiment site need to be collected and analyzed to determine the fuel characteristics. Fuel properties of interest are: fuel bed depth, the average height of the fuel above the ground; fuel loading, the amount of fuel present expressed as weight per unit area; and percentage fuel moisture content, the amount of moisture present in a fuel expressed as a percentage fuel after it has been dried in an oven. Another reason to select a grass fuel is that it represents a light flashy fuel which is a common denominator of fatality fires (Wilson 1977). An understanding of the fire behavior in these fuel types may lead to increased fire fighter safety (Butler, 2014). 


\subsubsection{Weather}

Weather is the state of the atmosphere and is described in terms of the shortterm (minutes to days) variations in the atmosphere such as temperature, humidity, precipitation, cloudiness, visibility, and wind (American Meteorological Society 2019).

The weather factors that most strongly influence fire behavior are wind speed, wind direction, temperature, humidity, and insolation (NWCG 1996). Wind speed influences the rate of spread of the fire. Wind direction influences the direction of fire spread. Air temperature, humidity, and insolation affect the fuel moisture and thus the availability of the fuel to burn (Potter 2012a). Weather is the most variable of the three wildland fire factors.

The ideal conditions for the experiment would be to have no wind. Then the wind could be removed as a factor in the fire behavior calculations, and the direction of spread of the fire would be due only to other factors, in particular -

slope. The next most desirable condition would be to have the wind aligned with the upslope direction. The theory is that the slope becomes a multiplier for the effect of the wind. When the wind is at an angle to the slope, then the direction of fire spread is affected by both the wind and the slope (McArthur 1967; Rothermel 1972).

Since the mechanisms of fire-atmospheric interactions are only partially understood (Werth et al. 2011, Potter, 2012a), a wide range of instruments from the synoptic scale to the micrometeorological scale were selected to obtain as 
much meteorological data as possible. Both in situ instruments and remote sensing instruments were deployed due to the possibility of the in situ instruments being damaged during the fire front passage, as experienced in the Camp Parks experiment (Clements and Seto 2015).

The in situ instruments included: 3-D sonic anemometers; radiometers; thermocouple arrays; pressure sensors, and a radiosonde balloon sounding system. The remote sensing instruments included: a Doppler Wind Lidar; a microwave temperature profiler; and an acoustic wind profiler.

\subsubsection{Fire Behavior}

The rate of spread (ROS) and direction of spread of the fire front can be obtained from video recordings and still camera photographs of the fire. The flame characteristics of flame height, flame length, and flame angle can be estimated from the still camera photographs. Both radiative and convective heat transfer, generally combined and expressed as fire line intensity (heat per unit length of the fire line per second) (Byram 1959), can be calculated from the radiative flux and heat flux measurements from the radiometers and sonic anemometers.

\subsubsection{Fire Behavior Prediction}

Papadopoulos and Pavlidou (2011) described several software programs currently available to predict wildland fire behavior. The program BehavePlus (Andrews et al., 2005) was selected to provide a prediction of the fire behavior to aid in the instrument placement during the experimental design. The actual 
results could also then be compared with the prediction. BehavePlus was selected because it is a simple fire behavior prediction program that runs on a desktop or laptop computer and is commonly used in the field during campaign fires. An app version that runs on the iPhone (Covele 2008) is also available.

Given a set of easily measured inputs for topography, fuel and weather, BehavePlus predicts several properties of fire behavior such as the rate of spread, the direction of spread, the flame height, and the fire intensity. The slope angle (in degrees) and slope aspect are obtained from the topographical maps. The fuel model number and fuel moisture percentage are provided by the fuel sample analysis, and the horizontal wind speed and direction come from the meteorological instruments surrounding and within the experiment plot.

\subsection{Data Collection}

The instruments required to collect data to measure the topographic features, fuel characteristics, atmospheric condition, and fire behavior are detailed in this section.

\subsubsection{Topography}

The experimental site selected was a small ridge in the Stony Valley of Fort Hunter Liggett, Monterey County, California (Figure 3). The ridge was grass covered, had a west aspect, and had slope angles between $10^{\circ}$ and $20^{\circ}$.

The overall topographical data was obtained from the USDA (United States Department of Agriculture) Alder Peak Quadrangle Topographic Map and from GIS (Geographic Information Systems) data supplied by Fort Hunter Liggett. The 
detailed instrument locations, topographic feature locations, and fire ignition line location were obtained using GPS (Global Positioning System) instruments detailed in Table 1.

Table 1 - Geographic Instrument Selection and Data Collected

\begin{tabular}{|c|c|c|}
\hline Data Type & Instrument & Data Collected \\
\hline $\begin{array}{c}\text { Geographic } \\
\text { Data }\end{array}$ & Trimble GPS & $\begin{array}{c}\text { Boundaries of patches of different } \\
\text { fuel type, fuel sample locations, } \\
\text { instrument locations, marker } \\
\text { locations }\end{array}$ \\
\hline $\begin{array}{c}\text { Geographic } \\
\text { Data }\end{array}$ & $\begin{array}{c}\text { Garmin GPS } \\
\text { Model 60CSx }\end{array}$ & Fire ignition line \\
\hline
\end{tabular}

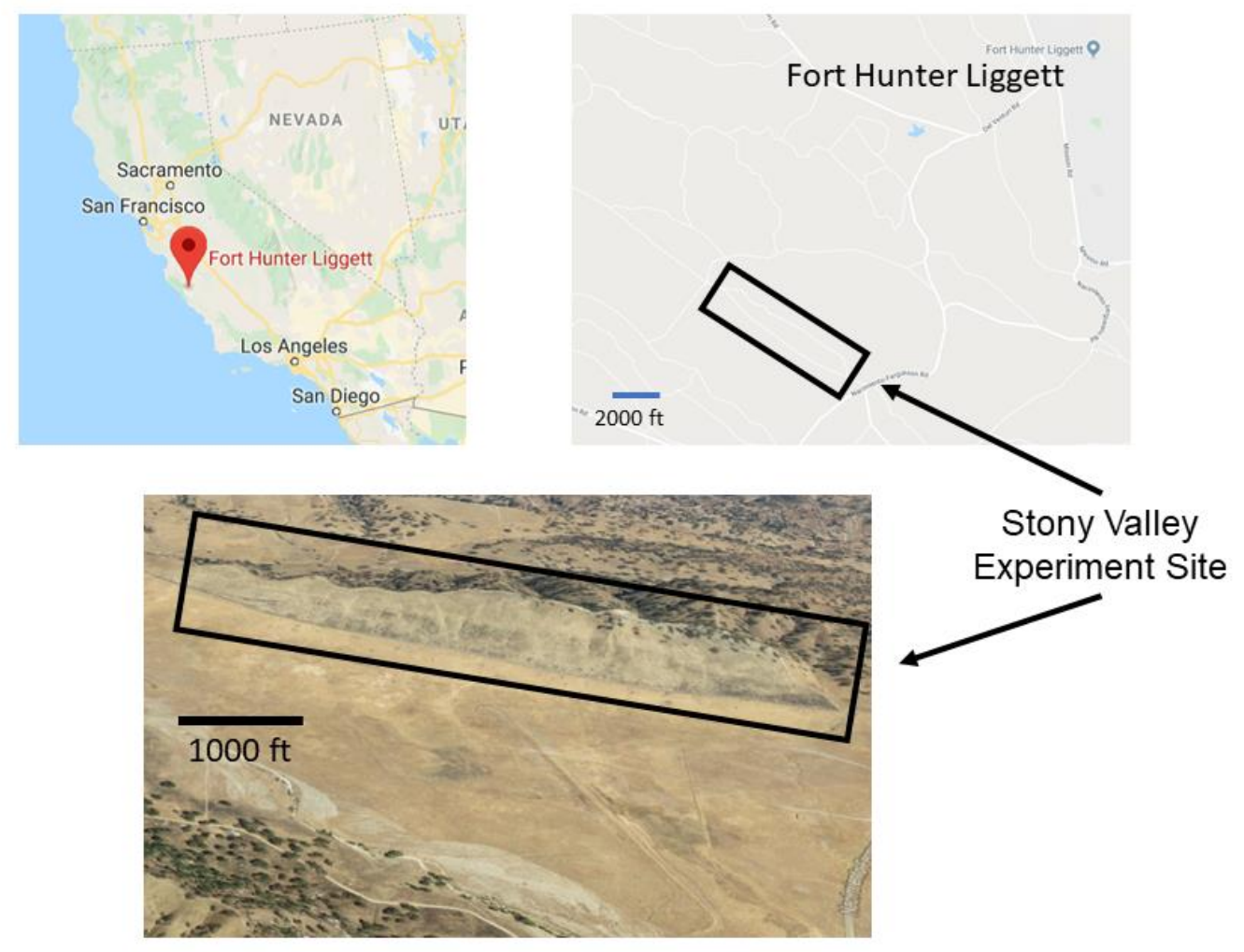

Figure 3 - Stony Valley experiment site 


\subsubsection{Fuel}

\subsubsection{Fuel Sample Collection}

Twenty (20) plots were selected from within the experiment site for sampling to determine the fuel characteristics. These plots were to the south of the line defined by 3 in situ towers which held the meteorological instruments and were in a line from the base of the hill to the top of the hill. The fuel sampling locations for plots 1-18 are shown in Figure 4. GPS locations of Plot 19 and Plot 20 were not obtained, but they were located $30 \mathrm{ft}(10 \mathrm{~m})$ east of the original fuel sampling line coming back down the hill. Each plot was spaced $30 \mathrm{ft}(10 \mathrm{~m})$ from the previous plot further up the hill, measured from the lower edge of the sample square to the lower edge of the next sample square. A GPS location of each plot was recorded using the lower left corner of the plot frame as facing up the hill, or the NW corner of the plot.

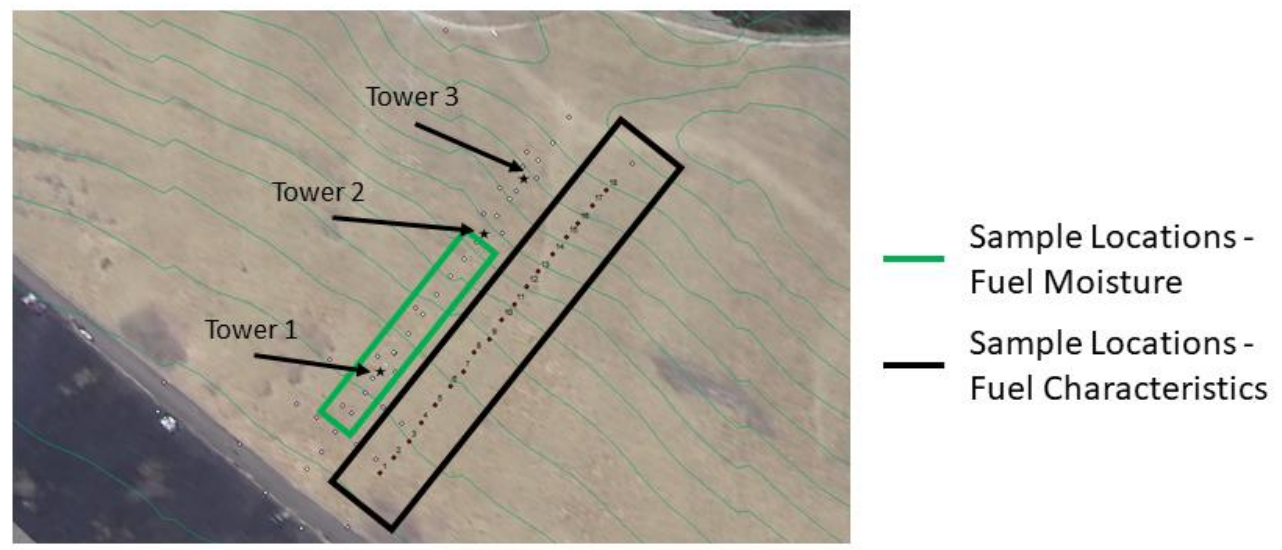

Figure 4 - Location of fuel samples site 1

Due to the amount of fuel and the observed uniformity of the fuel, only a half meter square sample size was required for each fuel sample plot. A $0.5 \times 0.5 \mathrm{~m}$ 
PVC frame was placed on the ground at each plot location, resulting in a sampling area of $0.25 \mathrm{~m}^{2}$. The vegetation bounded by the PVC fame was then collected. Only the vegetation that was in the vertical column created by the frame was collected. For example, if the grass roots were outside the frame and the grass stem was partially inside the frame and partially outside the frame, the portion of grass stem that was within the frame was collected and the portion of grass stem outside the frame was not collected. Since this site contained only grass, it was not necessary to separate the vegetation types into grass, forbs (herbaceous flowering plant), shrubs, etc. Only the vegetation from above the soil layer was collected, i.e., no soil or roots of the grass were collected. Each sample was placed in a brown paper bag and labeled with the collection site and plot number.

The fuel sample collection and subsequent fuel loading calculations for the fuel samples were performed by a team from the US Forest Service Pacific Northwest Research Station, Pacific Wildland Fire Sciences Laboratory. The collection was performed on 30 May 2012.

\subsubsection{Fuel Moisture Sample Collection}

Ten (10) fuel samples were collected on the morning of the experiment, June 20, 2012, at 09:45 PDT (16:45 UTC). Each fuel sample was collected from one of the first ten orange marker stakes on the tower line on the slope (Figure 4). The exact locations were not significant, as the intent was to obtain an approximate average fuel moisture content for the fuel bed. The locations of 
these markers are shown in Figure 7. Each sample consisted of a one gallon, plastic, sealable bag filled with grass clippings from the experiment site. Each bag was tightly sealed at the site and then stored in a cool place until it could be processed. The amount of fuel in each bag varied from $21 \mathrm{~g}$ to $35 \mathrm{~g}$. The amount was not material as long as each bag was reasonably full since fuel moisture calculations depend only on the difference in weight between the undried sample and the dried sample.

\subsubsection{Weather}

The experiment measured weather conditions from synoptic scale to micrometeorological scale. For the synoptic scale, a balloon radiosonde system was launched on the morning of the experiment, a fire spot weather forecast was requested from the National Weather Service (NWS) in Monterey, CA, and the NWS upper level maps were obtained for the day of the experiment.

For the local weather conditions, two standard Automated Weather Stations (AWS) were deployed, one at the bottom of the slope and one at the top of the slope. The CSU-MAPS (California State University Mobile Atmospheric Profiling System) designed by Clements and Oliphant (2014) was also deployed. This system includes a scanning doppler wind Lidar (Llght Detection And Ranging), a microwave profiling radiometer, both deployed west of the experiment site, and a $32 \mathrm{~m}$ micromet tower deployed south of the experiment site. A doppler mini sodar (SOnic Detection And Ranging) was also deployed south of the experiment site. The data collected by micromet tower was not used in this analysis. Sonic 
anemometers mounted on each of the three towers within the experiment site measured the micrometeorological conditions of temperature and $u, v$, and $w$ winds within the fire.

The planned instrument locations are shown in Figure 5, the location of the remote sensing instrument in Figure 7, and instruments within the plot in Figure 8. A brief description of the specific instruments deployed and the data each was intended to collect are detailed in Table 2, Table 3, and Table 4. A photo of the completely instrumented site before ignition is shown in Figure 6.
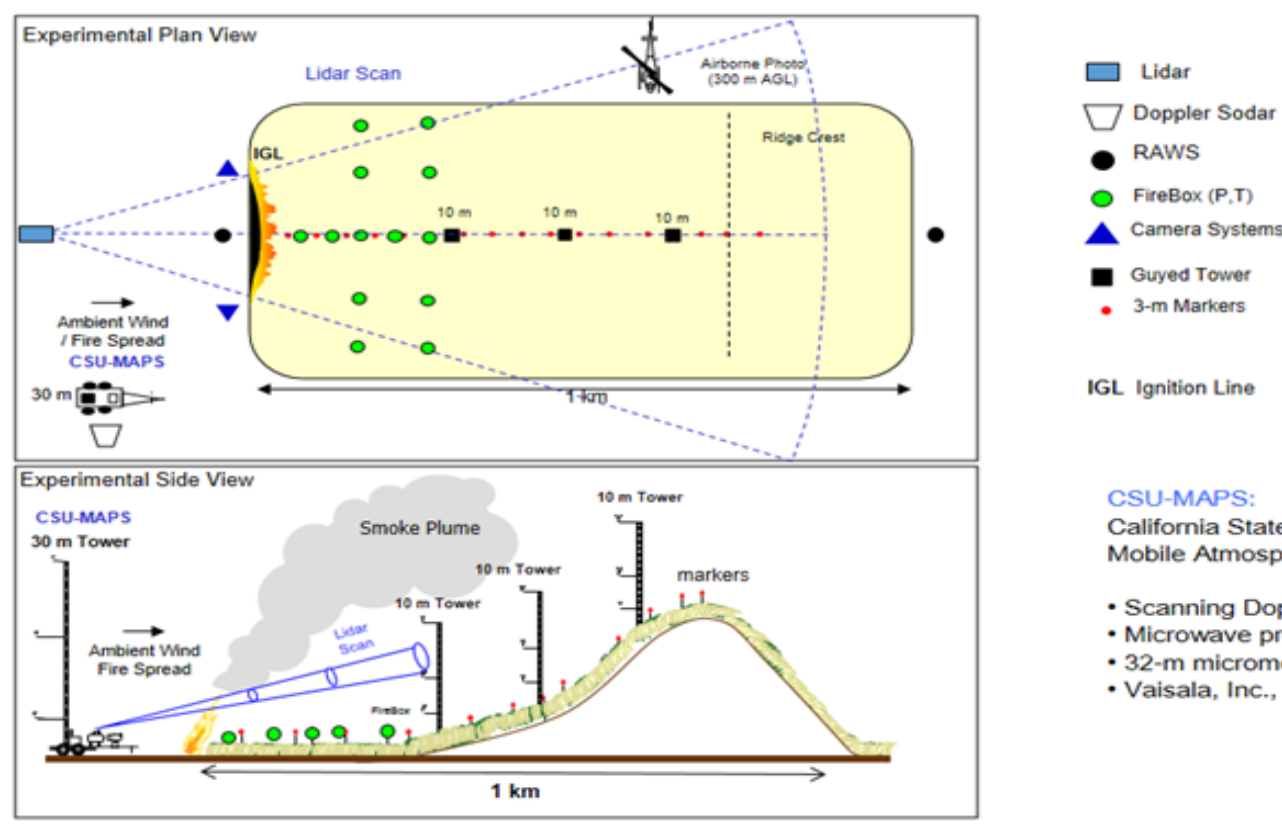

IGL Ignition Line

CSU-MAPS:

California State University-

Mobile Atmospheric Profiling System

- Scanning Doppler Wind Lidar

- Microwave profiling radiometer

- 32-m micromet tower / trailer

- Vaisala, Inc., Radiosonde System

Figure 5 - Instrument location plan 


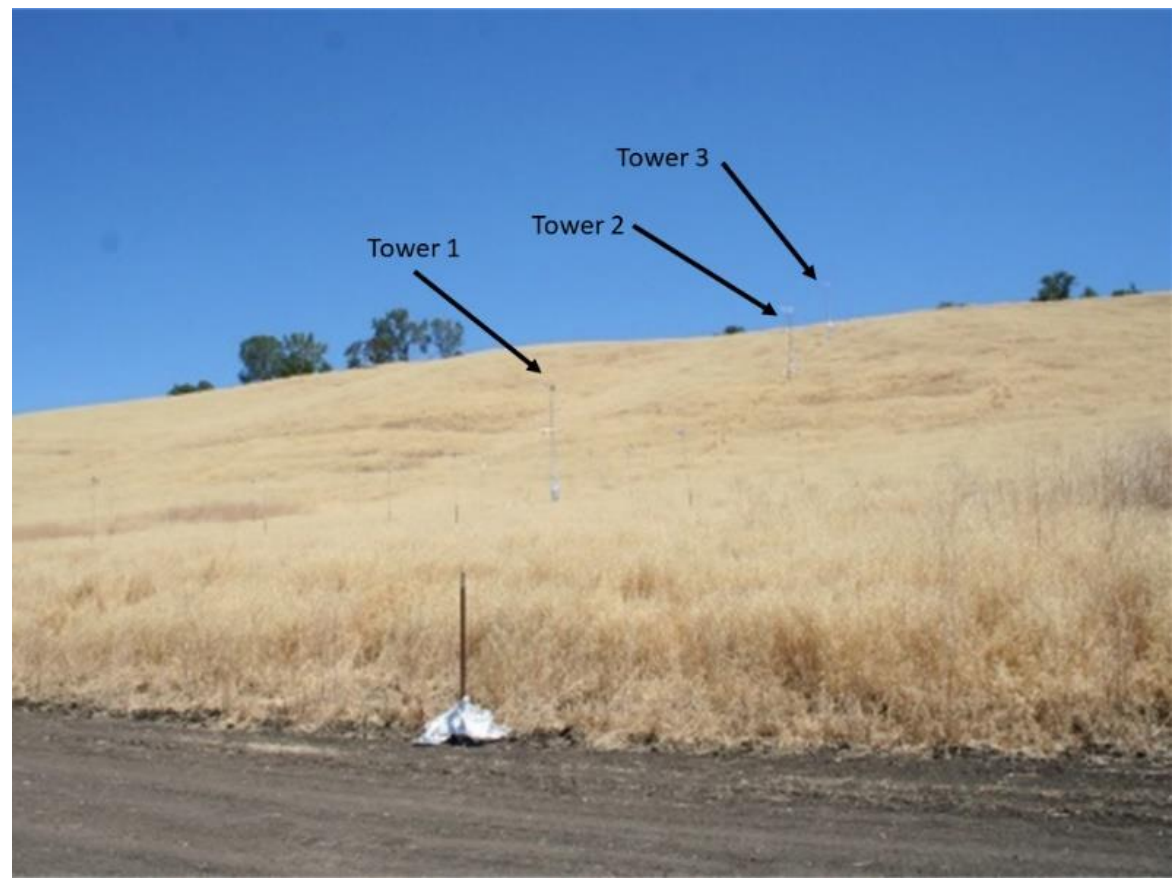

Figure 6 - Fort Hunter Liggett site 1 pre-ignition

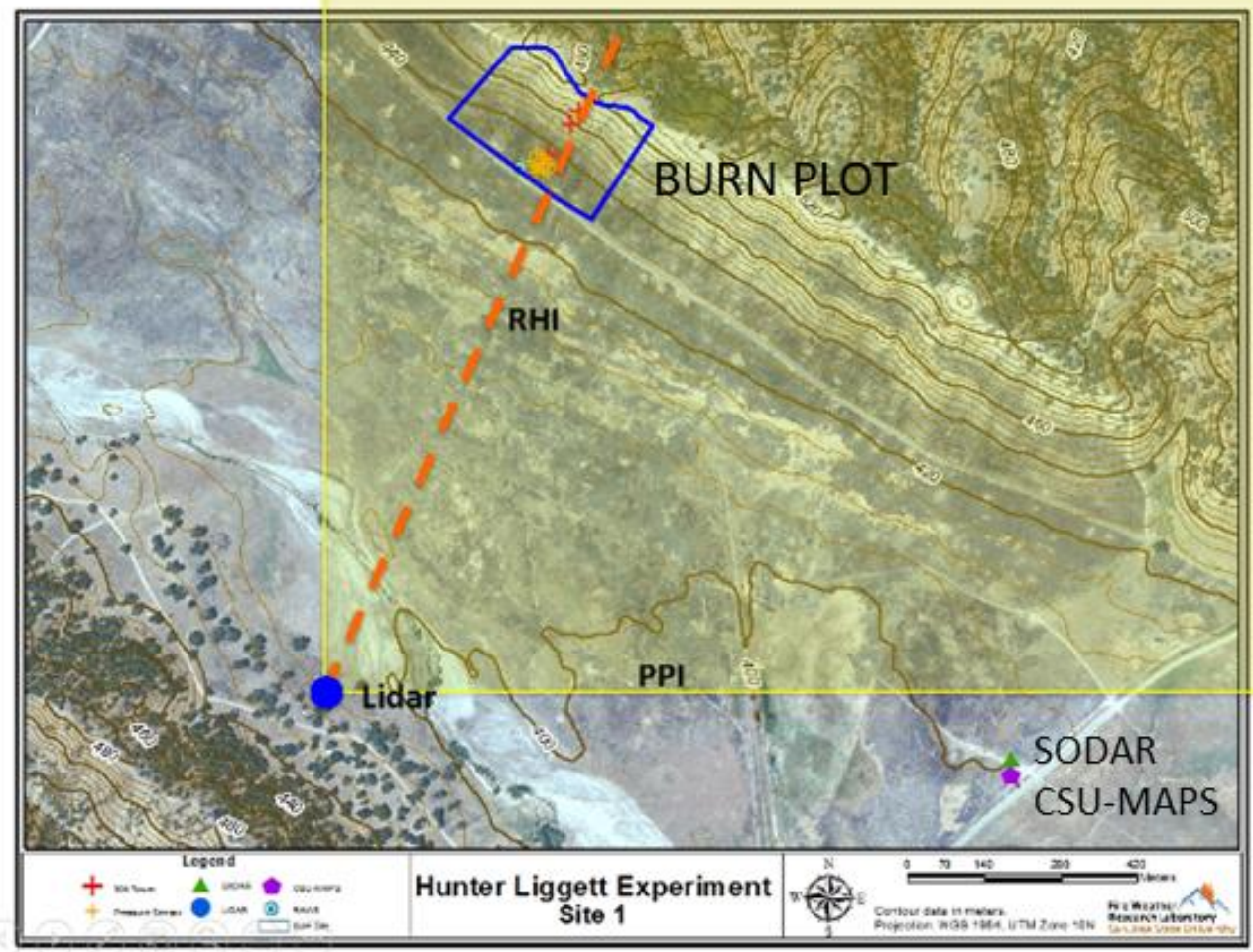

Figure 7 - Remote instrument layout Fort Hunter Liggett site 1 

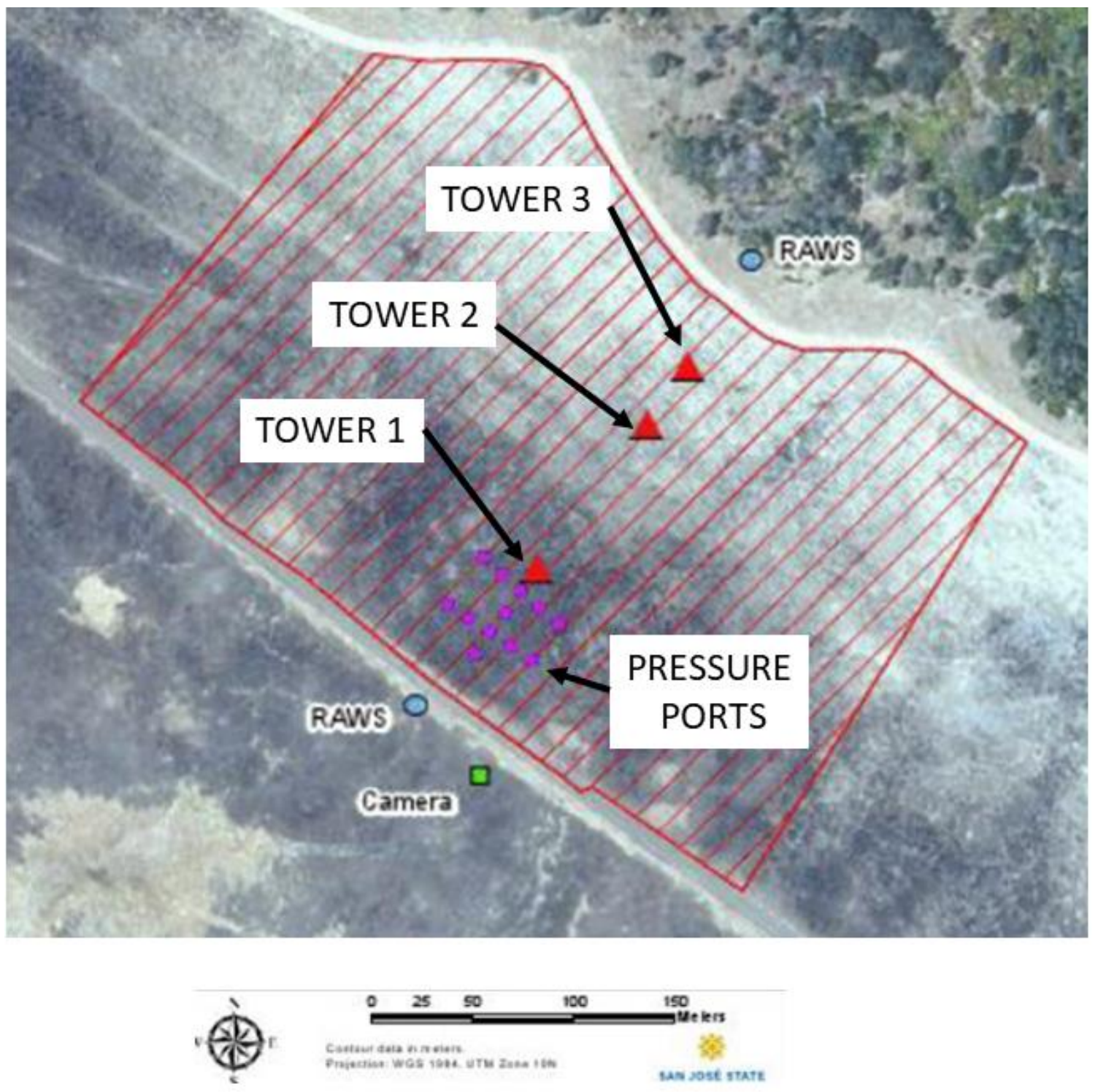

Figure 8 - Site 1 instrument layout detail 
Table 2 - Fort Hunter Liggett Site 1 In Situ Tower Instruments

\begin{tabular}{|c|c|c|c|c|}
\hline Platform & Type & Variables & $\begin{array}{l}\text { Measurement } \\
\text { Height }\end{array}$ & $\begin{array}{l}\text { Sampling } \\
\text { Frequency }\end{array}$ \\
\hline \multirow{6}{*}{ Tower \#1 } & $\begin{array}{c}\text { Sonic Anemometer } \\
\text { Applied Technologies, Inc., } \\
\text { Sx-probe, calibrated to } 110 \\
{ }^{\circ} \mathrm{C}\end{array}$ & $\mathrm{u}, \mathrm{v}, \mathrm{w}, \mathrm{T}_{\mathrm{s}}$ & $\begin{array}{c}10 \mathrm{~m} \\
(30 \mathrm{ft} .)\end{array}$ & $10 \mathrm{~Hz}$ \\
\hline & $\begin{array}{c}\text { Schmidt-Boelter } \\
\text { Radiometer } \\
\text { Medtherm Inc., } 64 \text { and } \\
\text { Hukseflux SBG-01 }\end{array}$ & Q & $\begin{array}{c}6 \mathrm{~m} \\
(20 \mathrm{ft} .)\end{array}$ & $10 \mathrm{~Hz}$ \\
\hline & $\begin{array}{c}\text { Type-K Fine-wire } \\
\text { Thermocouple } \\
\text { (Omega Inc. CHAL-005) }\end{array}$ & $\bar{T}$ & $1 \mathrm{~m}$ intervals & $10 \mathrm{~Hz}$ \\
\hline & GPS & $\begin{array}{l}\text { latitude, } \\
\text { longitude }\end{array}$ & $\begin{array}{c}3 \mathrm{~m} \\
(10 \mathrm{ft} .)\end{array}$ & $\mathrm{N} / \mathrm{A}$ \\
\hline & Pressure Sensors & $\mathrm{P}$ & $\begin{array}{c}3 \mathrm{~m}, 10 \mathrm{~m} \\
(10 \mathrm{ft} ., 30 \mathrm{ft} .)\end{array}$ & $1 \mathrm{~Hz}$ \\
\hline & $\begin{array}{c}\text { Data Logger } \\
\text { Campbell Scientific, } \\
\text { CR3000 }\end{array}$ & Data storage & $\begin{array}{l}2 \mathrm{~m} \\
(6 \mathrm{ft} .)\end{array}$ & $10 \mathrm{~Hz}$ \\
\hline \multirow{6}{*}{ Tower \#2 } & $\begin{array}{c}\text { 3D Sonic Anemometer } \\
\text { (Applied Technologies Inc. } \\
\text { SATI Sx) }\end{array}$ & $u, v, w, \mathrm{~T}_{\mathrm{s}}$ & $\begin{array}{l}10 \mathrm{~m} \\
(30 \mathrm{ft} .)\end{array}$ & $10 \mathrm{~Hz}$ \\
\hline & $\begin{array}{c}\text { Radiometer } \\
\text { (Medtherm 64 Series) }\end{array}$ & $Q_{r}$ & $\begin{array}{c}6 \mathrm{~m}, 8.5 \mathrm{~m} \\
(20 \mathrm{ft} ., 28 \mathrm{ft} .)\end{array}$ & $10 \mathrm{~Hz}$ \\
\hline & $\begin{array}{c}\text { Type-K Fine-wire } \\
\text { Thermocouple } \\
\text { (Omega Inc. CHAL-005) }\end{array}$ & $\mathrm{T}$ & $1 \mathrm{~m}$ intervals & $5 \mathrm{~Hz}$ \\
\hline & GPS & $\begin{array}{l}\text { latitude, } \\
\text { longitude }\end{array}$ & $\begin{array}{c}3 \mathrm{~m} \\
(10 \mathrm{ft} .)\end{array}$ & $1 \mathrm{~Hz}$ \\
\hline & Pressure Sensors & $\mathrm{P}$ & $10 \mathrm{ft}, 30 \mathrm{ft}$ & $1 \mathrm{~Hz}$ \\
\hline & $\begin{array}{c}\text { Data Logger } \\
\text { Campbell Scientific } \\
\text { CR3000 }\end{array}$ & Data storage & $2 \mathrm{M}$ & $10 \mathrm{~Hz}$ \\
\hline \multirow{5}{*}{ Tower \#3 } & $\begin{array}{c}\text { Sonic Anemometer } \\
\text { (Applied Technologies Inc. } \\
\text { SATI Sx) }\end{array}$ & $u, v, w, \mathrm{~T}_{\mathrm{s}}$ & $\begin{array}{l}10 \mathrm{~m} \\
30 \mathrm{ft}\end{array}$ & $10 \mathrm{~Hz}$ \\
\hline & $\begin{array}{c}\text { Type-K Fine-wire } \\
\text { Thermocouple } \\
\text { (Omega Inc. CHAL-005) }\end{array}$ & $\mathrm{T}$ & $1 \mathrm{~m}$ intervals & $5 \mathrm{~Hz}$ \\
\hline & GPS & $\begin{array}{l}\text { latitude, } \\
\text { longitude }\end{array}$ & $10 \mathrm{ft}$ & $1 \mathrm{~Hz}$ \\
\hline & Pressure Sensors & $\mathrm{P}$ & $10 \mathrm{ft}, 30 \mathrm{ft}$ & $1 \mathrm{~Hz}$ \\
\hline & $\begin{array}{c}\text { Data Logger } \\
\text { Campbell Scientific } \\
\text { CR3000 }\end{array}$ & Data storage & & $10 \mathrm{~Hz}$ \\
\hline
\end{tabular}


Table 3 - Fort Hunter Liggett Site 1 Non-Tower In Situ Instruments

\begin{tabular}{|c|c|c|c|c|}
\hline Platform & Type & Variables & $\begin{array}{c}\text { Measurement } \\
\text { Height }\end{array}$ & $\begin{array}{l}\text { Sampling } \\
\text { Frequency }\end{array}$ \\
\hline \multirow{3}{*}{$\begin{array}{c}\text { AWS } 1 \\
\text { (ignition line) }\end{array}$} & $\begin{array}{c}\text { CS215 } \\
\text { Campbell Scientific }\end{array}$ & $\mathrm{T}, \mathrm{RH}$ & $2 \mathrm{~m}$ & 5 minutes \\
\hline & $\begin{array}{c}\text { Wind Sentry Model } 03002 \\
\text { R.M Young }\end{array}$ & WS, WD & $2 \mathrm{~m}$ & 5 minutes \\
\hline & CS1000 Datalogger & Data storage & $2 m$ & $\mathrm{~N} / \mathrm{A}$ \\
\hline \multirow{3}{*}{$\begin{array}{c}\text { AWS } 2 \\
\text { (top of slope) }\end{array}$} & $\begin{array}{c}\text { CS215 } \\
\text { Campbell Scientific }\end{array}$ & $\mathrm{T}, \mathrm{RH}$ & $2 m$ & 5 minutes \\
\hline & $\begin{array}{c}\text { Wind Sentry Model } 03002 \\
\text { R.M Young }\end{array}$ & WS, WD & $2 m$ & 5 minutes \\
\hline & CS1000 Datalogger & Data storage & $2 \mathrm{~m}$ & $\mathrm{~N} / \mathrm{A}$ \\
\hline \multirow[t]{4}{*}{ FireBoxes } & \multirow{3}{*}{ SJSU custom design } & $\mathrm{P}$ & $10 \mathrm{ft} .(3 \mathrm{~m})$ & $2 \mathrm{~Hz}$ \\
\hline & & $\mathrm{T}$ & 10 ft. $(3 \mathrm{~m})$ & $2 \mathrm{~Hz}$ \\
\hline & & $\mathrm{RH}$ & $10 \mathrm{ft} .(3 \mathrm{~m})$ & $2 \mathrm{~Hz}$ \\
\hline & GPS & $\begin{array}{l}\text { latitude, } \\
\text { longitude }\end{array}$ & 10 ft. $(3 \mathrm{~m})$ & $1 \mathrm{~Hz}$ \\
\hline $\begin{array}{l}\text { Radiosonde } \\
\text { System }\end{array}$ & Vaisala Inc RS-92GPS & $\begin{array}{l}\text { WS, WD, P, RH, } \\
\text { T, GPS location }\end{array}$ & & $1 \mathrm{~Hz}$ \\
\hline
\end{tabular}

Table 4 - Fort Hunter Liggett Site 1 Remote Sensing Instruments

\begin{tabular}{|c|c|c|c|c|}
\hline Platform & Type & Variables & $\begin{array}{c}\text { Measurement } \\
\text { Height } \\
\text { (m AGL) }\end{array}$ & $\begin{array}{l}\text { Sampling } \\
\text { Frequency }\end{array}$ \\
\hline \multirow{3}{*}{$\begin{array}{l}\text { CSU- MAPS } \\
\text { 32-m } \\
\text { extendable } \\
\text { tower }\end{array}$} & $\begin{array}{c}\text { Thermistor-hygristor } \\
\text { sensors } \\
\text { (Vaisala, Inc. HMP45C) }\end{array}$ & $\mathrm{T}, \mathrm{RH}$ & $\begin{array}{c}1 \mathrm{~m} \text { intervals } \\
\text { from } 7 \mathrm{~m} \text { to } 31 \\
\mathrm{~m}\end{array}$ & $1 \mathrm{~min}$ \\
\hline & $\begin{array}{l}\text { 3D sonic anemometers } \\
\text { (RM Young 81000) }\end{array}$ & $u, v, w, T_{s}$ & $7 \mathrm{~m}$ and $31 \mathrm{~m}$ & $10 \mathrm{~Hz}$ \\
\hline & $\begin{array}{l}\text { 2D anemometers } \\
\text { (Gill, WindSonic) }\end{array}$ & $u, v$ & $7 \mathrm{~m}$ and $31 \mathrm{~m}$ & $1 \mathrm{~Hz}$ \\
\hline $\begin{array}{l}\text { Doppler } \\
\text { LIDAR }\end{array}$ & $\begin{array}{l}\text { Stream Line } 75 \\
\text { Halo Photonics Ltd. }\end{array}$ & $v_{r}, \beta$ & range gate: 18 & $1 \mathrm{~Hz}$ \\
\hline $\begin{array}{l}\text { Doppler Mini } \\
\text { SoDAR }\end{array}$ & $\begin{array}{c}\text { VT-1 } \\
\text { (Atmospheric Research } \\
\text { and Technology) }\end{array}$ & $u, v, w$ & $\begin{array}{c}15-200 \mathrm{~m} \\
\text { AGL }\end{array}$ & $1 \mathrm{~Hz}$ \\
\hline $\begin{array}{l}\text { Microwave } \\
\text { Profiler }\end{array}$ & $\begin{array}{c}\text { MP-3000A } \\
\text { (Radiometrics Inc) }\end{array}$ & $\mathrm{T}, \mathrm{RH}$ & $50-1 \times 10^{4}$ & $180 \mathrm{~s}$ \\
\hline
\end{tabular}

Key: $v_{r}$, radial velocity; $\beta$, aerosol backscatter intensity; CSU-MAPS, California State University - Mobile Atmospheric Profiling System; u horizontal streamwise velocity; v, horizontal cross-stream velocity; $w$, vertical velocity; $T_{s}$, sonic temperature; $T$, air temperature; $Q$, total heat flux, $Q_{r}$, radiative heat flux, $\mathrm{RH}$, relative humidity; WS, wind speed; WD, wind direction; $P$, atmospheric pressure 


\subsubsection{Fire Behavior}

\subsubsection{Ignition Line.}

A firing crew from Fort Hunter Liggett Fire Department used a drip torch with the standard 3:1 diesel:gas fuel ratio to ignite the fire. The firefighter setting the fire had a hand-held GPS on his web gear set to capture his position 10 times every second so that the exact ignition line was measured. The line initiated to the north of the tower line marker and moved southward along the road. The experimental design assumed winds from the west or upslope. However, on the day of the experiment, the wind was southwesterly, so the ignition line had to be extended well past the initially planned line so that the fire would burn through the meteorological towers if the direction of spread became wind dominated rather than slope dominated.

There was a patch of mustard grass close to the road south of the experimental plot. This mustard grass was a different fuel type than the grass in the rest of the experimental plot, so the decision was made to take the ignition line at an angle away from the road towards the hill crest and around the mustard grass to eliminate any variability in the fuels. The firing was stopped just past the mustard grass patch. The ignition line is shown as the solid black line in Figure 9. 


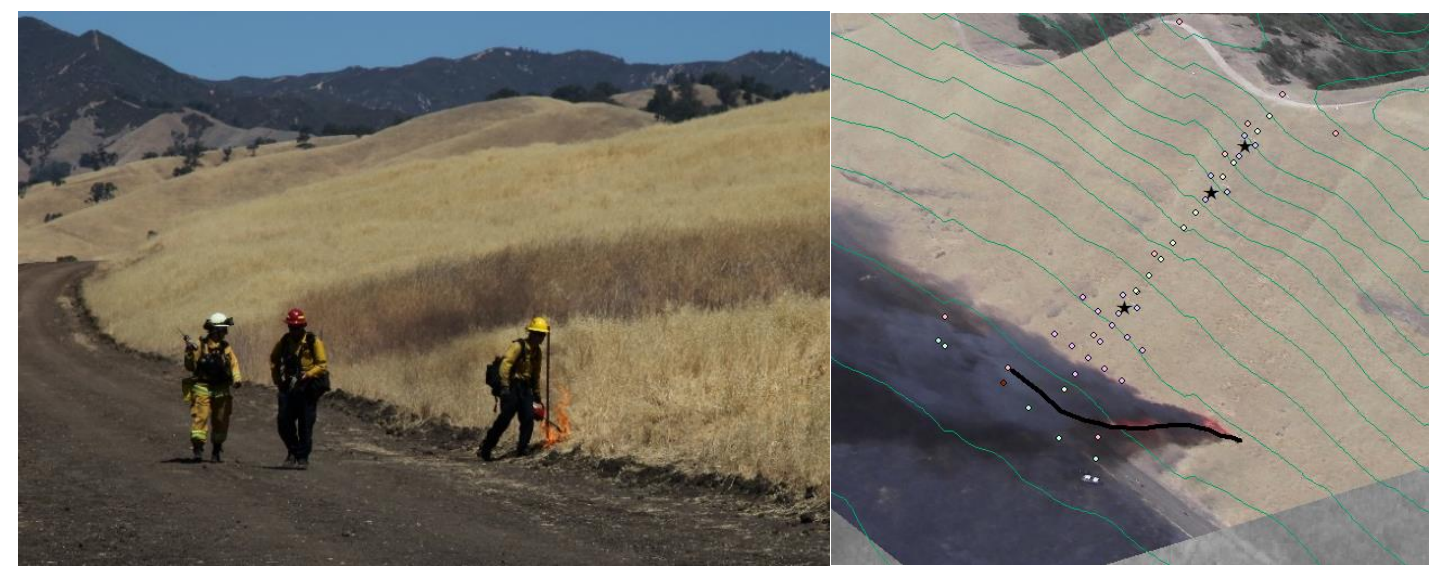

Figure 9 - Ignition and ignition line

\subsubsection{Determination of Ignition Time}

To determine the exact ignition time, the camera used to photograph the ignition was calibrated to the GPS clock on the lower AWS station. The fire was ignited at 11:18:10 PDT (181810 UTC) on 20 June 2012.

\subsubsection{Rate of Spread Markers}

The 15 rate of spread marker stakes, shown as yellow dots in Figure 10, were placed along the tower transect at $10 \mathrm{~m}$ intervals The measurement criteria are shown in Table 5.

Table 5 - Fort Hunter Liggett Site 1 Rate of Spread (ROS) Markers

\begin{tabular}{|c|c|c|c|c|}
\hline Platform & Type & Variables & $\begin{array}{c}\text { Measurement } \\
\text { Height }\end{array}$ & $\begin{array}{c}\text { Sampling } \\
\text { Frequency }\end{array}$ \\
\hline $\begin{array}{c}\text { ROS } \\
\text { Markers } \\
1-15\end{array}$ & marker stakes & ROS $\left(\mathrm{m} \mathrm{s}^{-1}\right)$ & $2 \mathrm{~m}$ & $\begin{array}{c}10 \mathrm{~m} \\
\text { increments }\end{array}$ \\
\hline
\end{tabular}




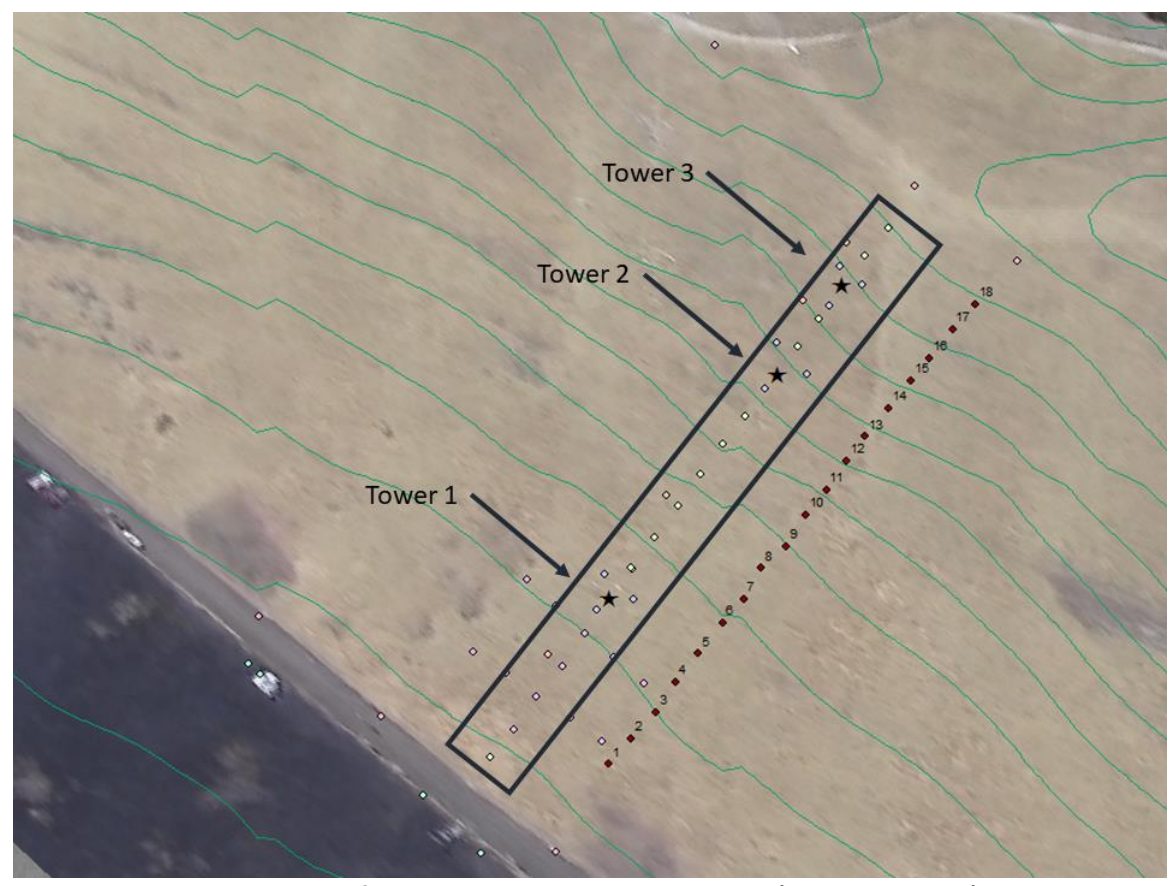

Figure 10 - Rate of spread marker stake (yellow dot) locations

\subsubsection{Still Photographic Sequences}

Three (3) still cameras were used to capture photographs of the fire during the experiment. Table 6 gives the details on the cameras used.

Table 6 - Cameras

\begin{tabular}{|c|c|c|c|c|}
\hline Platform & Type & Variables & $\begin{array}{c}\text { Measurement } \\
\text { Height }\end{array}$ & $\begin{array}{c}\text { Sampling } \\
\text { Frequency }\end{array}$ \\
\hline $\begin{array}{c}\text { Tripod \#1 } \\
\text { (North Still) }\end{array}$ & $\begin{array}{c}\text { Canon EOS 40D } \\
\text { still-image, time- } \\
\text { lapse, digital SLR } \\
\text { camera }\end{array}$ & $\begin{array}{c}\text { Flame length } \\
\text { m, flame } \\
\text { height m, } \\
\text { flame angle }\end{array}$ & $1.5 \mathrm{~m}$ & $1 \mathrm{~Hz}$ \\
\hline $\begin{array}{c}\text { Tripod \#3 } \\
\text { (South Still) }\end{array}$ & $\begin{array}{c}\text { Canon EOS } \\
\text { DIGITAL REBEL } \\
\text { XT } \\
\text { still-image, time- } \\
\text { lapse, digital SLR } \\
\text { camera }\end{array}$ & $\begin{array}{c}\text { Flame length } \\
\text { m, flame } \\
\text { height m, } \\
\text { flame angle }\end{array}$ & $1.5 \mathrm{~m}$ & $1 \mathrm{~Hz}$ \\
\hline $\begin{array}{c}\text { Camera 1 } \\
\text { (operated by } \\
\text { photographer) }\end{array}$ & $\begin{array}{c}\text { Canon EOS 5D } \\
\text { Mark II } \\
\text { still-image, time- } \\
\text { lapse, digital SLR } \\
\text { camera }\end{array}$ & Various & Varies & Random \\
\hline
\end{tabular}


A camera was positioned on tripod \#1 to the north end of the experimental site and across the road to ensure it would be out of the fire field. This camera, referred to as the 'North Still Camera', was aimed at the experimental setup and the slope. The camera was remotely triggered to start taking photographs at the fire ignition time. Figure 11 shows the perspective from the north still camera.

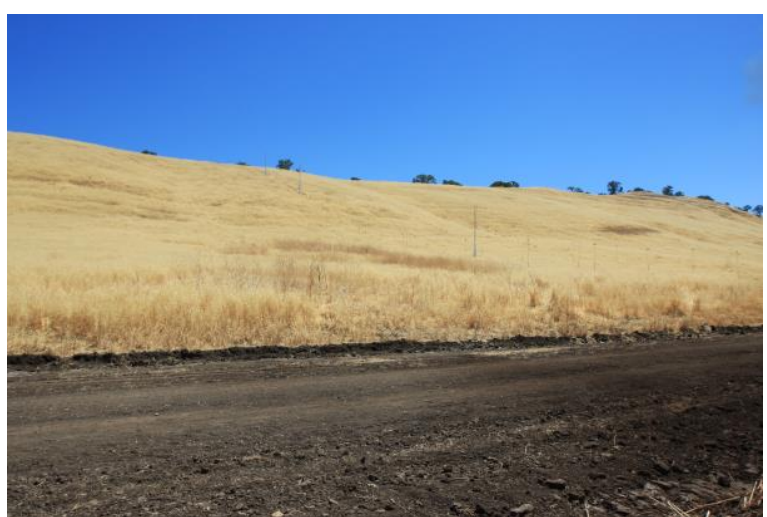

Figure 11 - Tripod \#1 perspective - north still camera

A second camera was positioned on tripod \#3 at the south end of the experimental site and across the road, again to ensure it was out of the fire field. This camera, referred to as the 'South Still Camera', was also aimed at the experimental setup and the slope (Figure 12). The camera was manually triggered to start taking pictures at the fire ignition time.

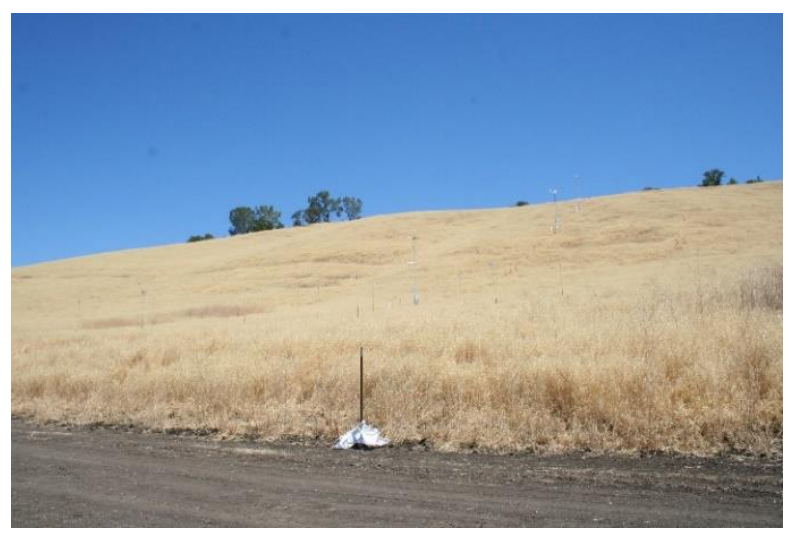

Figure 12 - Tripod \#3 perspective - south still camera 
A third camera, referred to as the "Mobile Camera", was operated by a photographer who walked along the road at the west end of the experimental site. This photographer took photos of the fire behavior at differing zoom levels and differing perspectives.

\subsubsection{Video}

Three (3) video recorders were deployed to capture video of the fire experiment. Table 7 gives the details of those video recorders.

Table 7 - Video Recorders

\begin{tabular}{|c|c|c|c|c|}
\hline Platform & Type & Variables & $\begin{array}{c}\text { Measurement } \\
\text { Height }\end{array}$ & $\begin{array}{c}\text { Sampling } \\
\text { Frequency }\end{array}$ \\
\hline $\begin{array}{c}\text { Airborne in } \\
\text { helicopter }\end{array}$ & $\begin{array}{c}\text { Cannon Digital } \\
\text { Video Recorder }\end{array}$ & $\begin{array}{c}\text { ROS } \mathrm{m} \mathrm{s}^{-1} \\
\text { fire perimeter m, } \\
\text { fire area } \mathrm{m}^{2}\end{array}$ & $300 \mathrm{~m}$ & $\begin{array}{c}30 \text { Frames } \\
\text { per second }\end{array}$ \\
\cline { 2 - 5 } & $\begin{array}{c}\text { Infrared Video } \\
\text { Recorder (Flir) }\end{array}$ & $\begin{array}{c}\text { ROS } \mathrm{m} \mathrm{s}^{-1} \\
\text { fire perimeter m, } \\
\text { fire area } \mathrm{m}^{2}\end{array}$ & $300 \mathrm{~m}$ & $\begin{array}{c}1 \text { Frame } \\
\text { per second }\end{array}$ \\
\hline Tripod \#2 & $\begin{array}{c}\text { Digital Video } \\
\text { Recorder }\end{array}$ & $\begin{array}{c}\text { ROS } \mathrm{m} \mathrm{s}^{-1} \\
\text { flame height } \mathrm{m}, \\
\text { flame length m }\end{array}$ & $1.5 \mathrm{~m}$ & $\begin{array}{c}30 \text { and } 60 \\
\mathrm{~Hz}\end{array}$ \\
\hline
\end{tabular}

A helicopter circled the fire from just before the ignition until the fire reached the third micrometeorological tower. There were two photographers and videographers onboard using the digital video recorder and the infrared video recorder to record the fire experiment. The Infrared (IR) video camera failed to record data, thus the IR data are not available.

A digital video camera was set up to the north of the instrumented slope on the road to the west of the slope on tripod \#2. This video recording was started just before the fire ignition and videotaped the fire progression until the fire reached the top of the slope after burning through the instrumented towers. 


\subsection{Data Processing Procedures}

\subsubsection{Topography}

A vertical transect of the tower line was taken in ArcGIS to obtain the cross section of the experiment site slope. The slope transect is shown in Figure 13. The initial part of the slope (ignition line to Tower 1 ) was $15 \%$ or $9^{\circ}$ and the second part of the slope (Tower 1 through Tower 3 ) was $30 \%$ or $17^{\circ}$.

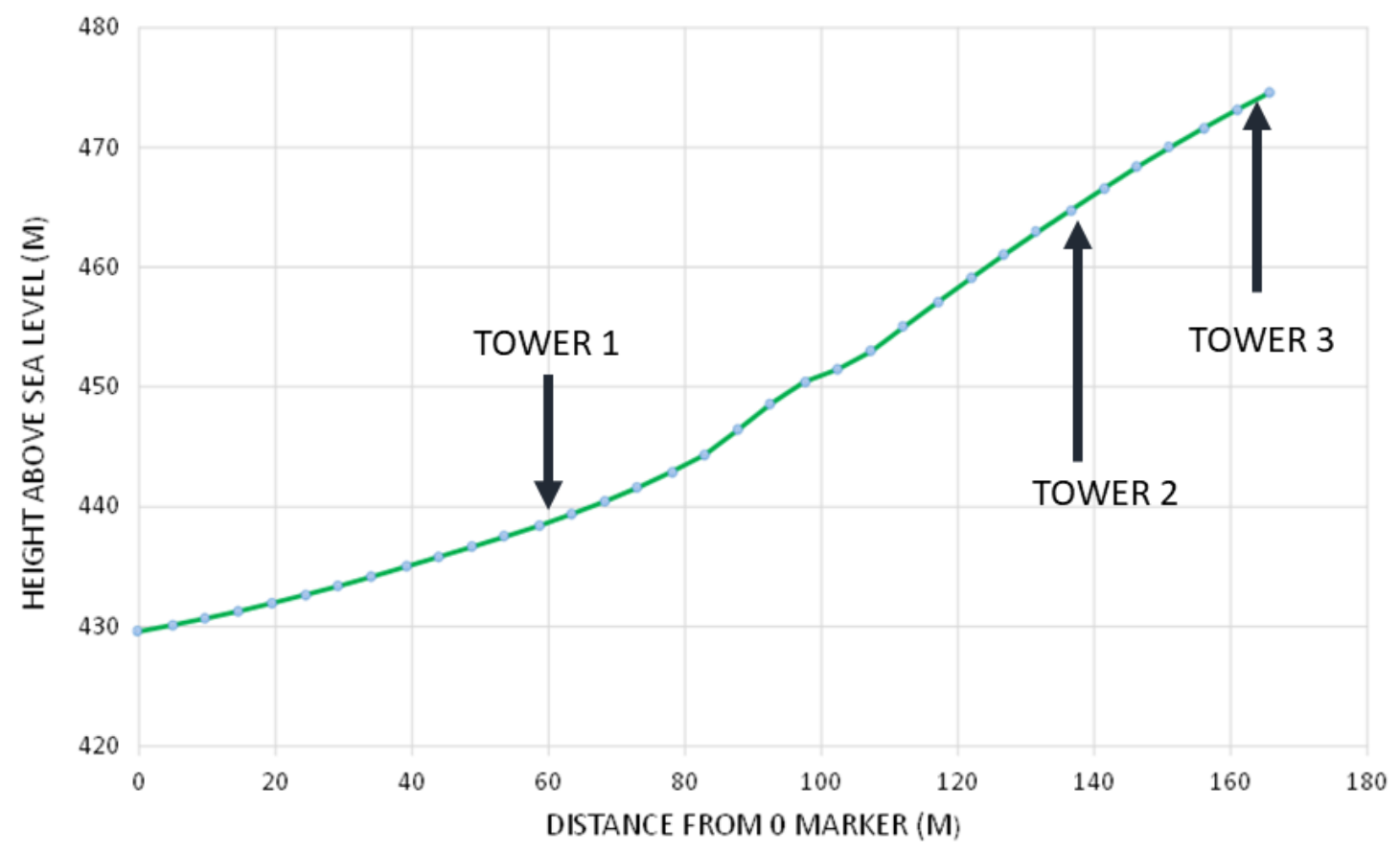

Figure 13 - Fort Hunter Liggett site 1 tower line transect

\subsubsection{Fuel Analysis}

\subsubsection{Fuel Moisture}

Fuel moisture is determined by the difference in weight of the fuel when collected and the weight of the fuel after it has been dried to force out all moisture. The general procedure followed in this study was recommended by 
the US Forest Service Pacific Northwest Research Station, Pacific Wildland Fire Sciences Laboratory (http://www.fs.fed.us/pnw/fera/).

Each of the 10 samples of fuel collected for fuel moisture analysis from site 1 was weighed and the weight recorded. Samples 1 through 7 were opened and the open bags were placed in the Fire Lab Oven for the first batch. Some samples from another experiment were also placed in the oven with these samples. The process was to dry the samples at $70{ }^{\circ} \mathrm{C}$ for 48 hours.

Unfortunately, the lab oven malfunctioned, and the samples were subjected to $92{ }^{\circ} \mathrm{C}$ within 90 minutes of the start of the drying cycle. This excessive temperature caused the plastic bags in which the samples were contained to melt. The various samples were mixed and it was not possible to determine the oven dry weight of the samples 1 through 7 . Samples 8 through 10 were more successfully dried after the Fire Lab oven was repaired. Table 8 shows the results for the samples.

As a result, the fuel moisture value used for the fire behavior models was 1.6\%. Simulations were also run using 2.25\%, the average of samples 9 and 10 . 
Table 8 - Site 1 Fuel Moisture

\begin{tabular}{|c|c|c|c|c|c|}
\hline Bag & $\begin{array}{l}\text { Pre Oven } \\
\text { Weight } \\
\text { (g) }\end{array}$ & $\begin{array}{l}\text { Post } \\
\text { Oven } \\
\text { Weight } \\
\text { (g) }\end{array}$ & $\begin{array}{c}\text { Net } \\
\text { Water } \\
\text { Weight } \\
\text { (g) }\end{array}$ & $\begin{array}{l}\text { Fuel Moisture } \\
\text { (Water weight / } \\
\text { dry weight) }\end{array}$ & Note \\
\hline 1 & 30.1 & & & & Destroyed \\
\hline 2 & 32.5 & * & & & Destroyed \\
\hline 3 & 30.5 & * & & & Destroyed \\
\hline 4 & 28.1 & * & & & Destroyed \\
\hline 5 & 26.1 & * & & & Destroyed \\
\hline 6 & 21 & * & & & Destroyed \\
\hline 7 & 21 & * & & & Destroyed \\
\hline 8 & 33.7 & 32.5 & 1.2 & $3.7 \%$ & $\begin{array}{l}\text { Hole in bag } \\
\text { absorbed } \\
\text { moisture } \\
\text { from } \\
\text { environment }\end{array}$ \\
\hline 9 & 24.7 & 24.3 & 0.4 & $1.6 \%$ & \\
\hline 10 & 35.2 & 34.2 & 1 & $2.9 \%$ & $\begin{array}{l}\text { Grass in seal } \\
\text { might be OK }\end{array}$ \\
\hline
\end{tabular}

\subsubsection{Fuel Type}

Each sample was weighed to determine the amount of biomass present. The data are shown in Table 9. Standard fire behavior fuel models currently employed in the United States express fuel loading as (US) tons / acre, so the data are given in both SI (Système Internationale) and the standard representation. 
Table 9 - Biomass Fuel Loading Fort Hunter Liggett Site 1

\begin{tabular}{|l|c|c|c|c|c|}
\hline Plot \# & $\begin{array}{c}\mathrm{g} / \\
\text { Plot 1 }\end{array}$ & $\begin{array}{c}\text { US } \\
\text { ton/acre }\end{array}$ & $\%$ Grass Cover & $\begin{array}{c}\text { \% Bare } \\
\text { Soil }\end{array}$ & Height $(\mathrm{m})$ \\
\hline Plot 2 & 167.17 & 3.45 & 100 & 0 & 0.8500 \\
\hline Plot 3 & 160.87 & 2.98 & 78 & 22 & 0.8600 \\
\hline Plot 4 & 227.40 & 4.06 & 100 & 0 & 0.7500 \\
\hline Plot 5 & 154.17 & 2.75 & 100 & 0 & 0.8600 \\
\hline Plot 6 & 141.67 & 2.53 & 95 & 0 & 0.8500 \\
\hline Plot 7 & 138.75 & 2.48 & 80 & 20 & 0.7112 \\
\hline Plot 8 & 66.83 & 1.19 & 65 & 5 & 0.7874 \\
\hline Plot 9 & 118.11 & 2.11 & 95 & 40 & 0.5842 \\
\hline Plot 10 & 78.98 & 1.41 & 85 & 5 & 0.7874 \\
\hline Plot 11 & 122.58 & 2.19 & 90 & 15 & 0.7112 \\
\hline Plot 12 & 88.93 & 1.59 & 60 & 10 & 0.8636 \\
\hline Plot 13 & 50.13 & 0.89 & 30 & 40 & 0.7874 \\
\hline Plot 14 & 68.50 & 1.22 & 55 & 45 & 0.5842 \\
\hline Plot 15 & 53.36 & 0.95 & 40 & 60 & 0.6604 \\
\hline Plot 16 & 87.49 & 1.56 & 75 & 25 & 0.5842 \\
\hline Plot 17 & 83.31 & 1.49 & 60 & 40 & 0.6858 \\
\hline Plot 18 & 42.92 & 0.77 & 55 & 45 & 0.8128 \\
\hline Plot 19 & 56.26 & 1.00 & 30 & 70 & 0.4064 \\
\hline Plot 20 & 44.94 & 0.80 & 35 & 65 & 0.6096 \\
\hline
\end{tabular}

The tons per acre for the fuel samples are plotted in Figure 14. Samples from

Plot 19 and 20 were omitted from the analysis because when they were included, the results were too heavily weighted towards the lower fuel loading at the top of the hill. To determine if the fuel collected from FHL Site 1 could be represented by an existing fuel model during the analysis phase, several fuel loadings from existing models were chosen and also plotted on Figure 14 for reference. From the grass group of Anderson (1982), Fuel Model 1 (FM1) Short Grass and Fuel Model 3 (FM3) Tall Grass were selected. Fuel Model 2 was not included since this model includes timber litter which was not present on the experiment plot. 
From the grass group of Scott and Burgan (2005) Fuel Models GR1 (Short, Sparse, Dry Climate Grass), GR2 (Low Load, Dry Climate Grass) and GR4 (Moderate Load, Dry Climate Grass) were selected for review. The other grass group models are for humid climates and are thus not applicable. The average fuel loading of the first 18 plots was 2.03 tons acre $^{-1}$ which is very close to 2.15 tons acre ${ }^{-1}$ specified for GR4, so Standard Fire Behavior Fuel Model GR4 was selected for the fuel input for the fire behavior models. This will very slightly overestimate the amount of available fuel.

The fuel at the bottom of the slope had a higher percentage of ground coverage than at the top (Figure 15). The fuel height was shorter at the top of the slope than at the bottom (Figure 16). The fuel height of the samples versus the height of several standard fuel models selected previously are included in Figure 16 for reference. As the slope ascended, the reducing density and reducing height contributed to a lessening of available fuel. 


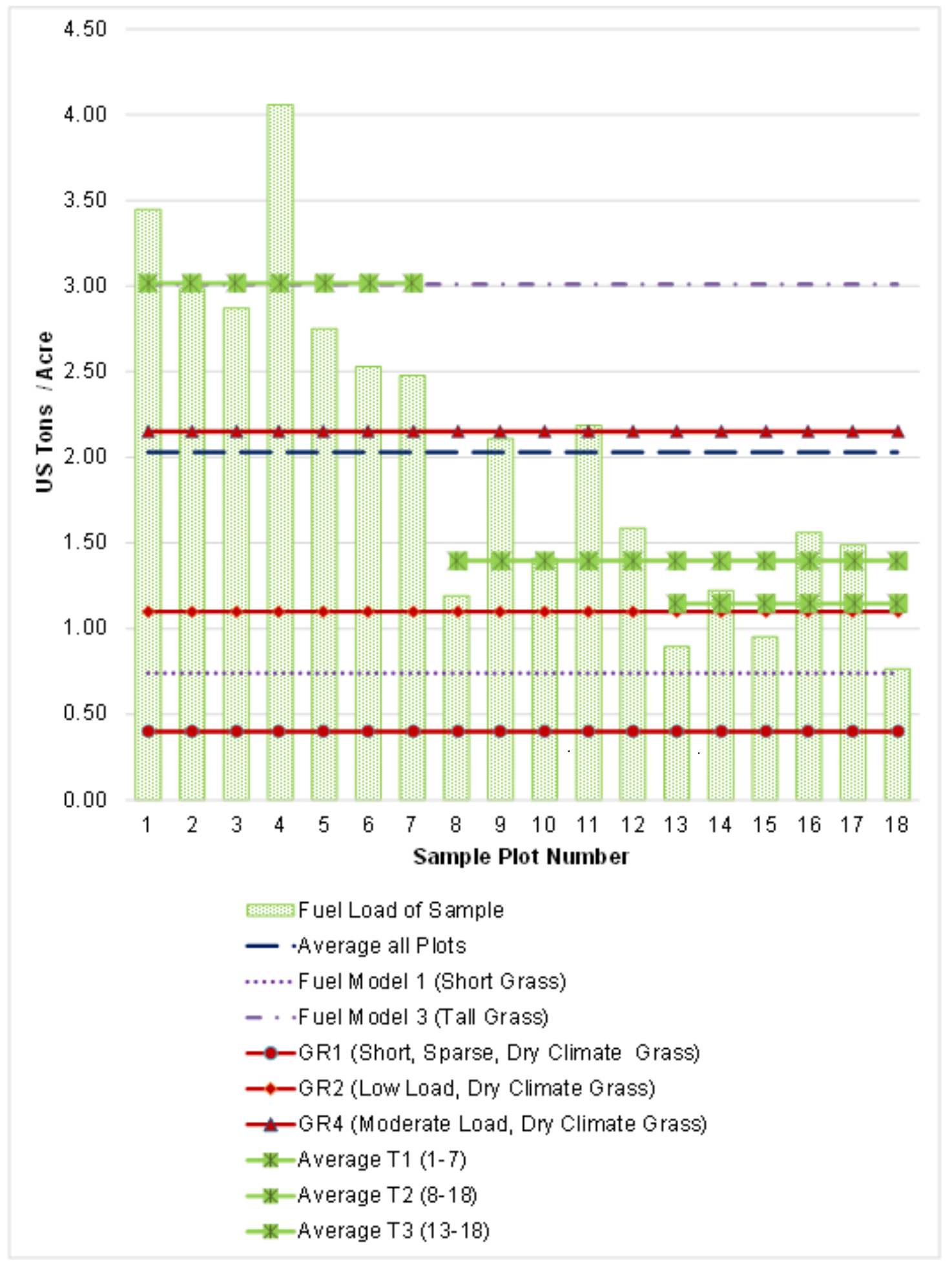

Figure 14 - FHL site 1 fuel sample analysis 


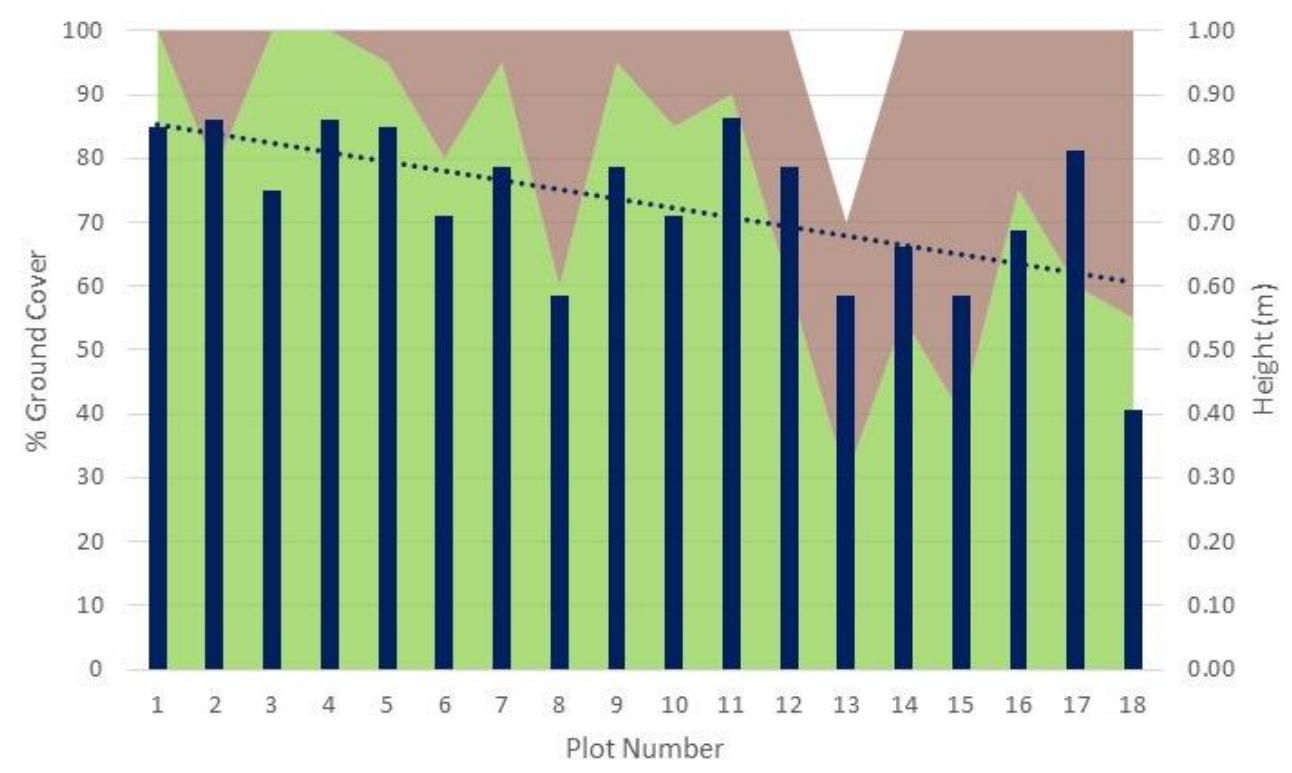

$\%$ Grass Cover Height $(\mathrm{m}) \quad$....... Linear (Height $(\mathrm{m}))$

Figure 15 - FHL site 1 ground cover analysis

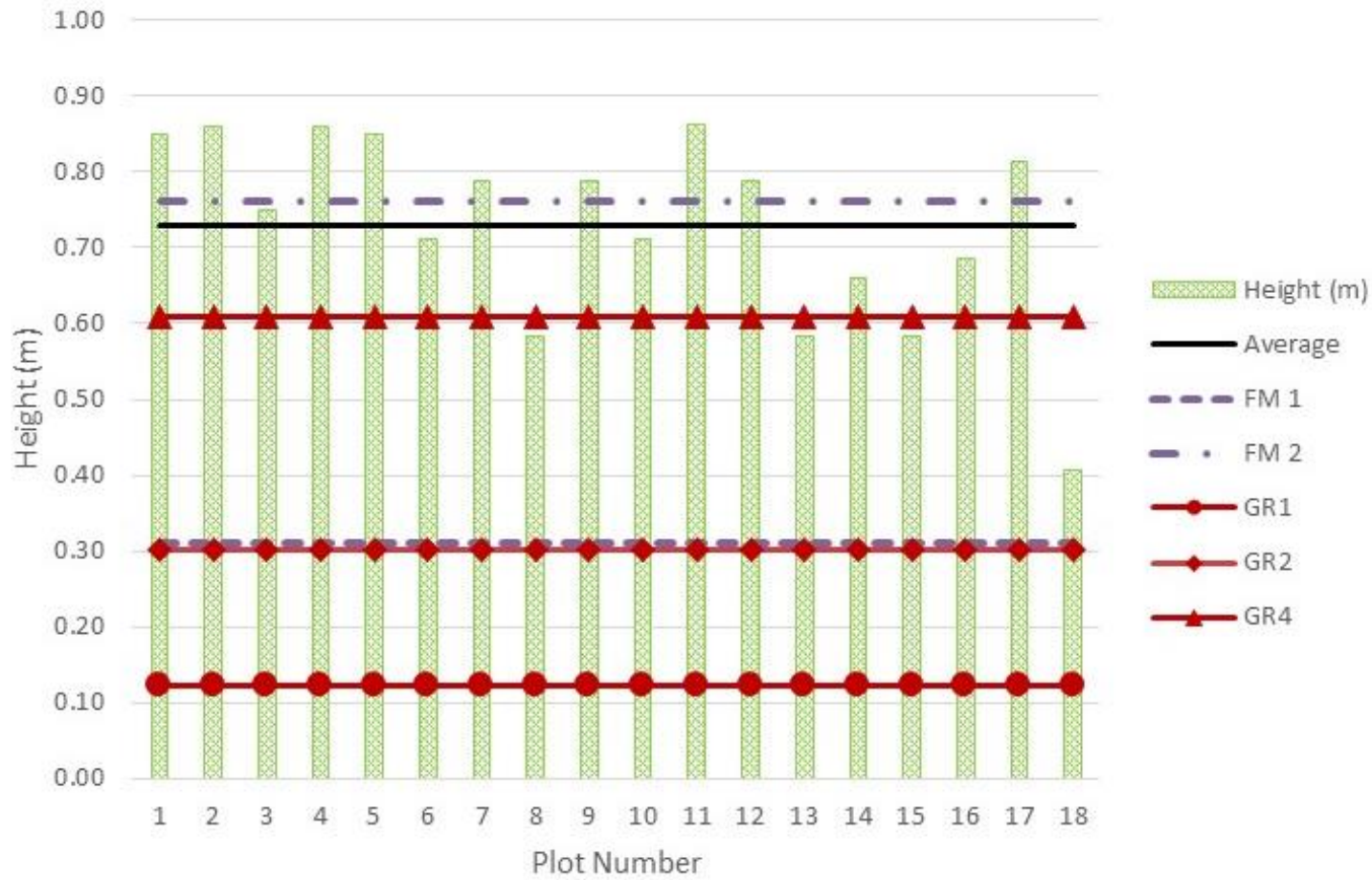

Figure 16 - FHL site 1 fuel sample height 


\subsubsection{Weather}

\subsubsection{Synoptic Conditions}

The $12 \mathrm{Z} 850 \mathrm{hPa}$ analysis from NOAA is shown in Figure 17. The ridge shown on the west coast centered at San Diego, CA, is generally associated with light winds throughout the atmosphere. The surface analysis (Figure 18) also shows light winds at the experiment site in California.

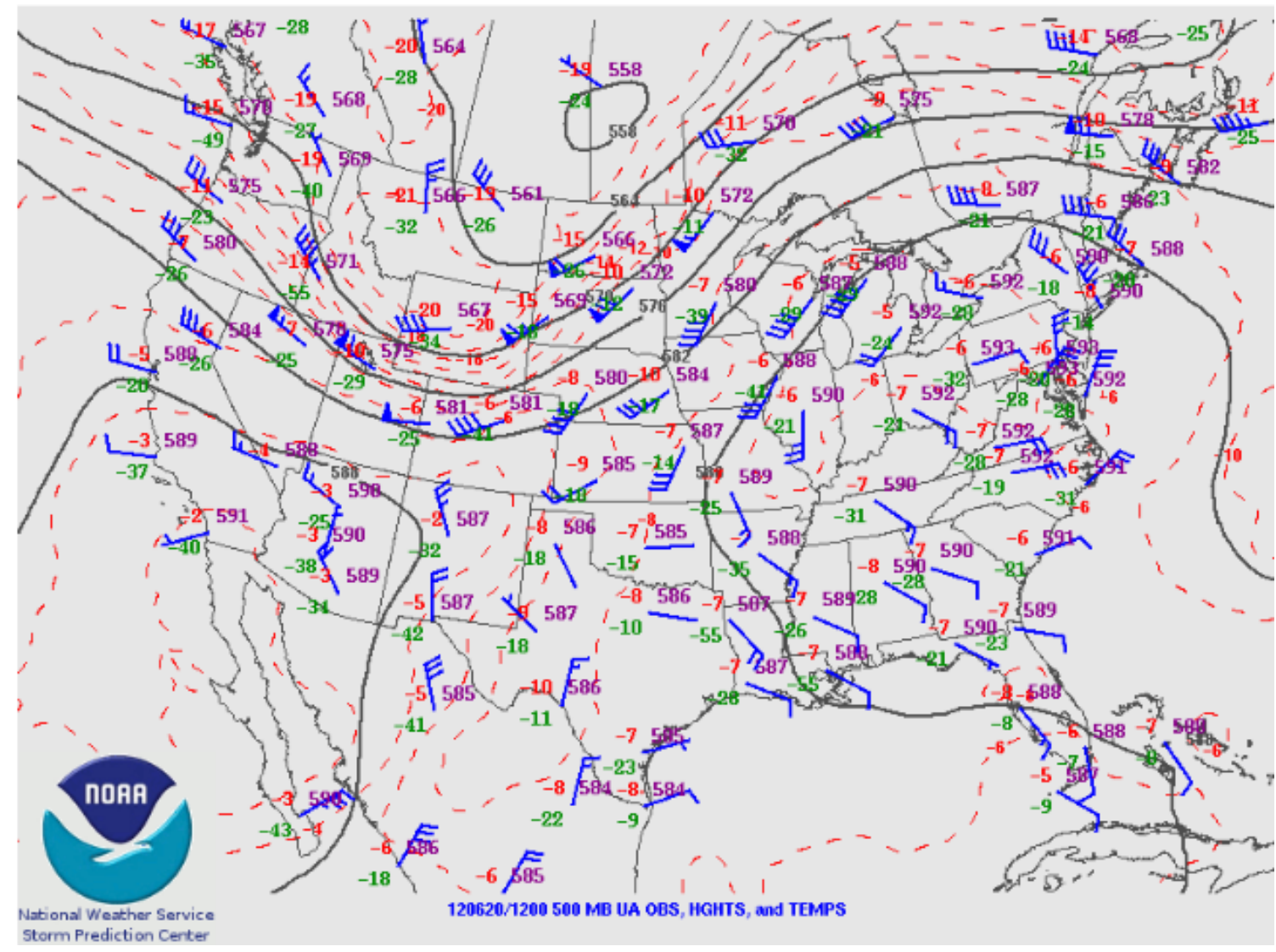

Figure 17 - $12 Z 850 \mathrm{hPa}$ analysis 20 June 2012 (from NOAA) 


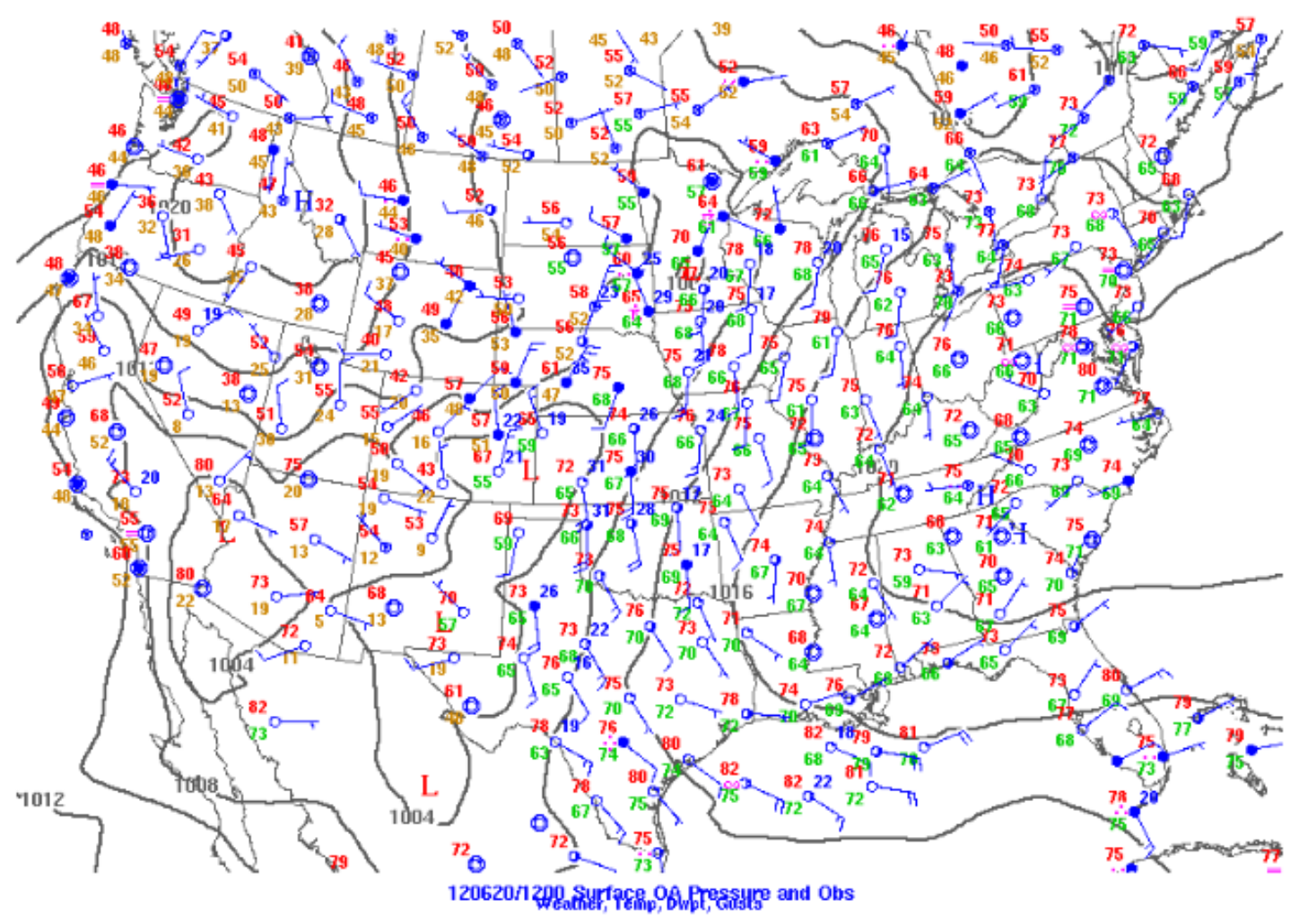

Figure 18 - $12 Z$ surface analysis 20 June 2012 (From NOAA)

The spot weather forecast, shown in Figure 19, issued by the National Weather Service at Monterey, CA, indicated that the surface winds would be from the west to southwest and weak. 


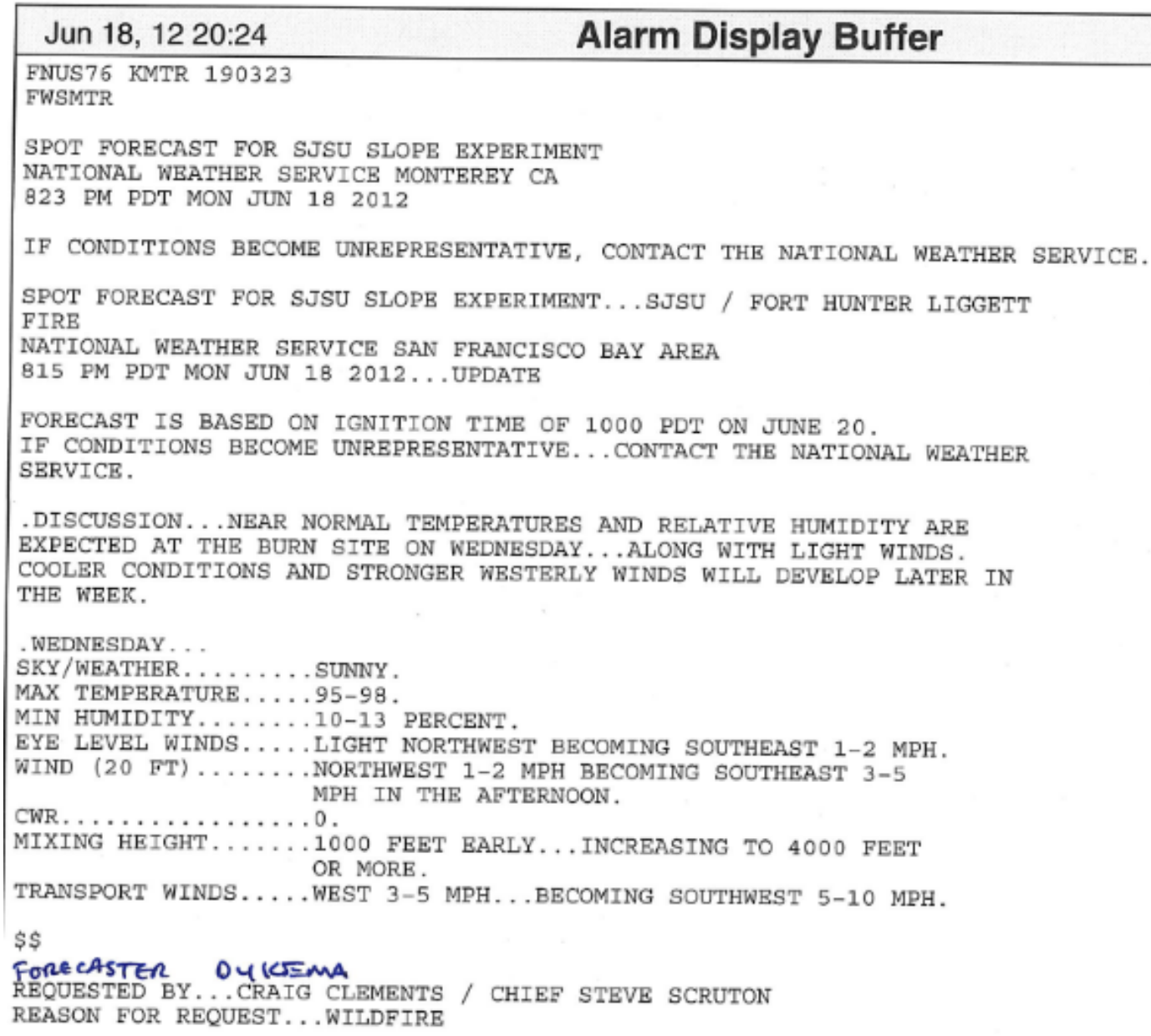

Figure 19 - Spot weather forecast

\subsubsection{Sounding}

A sounding was taken at 0800 PDT (15:00 UTC) on June 20, 2012, and the wind speed and direction are shown in Figure 20. This sounding shows the winds above the experiment site were light at $0-10 \mathrm{~m} \mathrm{~s}^{-1}$ and from the south and west until around $600 \mathrm{hPa}$. Above $600 \mathrm{hPa}$, the winds became stronger at $10-30 \mathrm{~m} \mathrm{~s}^{-1}$ and the direction changed so that the winds were from the north to northeast. 

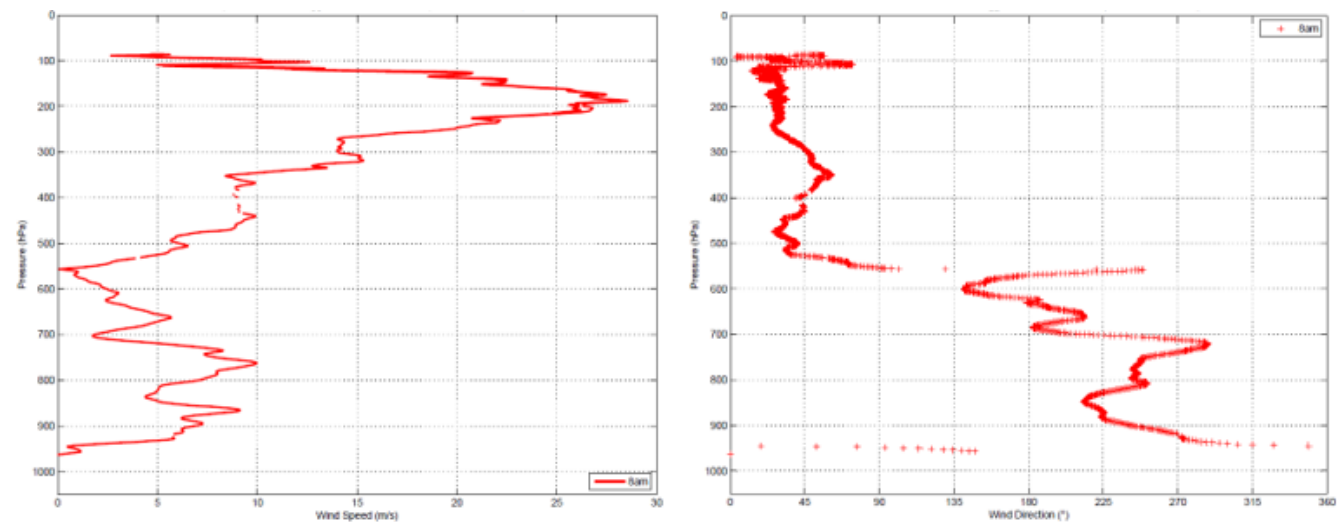

Figure 20 - Sounding wind speed (left) and direction (right)

The air temperature and dewpoint are shown in Figure 21. The separation of the temperatures indicates dry conditions at all levels of the atmosphere, but very dry conditions below $600 \mathrm{hPa}$.

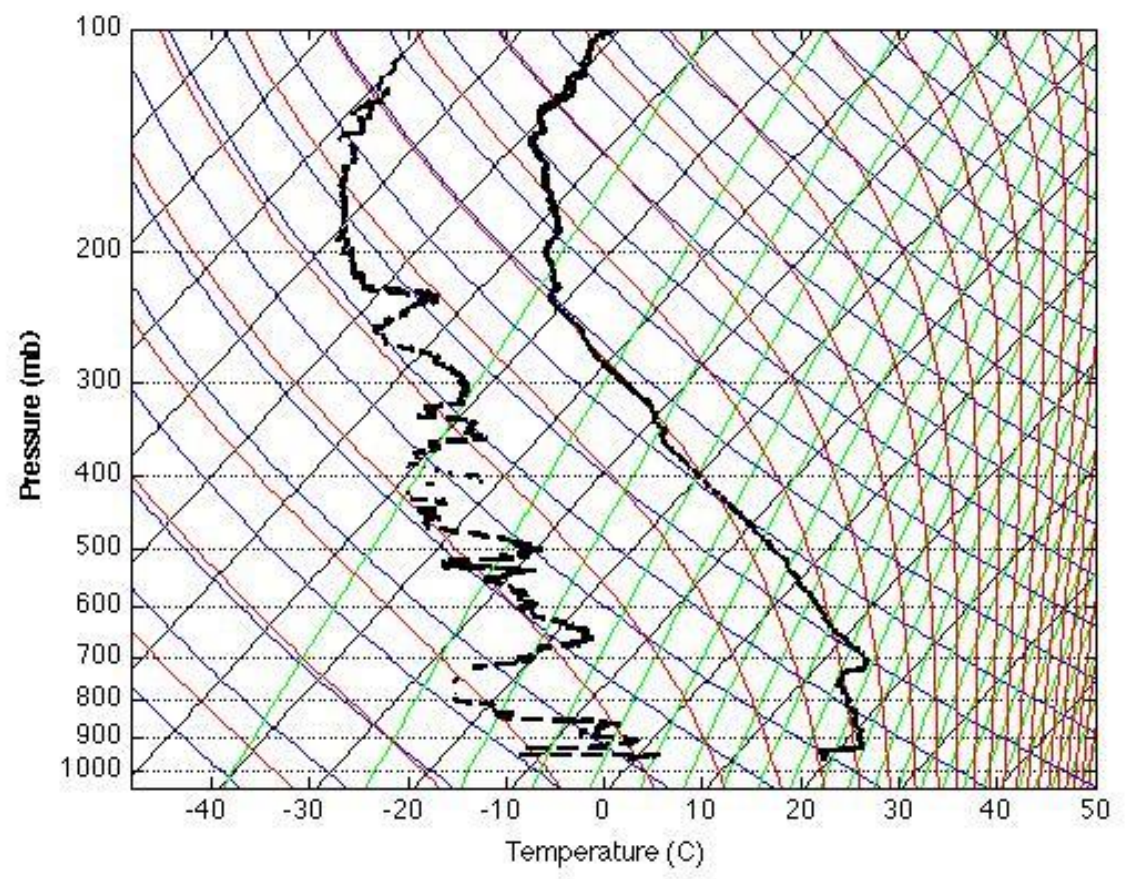

Figure 21 - Sounding temperature and dew point 


\subsubsection{Sodar}

The sodar profile (Figure 22) shows the winds were from the west around 0800 PDT (1500 UTC) and had shifted to from the north by 0900 PDT (1600 UTC). Prior to ignition at 11:18 PDT (1818 UTC), the winds were again shifting and were from the east just after ignition. The wind speeds were very light both prior to and after ignition. Ignition time is indicated by the red line.

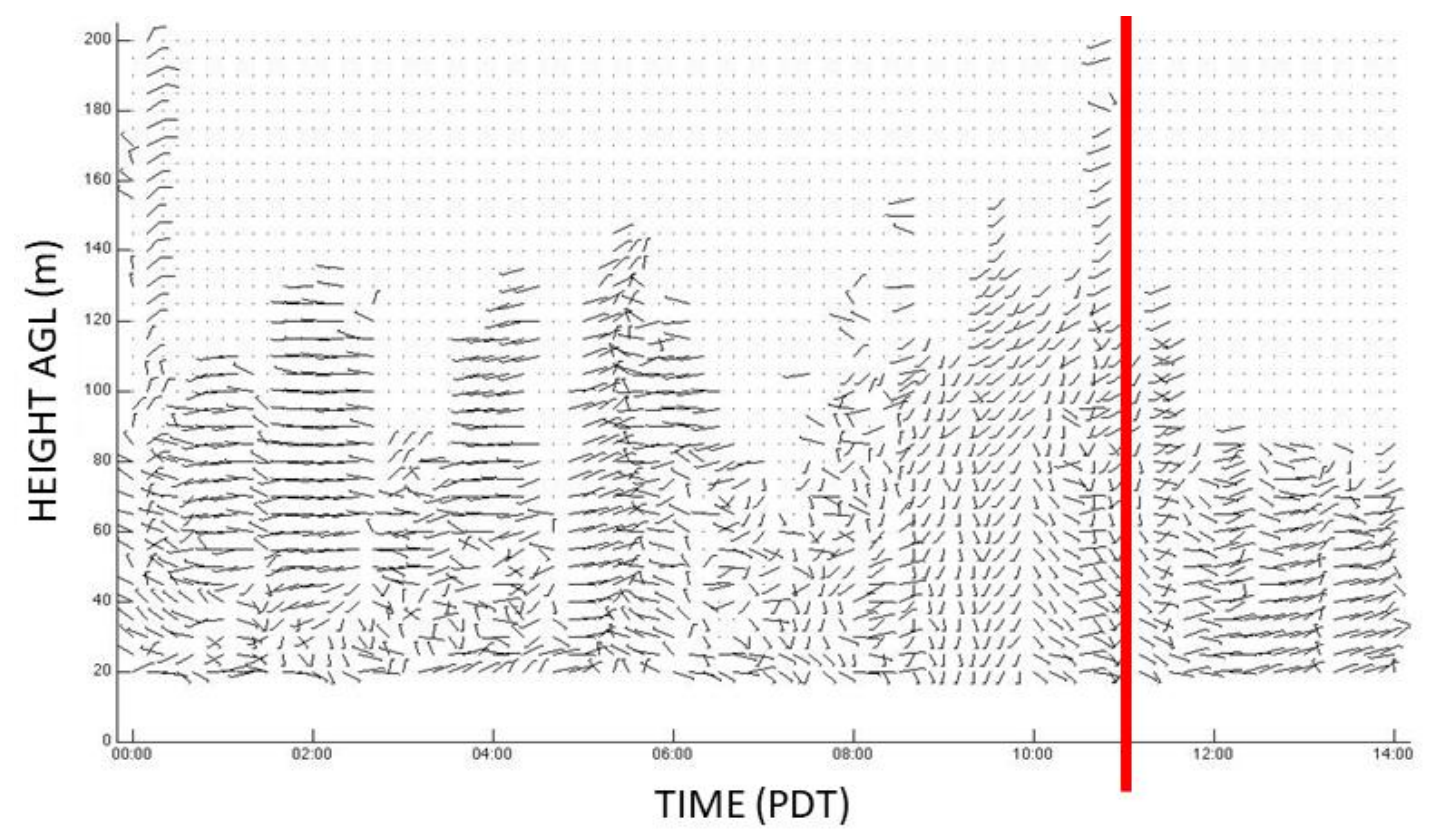

Figure 22 - Sodar wind profile 20 June 2012

\subsubsection{Lidar}

The Lidar was located east of the experiment site (Figure 7). The wind was analyzed at 0800 PDT (Figure 23) and 1119 PDT (Figure 24). Positive wind velocities, shown as the greens, yellows, and reds for this experiment, indicate wind from the east, blowing away from the Lidar. Negative wind velocities are shown as turquoise to blue and indicate wind blowing from the west, from the 
experiment site towards the Lidar. The RHI (Range Height Indicator) Lidar scan prior to the experiment at 0832 PST (Figure 23) shows an easterly wind of $1 \mathrm{~m} \mathrm{~s}^{-}$ 1 in a layer from the surface to around 200 m AGL (above Ground Level). The winds above $300 \mathrm{~m}$ were more westerly with velocities closer to $2 \mathrm{~m} \mathrm{~s}^{-1}$. The second scan, at the time of ignition, shows the upper-level winds had moved lower in the atmosphere and the winds at the experiment site were mixed to more westerly (Figure 24).

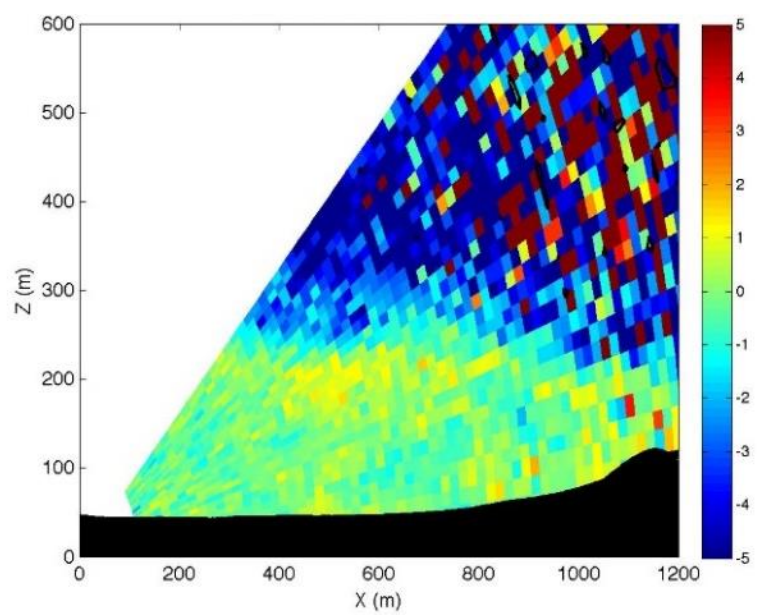

Figure 23 - Lidar RHI profile 08:32 PDT (1532 UTC) 20 June 2012

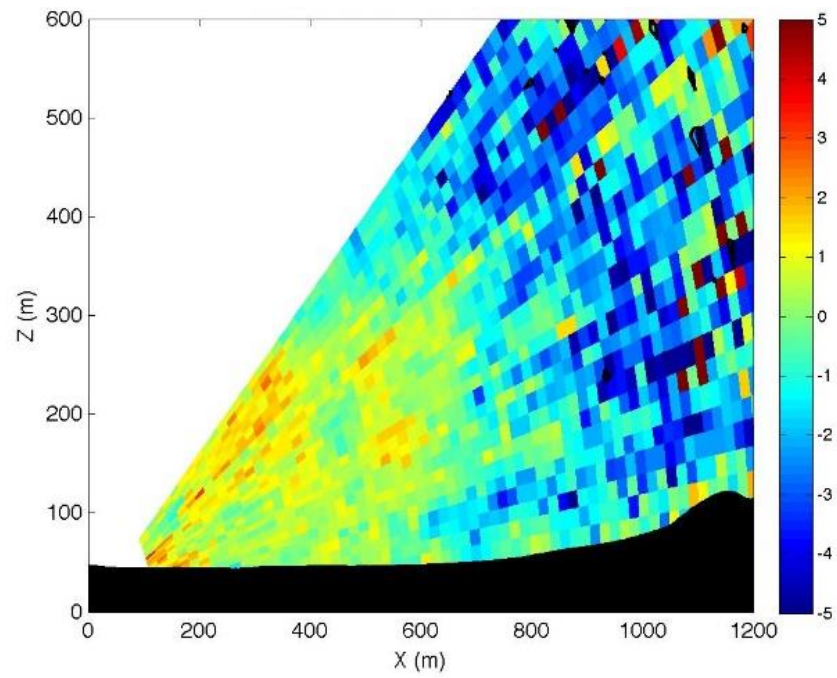

Figure 24 - Lidar at ignition 11:19 PDT (1919 UTC) 20 June 2012 


\subsubsection{AWS}

The wind speed and direction are shown for the lower AWS in Figure 25. Ignition time is indicated by the dotted line. The wind speed varied between $1 \mathrm{~m}$ $\mathrm{s}^{-1}$ and $3.5 \mathrm{~m} \mathrm{~s}^{-1}$. This AWS was located on the ignition line. There was some variation of the wind direction at the ignition line from east to west as the fire progressed. At the time of ignition, the wind speed was $2.1 \mathrm{~m} \mathrm{~s}^{-1}$ and the wind direction was $135^{\circ}$ or from the SE and these values were later used in the BehavePlus simulations.

It was discovered after the experiment that the upper AWS had not been adequately secured and had moved some time after installation, so the data could not be used.

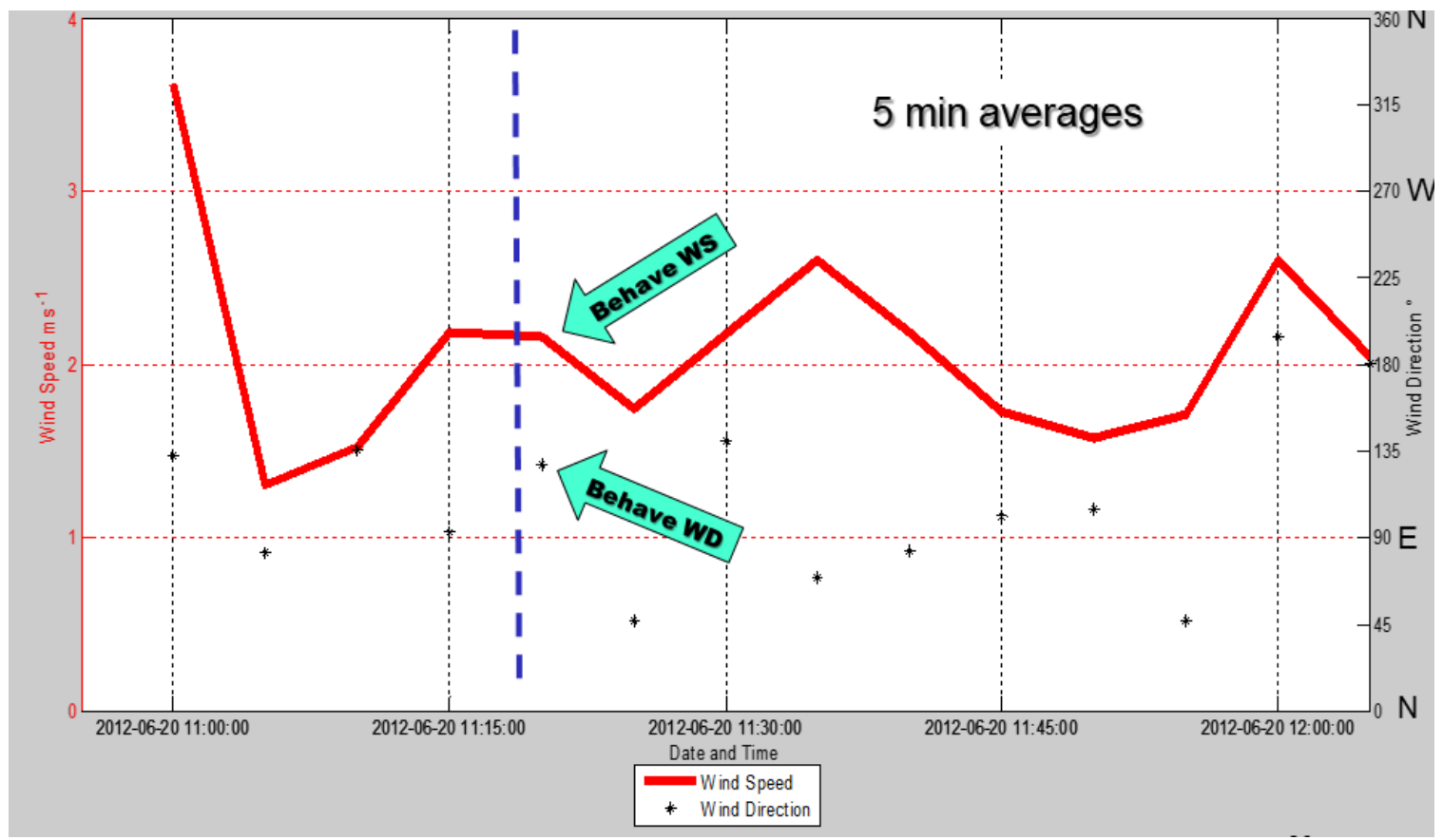

Figure 25 - Lower AWS 


\subsubsection{Micromet Sonics}

The wind speed and direction were measured at each of the 3 towers within the experiment site. Tower 1 was the lowest on the slope and was designated as bottom, Tower 2 was middle, and Tower 3 was top. These measurements are shown in Figure 26. The ignition time is shown by the dotted line and the time the fire front progressed through each tower is shown by the arrows. The wind speed, in red, increased from $1 \mathrm{~m} \mathrm{~s}^{-1}$ to $9 \mathrm{~m} \mathrm{~s}^{-1}$ at Tower 1 (bottom) as the fire front passed, but the wind decreased from 6 to $3 \mathrm{~m} \mathrm{~s}^{-1}$ as the fire front passed Tower 2 (middle), and there was no change in wind speed as the fire front passed Tower 3 (top). The wind direction was from the west $\left(270^{\circ}\right)$ at Tower 1 and Tower 2, but was from the east $\left(90^{\circ}\right)$ at Tower 3.

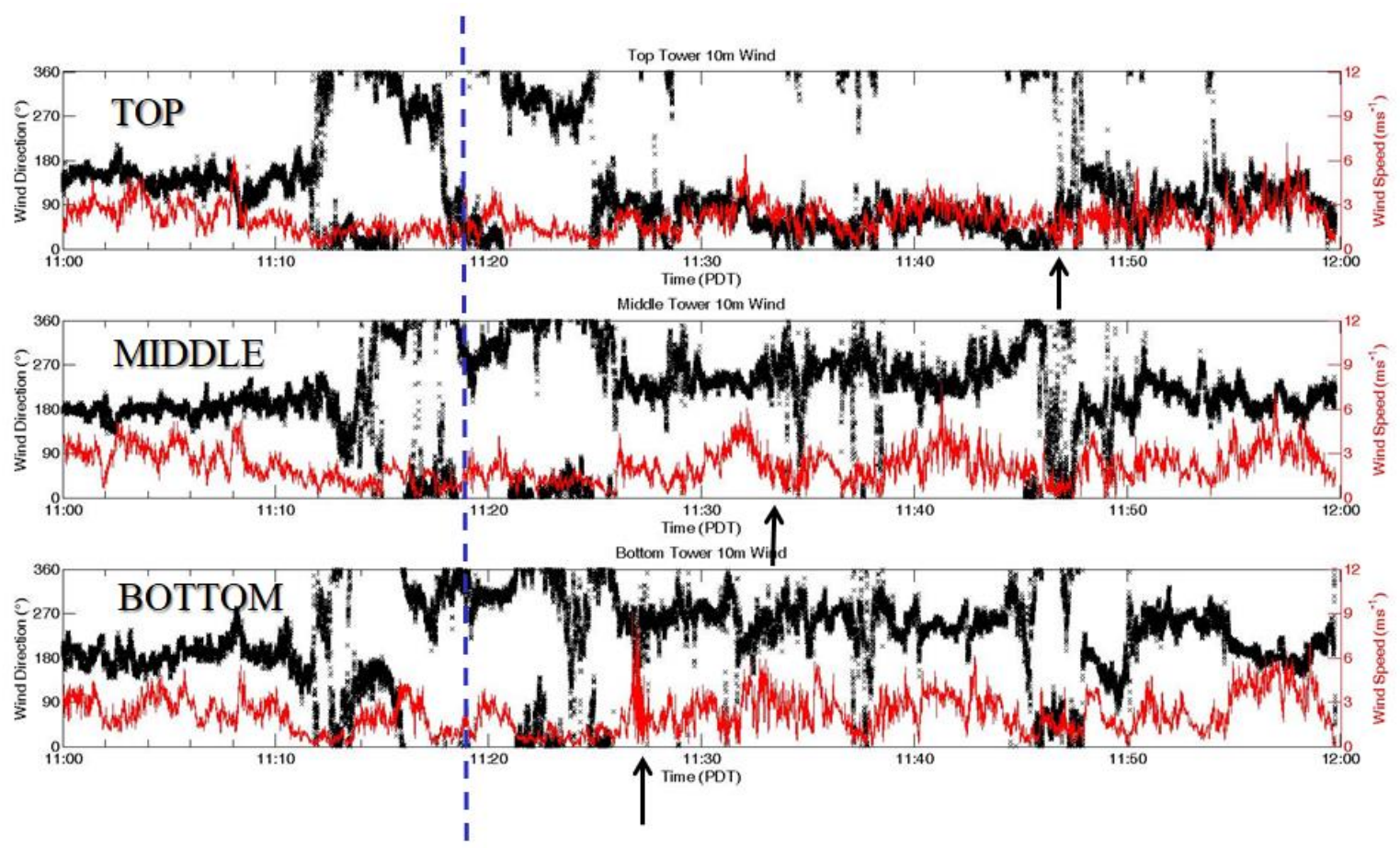

Figure $26-10 \mathrm{~m}$ wind speed and direction for the 3 towers 


\subsubsection{Fire Behavior}

\subsubsection{Fire Boundary Determination}

The fire boundary was manually drawn on georeferenced images of the fire. The fire was videoed from a helicopter overhead. The videos were processed in Photoshop to collect images of the fire progression at regular time intervals. These images were then georeferenced to the fire site using ArcGIS. The process to collect and create these images is detailed below.

A helicopter flew above the fire and a video of the fire progression was generated using a Canon Digital Video Recorder shooting at 30 frames per second. The size of the video files prevented recording the video in one complete segment. The first 25 minutes of the fire were recorded in 5 separate video segments. In addition, several files were desired in case there was a malfunction of the camera during the video capture. The video images were recorded in high definition video MTS (MPEG (Moving Picture Experts Group) Transport Stream) format. The last 10 - 15 minutes of the fire were not recorded as the fire progression was so slow that little additional information would be gained. The helicopter was released from the incident at that time. The metadata for each of the 5 segments were obtained using ExifTool version 9.28 (Harvey 2013) and the results are shown in Table 10. These data were used to calculate the precise frame needed in each video to show the fire activity at desired increments. Please note that the times shown here are the metadata times and not the GPS times. 
Table 10 - Video Segment Metatdata Summary

\begin{tabular}{|l|c|c|c|c|c|}
\hline Video File Name & $\begin{array}{c}\text { Date and Starting Time } \\
\text { from meta data }\end{array}$ & $\begin{array}{c}\text { Start } \\
\text { Time }\end{array}$ & Duration & $\begin{array}{c}\text { Calculated } \\
\text { Ending } \\
\text { Time }\end{array}$ & $\begin{array}{c}\text { Gap Until } \\
\text { Next } \\
\text { Video }\end{array}$ \\
\hline 00005Ignition.MTS & 2012:06:20 11:17:31-08:00 & $11: 17: 31$ & $0: 04: 53.00$ & $11: 22: 24.00$ & $0: 00: 06.00$ \\
\hline 00006Tower1.MTS & 2012:06:20 11:22:30-08:00 & $11: 22: 30$ & $0: 06: 34.00$ & $11: 29: 04.00$ & $0: 00: 05.00$ \\
\hline 00007Tower1-2.MTS & $2012: 06: 20$ 11:29:09-08:00 & $11: 29: 09$ & $0: 04: 15.00$ & $11: 33: 24.00$ & $0: 00: 03.00$ \\
\hline 00008Tower2.MTS & 2012:06:20 11:33:27-08:00 & $11: 33: 27$ & $0: 01: 53.00$ & $11: 35: 20.00$ & $0: 02: 13.00$ \\
\hline 00009Tower2-3.MTS & 2012:06:20 11:37:33-08:00 & $11: 37: 33$ & $0: 05: 29.00$ & $11: 43: 02.00$ & \\
\hline
\end{tabular}

Each video segment was imported into Adobe Photoshop CS6. Adobe

Photoshop CS6 allows manipulation of the video data so that the pixels in every frame of the video may be examined. It was difficult to determine exactly which frame was the first for the ignition of the fire since the distance of the helicopter from the ignition point caused the fire ignition to be contained in only a small number of pixels. However, by manually scanning the images for the first appearance of pixels with the color of the flames, the video time for ignition was determined to be 5 seconds after the start of the first video segment (00005lgnition.mts). This corresponds with a recorded GPS ignition time of 11:18:10 PDT (19:19:10 UTC). Unfortunately, the video camera was never synched to a GPS clock, so there may be a very small error in the times associated with the video images. This is one limitation of the study.

Once the ignition time and frame were determined, the snapshot tool in Photoshop was used to capture the image of the frame. This snapshot was then saved in two formats: as a Photoshop file (.psd) for further pixel image analysis, and as a tiff (Tagged Image File Format) for georeferencing. 
The video was then advanced exactly 30 seconds and new tiff and Photoshop images were captured for that frame. This process was repeated until the end of the video segment.

There were time gaps between the separate video segments. The metadata were used to determine gap length so that the target time in the next segment for the next image could be calculated. Table 11 shows the image times for the first video segment as a representative example. This table includes the actual (GPS) time, corresponding video time stamp, and the corresponding elapsed time of the video segment (Photoshop time). Photoshop images were collected every 30 seconds. Tiff images were collected either every 30 seconds or 60 seconds depending on the rate of change of the fire activity. This analysis was done for all the video segments and the results are shown in Appendix A.

Table 11 - Video Segment 1 Image Times

\begin{tabular}{|c|c|c|c|c|c|c|}
\hline GPS Time & Video Time Stamp & Photoshop Time & Elapsed Time & Comment & Tiff File Name & Photoshop File Name \\
\hline 11:18:05 & 11:17:31 & 0:00:00 & & video start & & \\
\hline 11:18:10 & 11:17:36 & 0:00:05 & 0:00:00 & ignition estimate & 0_00_05_00lgnition.tif & 0_00_05_00Ignition.psd \\
\hline $11: 18: 40$ & 11:18:06 & 0:00:35 & & & & 0_00_35_00.psd \\
\hline $11: 19: 10$ & 11:18:36 & 0:01:05 & 0:01:00 & & 0_01_05_00.tif & 0_01_05_00.psd \\
\hline $11: 19: 40$ & 11:19:06 & 0:01:35 & & & & 0_01_35_00.psd \\
\hline $11: 20: 10$ & 11:19:36 & 0:02:05 & 0:02:00 & & 0_02_05_00.tif & 0_02_05_00.psd \\
\hline $11: 20: 40$ & 11:20:06 & 0:02:35 & & & & 0_02_35_00.psd \\
\hline $11: 21: 10$ & $11: 20: 36$ & 0:03:05 & 0:03:00 & & 0_03_05_00.tif & 0_03_05_00.psd \\
\hline $11: 21: 40$ & 11:21:06 & 0:03:35 & & & & 0_03_35_00.psd \\
\hline $11: 22: 10$ & $11: 21: 36$ & 0:04:05 & 0:04:00 & & 0_04_05_00.tif & 0_04_05_00.psd \\
\hline $11: 22: 40$ & 11:22:06 & 0:04:35 & & & & 0_04_35_00.psd \\
\hline $11: 22: 58$ & $11: 22: 24$ & 0:04:53 & & video end & & \\
\hline $11: 23: 10$ & $11: 22: 36$ & & & target next image & & \\
\hline
\end{tabular}

An ArcGIS project was set up including GIS data obtained from Fort Hunter Liggett and the fire progression images. Fort Hunter Liggett is located within the USDA (United States Department of Agriculture) Alder Peak Quadrangle Topographic Map. Within the Alder Peak Quad, the site is more specifically 
located within the North East Digital Ortho Quarter Quad (NE DOQQ). A digital copy of the Alder Peak NE DOQQ was downloaded from the State of California Geoportal and loaded as the initial layer into an ArcGIS project to establish the UTM Zone 10N projection using the World Geodetic System (WGS) 1984 Datum. Fort Hunter Liggett also provided a digital 5m contour map. During the setup of the experiment, the GPS locations of the field instruments, other key markers, and patches of differing vegetation were recorded. Each subset of information was imported into a different ArcGIS map layer. Table 12 shows the layers contained within the map and the information contained within each of layers. The tiff images created earlier were also loaded into ArcGIS, each as a separate layer.

Table 12 - ArcGIS Layer Definitions

\begin{tabular}{|c|c|}
\hline Layer Name & Information Contained within the Layer \\
\hline hl_field_instruments & $\begin{array}{c}\text { GPS location of all the instruments, towers, } \\
\text { location markers. }\end{array}$ \\
\hline hl_cameras & GPS location of the cameras \\
\hline hl_5m_contours & m topographic contours lines \\
\hline hl_trees_from_ortho & $\begin{array}{c}\text { GPS location of trees georeferenced from the } \\
\text { Alder Peak Ortho Quad. }\end{array}$ \\
\hline hl_veg_poly & $\begin{array}{c}\text { Outline of the differing vegetation on the site. } \\
\text { Generally mustard. }\end{array}$ \\
\hline hl_vegdamage_line & $\begin{array}{c}\text { The trampled vegetation line created during the } \\
\text { installation of the instruments. }\end{array}$ \\
\hline o35121h3ne & $\begin{array}{c}\text { North East Digital Ortho Quarter Quadrangle } \\
\text { the outline of the fire front during each minute of } \\
\text { the fire. }\end{array}$ \\
\hline FireFront & \begin{tabular}{c} 
Tiff Images from the helicopter video \\
\hline Minute_1 (example)
\end{tabular} \\
\hline
\end{tabular}

Each photograph was georeferenced independently in a separate layer within the ArcGIS project. All photograph layers except for the layer of interest were 
turned off to isolate the layer of interest. The helicopter moved location during the videotaping, so the viewing angles of the fire varied in the video. Therefore, the same set of reference points could not be used to georeference every image. Three to five points were selected to use for georeferencing for each image. The points chosen depended on the location of the active fire line. This ensured that the portion of the photograph containing the active fire was georeferenced accurately. For example, two points on the ignition line and the first meteorological tower were selected for the ignition image. As the fire moved up the slope, different points were chosen based on where the fire front was located and what points could be seen through the smoke.

Since the photos were at an oblique angle to the map, it was difficult to match the photograph to the map exactly. Warping of the photo occurred inconsistently, with some sections of the photograph warped slightly and some severely warped. Generally with satellite photographs, the entire photograph is georeferenced to minimize the Root Mean Square (RMS) error. However, only the fire section of the photographs was of interest here, so the georeferencing points were selected to have a good visual match at the area of interest (fire line) and RMS error was ignored in this case. Minute 4 is shown, for example, in Figure 27, and the georeferenced points are shown in Table 13. The complete list of georeference points and the meaning for each reference point designation are given in Appendix C. 
Table 13 - Sample Georeference Points (Minute 4)

\begin{tabular}{|c|c|c|c|c|c|}
\hline Photo & $\begin{array}{c}\text { Point \#1 } \\
\text { Description } \\
\text { Layer }\end{array}$ & $\begin{array}{c}\text { Point \#2 } \\
\text { Description } \\
\text { Layer }\end{array}$ & $\begin{array}{c}\text { Point \#3 } \\
\text { Description } \\
\text { Layer }\end{array}$ & $\begin{array}{c}\text { RMS } \\
\text { Error }\end{array}$ \\
\hline 4 & $\begin{array}{c}\text { O_04_0 } \\
\overline{5} \_00\end{array}$ & $\begin{array}{c}\text { FID50 } \\
\text { LoNRefPost } \\
\text { hl_field_instru } \\
\text { ments }\end{array}$ & $\begin{array}{c}\text { FID2 } \\
\text { Tower1 } \\
\text { hl_field_instru } \\
\text { ments }\end{array}$ & $\begin{array}{c}\text { FID5 } \\
\text { Tower2 } \\
\text { hl_field_instrument } \\
\text { s }\end{array}$ & 0.00 \\
\hline
\end{tabular}

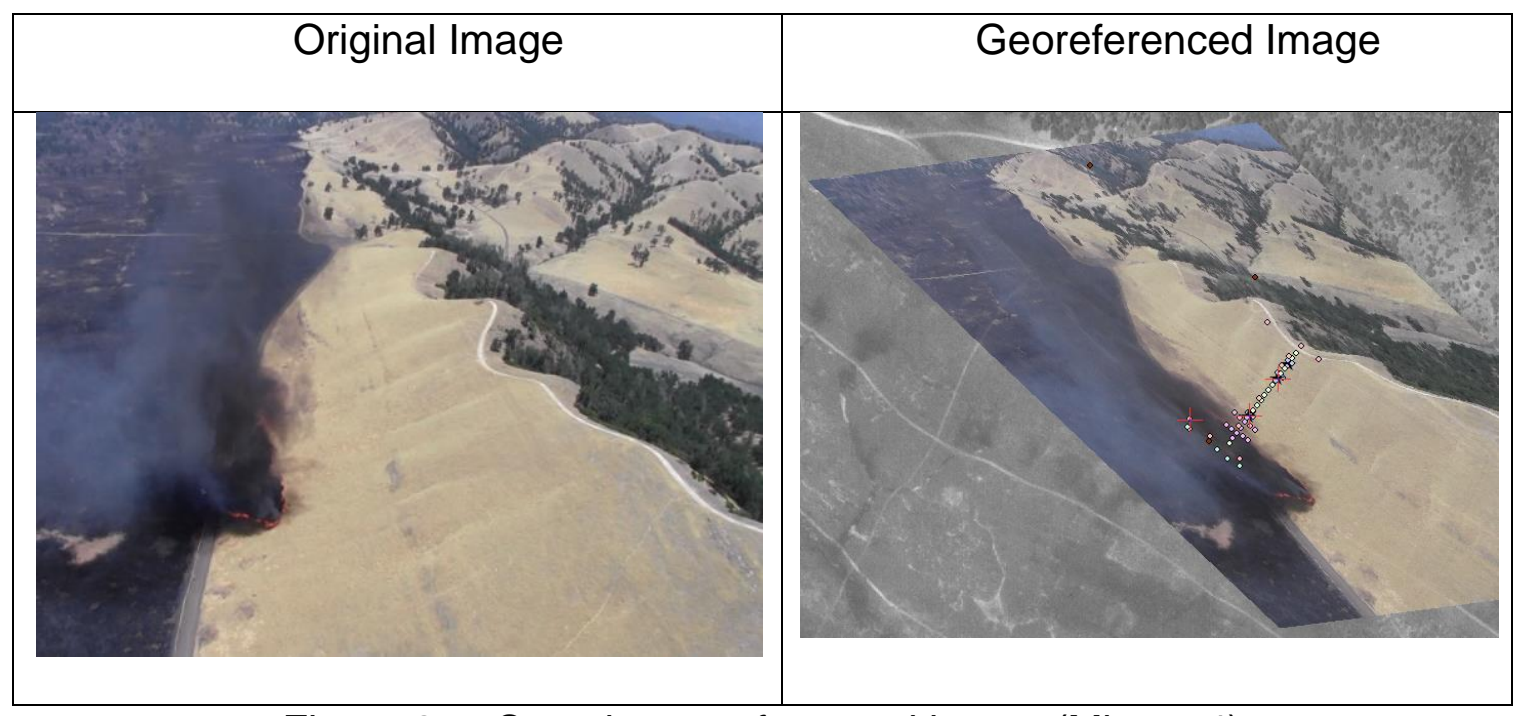

Figure 27 - Sample georeferenced image (Minute 4)

Once the images had been georeferenced, the fire boundary line could then be created. A separate, empty, shapefile (FireFront) for the fire boundaries was created and added to the GIS project. This shapefile used the same coordinate system as the other layers in the project. For each georeferenced photo of the fire, a new map feature was created and saved in the FireFront shapefile. The new feature was a polyline and was manually created by selecting points with the Sketch tool along the visible portions of the fireline. Multiple points were used for each polyline so that the fire boundary line had detail. The name attribute for each polyline was edited to ensure the fire boundaries were associated with the 
correct minute of the fire. The fire boundary for minute four is shown as the black line in Figure 28. All fire boundaries are shown in Figure 29. A table with the original picture, the georeferenced picture, and the fire boundary for each minute may be found in Appendix C.

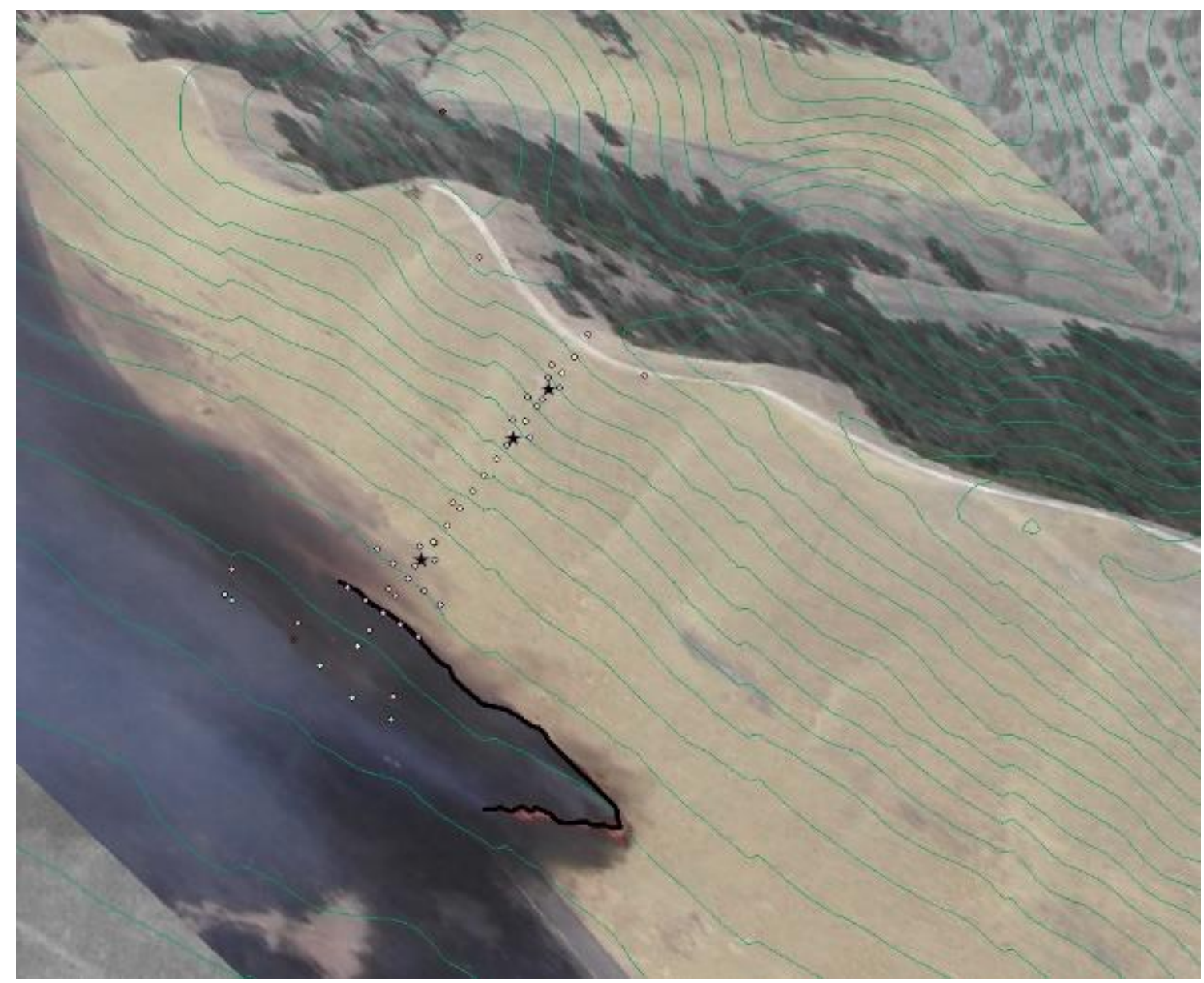

Figure 28 - Fire boundary - shown as a black line for minute 4 


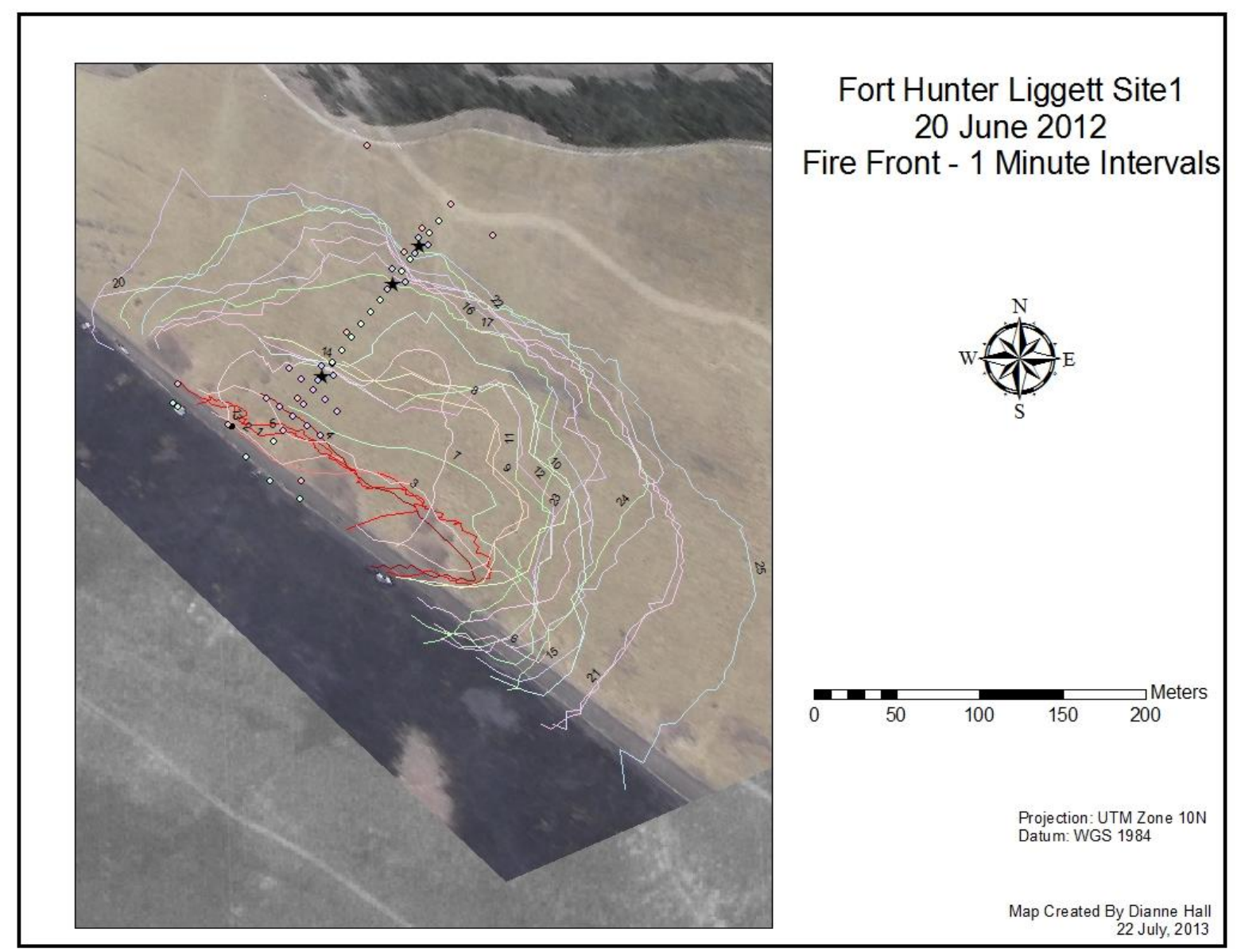

Figure 29 - FHL Site 1 fire boundaries at each minute

\subsubsection{Flame Height and Flame Length Determination}

The images from the still cameras were used to determine flame height and flame length. At each minute, the still camera pictures available were examined to determine the one with the best view of the fire activity. That picture was then analyzed to determine flame height and flame length. Items with known heights, such as the towers and pressure port poles, were identified in the photos and compared with the flames. Flame height, the vertical distance of the flame from the ground, was estimated in each case. The flame length, the distance from the 
base of the flame to the tip of the flame, was also determined. Analysis at minute six is shown in Figure 30 as a sample of the photo analysis technique.

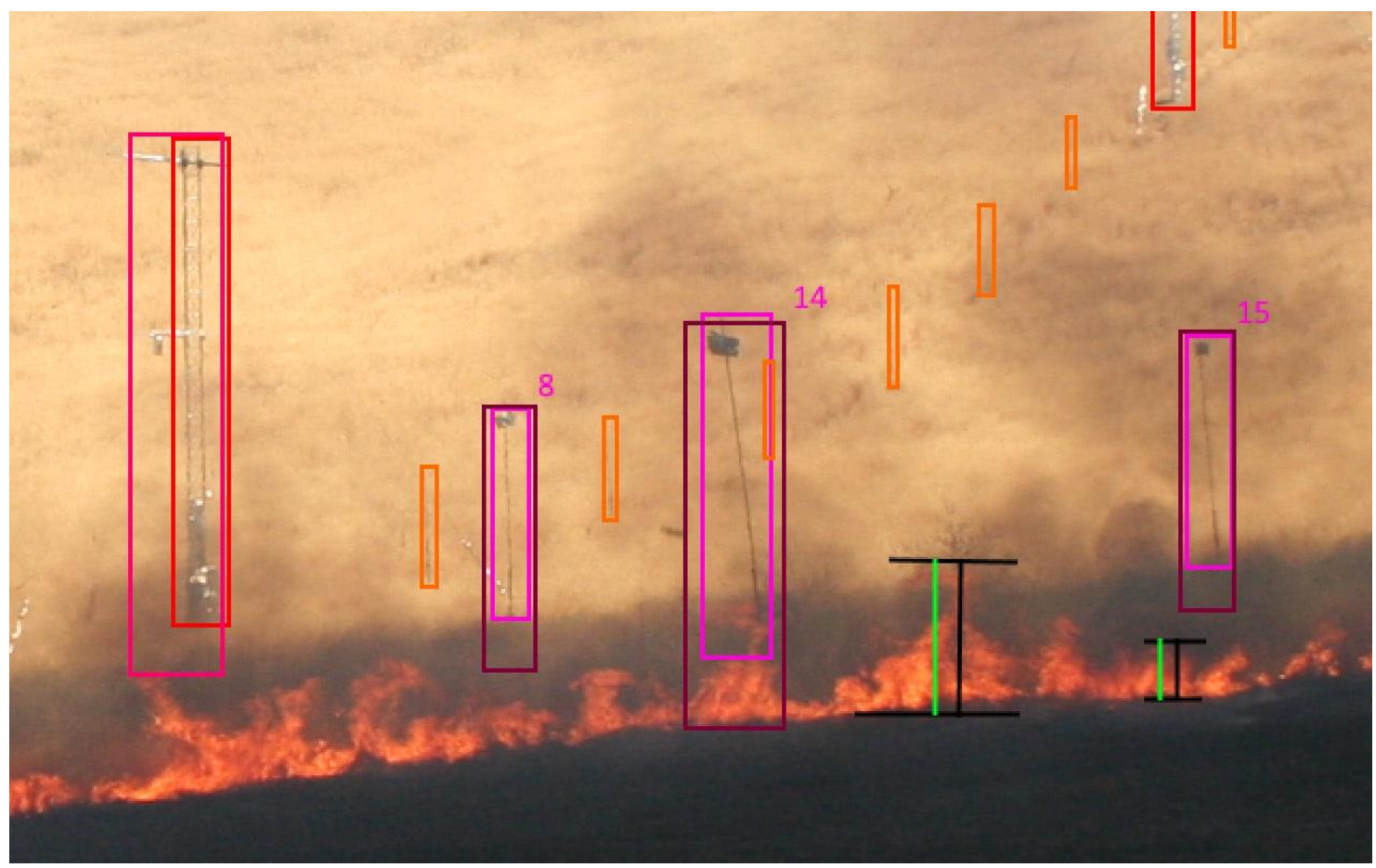

Figure 30 - Sample flame height and length - minute 6

Key

\begin{tabular}{|c|c|}
\hline Black & flame height \\
\hline Green & flame length \\
\hline Purple & $10 \mathrm{ft}$ pole for pressure ports \\
\hline Red & $10 \mathrm{~m}$ micrometeorological tower \\
\hline Orange & Rate of Spread markers $(6 \mathrm{ft})$ \\
\hline Blue & ft fence marker \\
\hline
\end{tabular}

\subsubsection{Heat Flux}

The radiative heating from the fire was measured using the radiometers on each of the $10 \mathrm{~m}$ towers in the experiment site. For a detailed discussion of the setup and analysis see Contezac (2019). 


\section{CHAPTER 3 \\ Observed Fire Behavior}

\subsection{Rate of Spread (ROS)}

To obtain the rate of spread at the fire front, the measurement tool was used on the georeferenced pictures in ArcGIS. For the overall ROS (Show 1919), the distance of the fire front from the ignition line was measured for each minute. Since the ROS observed was not uniform, the ROS for each minute, the distance from the fire front for the previous minute to the current minute, was also measured. These calculations are shown in Table 14 and results presented in Figure 31. Data were not available for every minute; however, the average ROS over the fire experiment was $0.1 \mathrm{~m} \mathrm{~s}^{-1}$. The highest observed ROS were at minute three of $0.4 \mathrm{~m} \mathrm{~s}^{-1}$ and at minute 16 of $0.5 \mathrm{~m} \mathrm{~s}^{-1}$. At minute three, the fire was burning through the taller grass at the base of the slope and through the mustard grass. The high ROS at minute 16 is inconsistent with the fire behavior photographed at that minute. The helicopter changed positions at minute 17 , so the video perspective of the fire changed, and this affected the graphed perimeter of the fire. Table 14 shows a negative progression of the fire for minute 17. Since this is not possible, the method used to obtain the fire perimeter and area may not be the best in this case. 
Table 14 - Calculated Rate of Spread per minute

\begin{tabular}{|c|c|c|c|c|c|c|c|}
\hline $\begin{array}{l}\text { Time since } \\
\text { ignition } \\
\text { (minutes) }\end{array}$ & $\begin{array}{l}\text { Fire Front } \\
\text { Distance } \\
\text { from } \\
\text { Ignition Line } \\
\text { (m) }\end{array}$ & $\begin{array}{c}\text { Fire Front } \\
\text { Distance } \\
\text { Travelled Since } \\
\text { Last } \\
\text { Measurement }\end{array}$ & $\begin{array}{l}\text { Average Rate } \\
\text { of Spread } \\
\text { Since Start of } \\
\text { Fire }\left(\mathrm{m} \mathrm{min}^{-1}\right)\end{array}$ & $\begin{array}{c}\text { Average } \\
\text { Rate of } \\
\text { Spread } \\
\text { Since Start } \\
\text { of Fire } \\
\left(\mathrm{m} \mathrm{sec}^{-1}\right) \\
\end{array}$ & $\begin{array}{l}\text { Rate of Spread } \\
\text { Between } \\
\text { Measurements } \\
\text { of Fire }\left(\mathrm{m} \mathrm{min}^{-1}\right)\end{array}$ & $\begin{array}{c}\text { Rate of } \\
\text { Spread } \\
\text { during Most } \\
\text { Recent } \\
\text { Minute of } \\
\text { Fire }\left(\mathrm{m} \mathrm{s}^{-1}\right) \\
\end{array}$ & Note \\
\hline 0 & 0 & $\mathrm{n} / \mathrm{a}$ & $\mathrm{n} / \mathrm{a}$ & & $n / a$ & & \\
\hline 1 & 0 & $\mathrm{n} / \mathrm{a}$ & $\mathrm{n} / \mathrm{a}$ & & $\mathrm{n} / \mathrm{a}$ & & \\
\hline 2 & 0 & 0 & 0 & 0 & 0 & 0 & $\begin{array}{c}\text { baseline } \\
\text { starting pt }\end{array}$ \\
\hline 3 & 22.728 & 22.728 & 7.58 & 0.13 & 22.728 & 0.379 & 1 minute \\
\hline 4 & 29.245 & 6.517 & 7.31 & 0.12 & 6.517 & 0.109 & 1 minute \\
\hline 5 & $\begin{array}{c}\text { negative } \\
\text { progression }\end{array}$ & $\mathrm{n} / \mathrm{a}$ & $\mathrm{n} / \mathrm{a}$ & $\mathrm{n} / \mathrm{a}$ & $\mathrm{n} / \mathrm{a}$ & $\mathrm{n} / \mathrm{a}$ & \\
\hline 6 & $\begin{array}{c}\text { negative } \\
\text { progression }\end{array}$ & $\mathrm{n} / \mathrm{a}$ & $\mathrm{n} / \mathrm{a}$ & $\mathrm{n} / \mathrm{a}$ & $\mathrm{n} / \mathrm{a}$ & $\mathrm{n} / \mathrm{a}$ & $\mathrm{n} / \mathrm{a}$ \\
\hline 7 & 32.9 & 3.655 & 4.70 & 0.08 & 1.218 & 0.020 & $\begin{array}{c}3 \text { minutes of } \\
\text { data } \\
\text { (averaged) }\end{array}$ \\
\hline 8 & $\begin{array}{l}\text { Unable to } \\
\text { measure }\end{array}$ & $n / a$ & $\mathrm{n} / \mathrm{a}$ & $\mathrm{n} / \mathrm{a}$ & $\mathrm{n} / \mathrm{a}$ & $\mathrm{n} / \mathrm{a}$ & Smoke \\
\hline 9 & $\begin{array}{c}\text { negative } \\
\text { progression }\end{array}$ & $\mathrm{n} / \mathrm{a}$ & $\mathrm{n} / \mathrm{a}$ & $n / a$ & $\mathrm{n} / \mathrm{a}$ & $\mathrm{n} / \mathrm{a}$ & $\begin{array}{l}\text { Helicopter } \\
\text { movement }\end{array}$ \\
\hline 10 & $\begin{array}{c}\text { negative } \\
\text { progression }\end{array}$ & $\mathrm{n} / \mathrm{a}$ & $n / a$ & $n / a$ & $\mathrm{n} / \mathrm{a}$ & $\mathrm{n} / \mathrm{a}$ & $\begin{array}{l}\text { Helicopter } \\
\text { movement }\end{array}$ \\
\hline 11 & 63.655 & 30.755 & 5.79 & 0.10 & 7.689 & 0.128 & $\begin{array}{c}4 \text { minutes of } \\
\text { data } \\
\text { (averaged) }\end{array}$ \\
\hline 12 & 64.278 & 0.623 & 5.36 & 0.09 & 0.623 & 0.010 & $\begin{array}{c}1 \text { minute of } \\
\text { data }\end{array}$ \\
\hline 13 & 64.778 & 0.5 & 4.98 & 0.08 & 0.5 & 0.008 & $\begin{array}{c}1 \text { minute of } \\
\text { data }\end{array}$ \\
\hline 14 & 68.515 & 3.737 & 4.89 & 0.08 & 3.737 & 0.062 & $\begin{array}{c}1 \text { minute of } \\
\text { data }\end{array}$ \\
\hline 15 & $\begin{array}{l}\text { Unable to } \\
\text { measure }\end{array}$ & $\mathrm{n} / \mathrm{a}$ & $\mathrm{n} / \mathrm{a}$ & $n / a$ & $\mathrm{n} / \mathrm{a}$ & $\mathrm{n} / \mathrm{a}$ & \\
\hline 16 & 132.424 & 63.909 & 8.28 & 0.14 & 31.955 & 0.533 & $\begin{array}{c}2 \text { minutes of } \\
\text { data } \\
\text { (averaged) }\end{array}$ \\
\hline 17 & $\begin{array}{c}\text { negative } \\
\text { progression }\end{array}$ & $\mathrm{n} / \mathrm{a}$ & $\mathrm{n} / \mathrm{a}$ & $\mathrm{n} / \mathrm{a}$ & $\mathrm{n} / \mathrm{a}$ & $\mathrm{n} / \mathrm{a}$ & $\begin{array}{l}\text { Helicopter } \\
\text { movement }\end{array}$ \\
\hline 18 & no photo & $\mathrm{n} / \mathrm{a}$ & $n / a$ & $n / a$ & $\mathrm{n} / \mathrm{a}$ & $\mathrm{n} / \mathrm{a}$ & \\
\hline 19 & no photo & $\mathrm{n} / \mathrm{a}$ & $\mathrm{n} / \mathrm{a}$ & $n / a$ & $\mathrm{n} / \mathrm{a}$ & $\mathrm{n} / \mathrm{a}$ & \\
\hline 20 & 137.048 & 4.624 & 6.85 & 0.11 & 1.156 & 0.019 & $\begin{array}{c}4 \text { minutes of } \\
\text { data } \\
\text { (averaged) }\end{array}$ \\
\hline 21 & 140.826 & 3.778 & 6.71 & 0.11 & 3.778 & 0.063 & $\begin{array}{c}1 \text { minute of } \\
\text { data }\end{array}$ \\
\hline 22 & 141.003 & 0.177 & 6.41 & 0.11 & 0.177 & 0.003 & $\begin{array}{c}1 \text { minute of } \\
\text { data }\end{array}$ \\
\hline 23 & 142.3 & 1.297 & 6.19 & 0.10 & 1.297 & 0.022 & $\begin{array}{c}1 \text { minute of } \\
\text { data }\end{array}$ \\
\hline 24 & 147.862 & 5.562 & 6.16 & 0.10 & 5.562 & 0.093 & $\begin{array}{c}1 \text { minute of } \\
\text { data }\end{array}$ \\
\hline 25 & $\begin{array}{c}\text { negative } \\
\text { progression }\end{array}$ & $\mathrm{n} / \mathrm{a}$ & $\mathrm{n} / \mathrm{a}$ & $\mathrm{n} / \mathrm{a}$ & $\mathrm{n} / \mathrm{a}$ & $\mathrm{n} / \mathrm{a}$ & \\
\hline
\end{tabular}




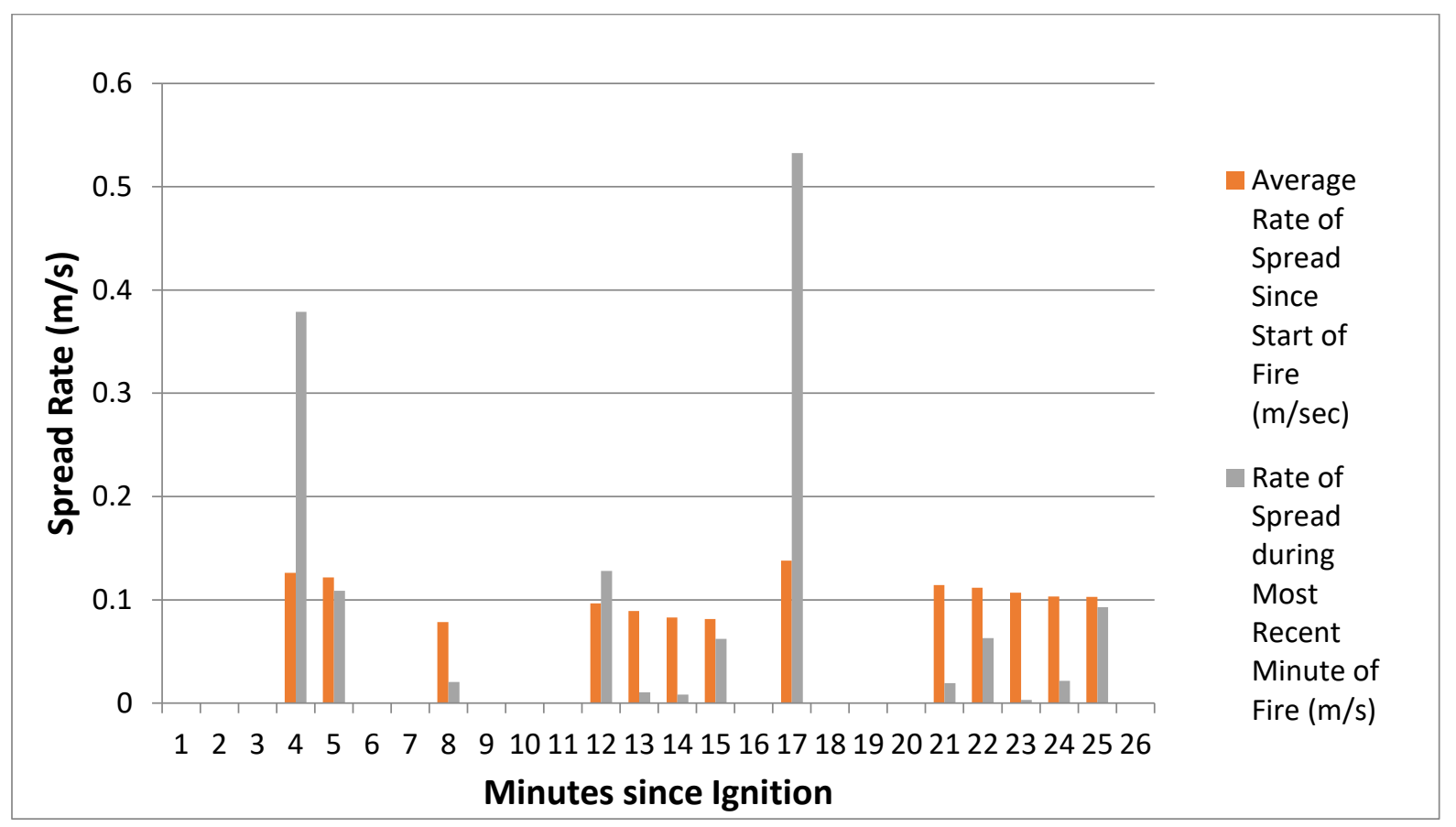

Figure 31 - Upslope rate of spread

\subsection{Direction of Spread}

The direction of spread was identified for each minute from the increase in fire perimeter. Upslope is defined as $0^{\circ}$. The location and direction of maximum spread for each minute is shown in Figure 32 and Table 15. Several minutes, such as 2, 5, and 9, demonstrated maximum ROS upslope. In minutes 12 and 13, for example, the maximum ROS was on the left flank. In minutes 5, 13, 17, for example, the maximum ROS was on the right flank and was cross slope rather than up slope. 
Table 15 - Direction of Maximum Fire Spread (in degrees)

\begin{tabular}{|c|c|}
\hline Minute Since Ignition & $\begin{array}{l}\text { Direction of Maximum Fire Spread } \\
\text { in degrees }\left(0^{\circ} \text { is upslope) }\right.\end{array}$ \\
\hline 2 & 0 \\
\hline 3 & 110 \\
\hline 4 & 30 \\
\hline $5-1$ & 0 \\
\hline $5-2$ & 105 \\
\hline 6 & 0 \\
\hline 7 & 0 \\
\hline $9-1$ & 40 \\
\hline $9-2$ & 0 \\
\hline 11 & 0 \\
\hline 12 & 310 \\
\hline 13 & 300 \\
\hline $13-2$ & 80 \\
\hline 14 & 30 \\
\hline 15 & 30 \\
\hline 16 & 0 \\
\hline $17-1$ & 65 \\
\hline $17-2$ & 0 \\
\hline $17-3$ & 310 \\
\hline 20 & 310 \\
\hline 21 & 280 \\
\hline 22 & 0 \\
\hline 23 & 0 \\
\hline 24 & 300 \\
\hline
\end{tabular}




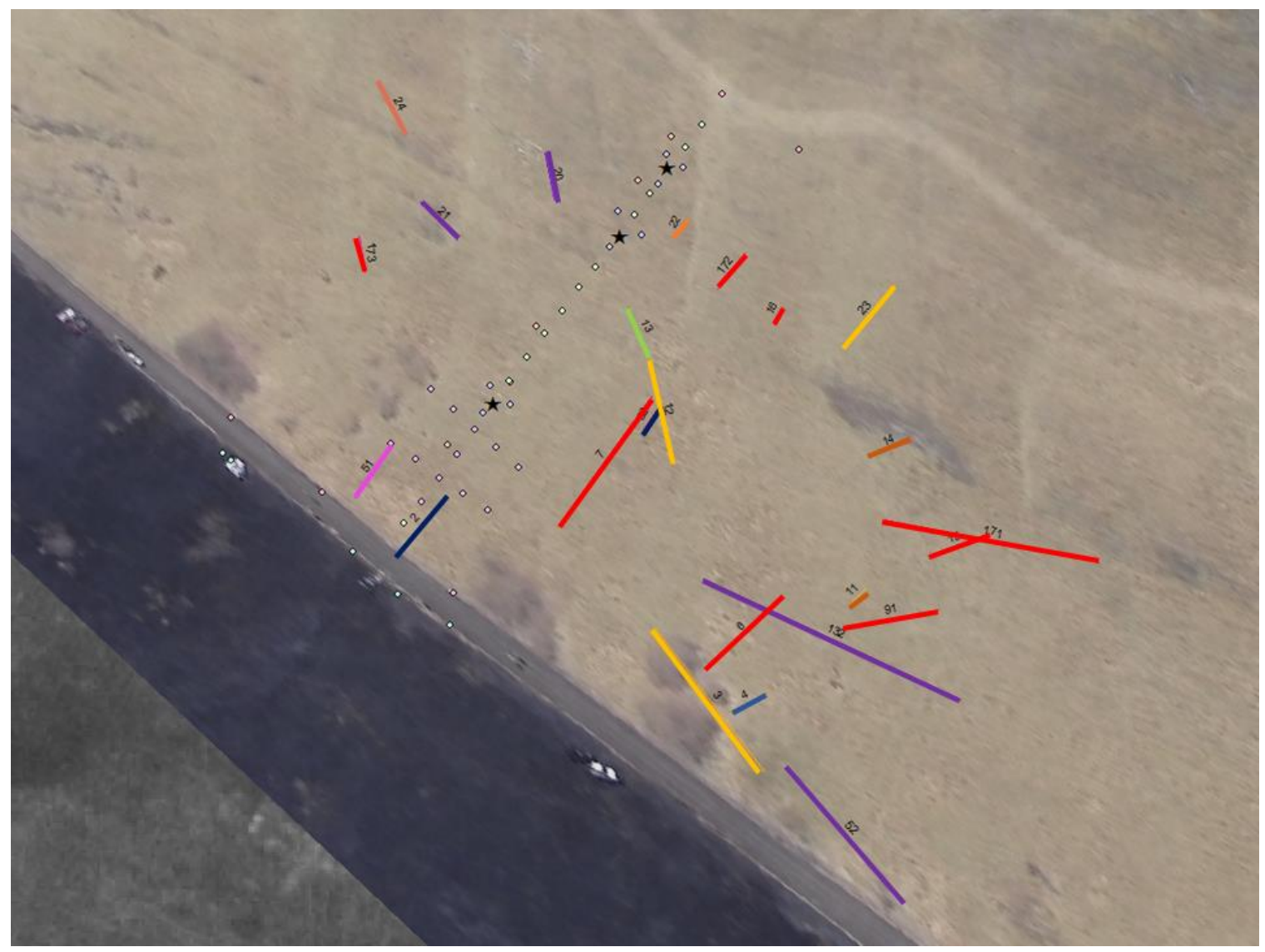

Figure 32 - Location of maximum fire rate of spread at each minute

\subsection{Flame Length, Flame Height, Flame Angle}

The observed flame heights, flame lengths and flame angles are given in Table 16 below. The flame angle is given from the vertical. When the flame angle is $0^{\circ}$, then the flame is not influenced by wind. This is the case for minutes 0-3. At minutes 4 through 12 there is a flame angle indicating that the flames were being influenced by wind. From Minute 13 the flame angle was $0^{\circ}$, indicating that the flame was no longer under the influence of wind. The largest 
flame angle occurred at minutes 4 and 5 which is consistent with the increase in wind (Figure 25).

Table 16 - Observed Flame Height, Length, and Angle at Each Minute

\begin{tabular}{|c|c|c|c|}
\hline Minute & Flame Height $(\mathrm{m})$ & Flame Length $(\mathrm{m})$ & Flame Angle \\
\hline 0 & 0.7 & 0.7 & 0 \\
\hline 1 & $1-1.5$ & $1-1.5$ & 0 \\
\hline 2 & $0.5-1.0$ & $0.75-1.5$ & 0 \\
\hline 3 & $0.5-1.0$ & $0.5-1.0$ & 0 \\
\hline 4 & $0.1-0.3$ & $0.1-0.3$ & 45 \\
\hline 5 & $0.5-1.0$ & $0.5-1.0$ & 45 \\
\hline 6 & $0.5-1.0$ & $0.5-1.0$ & 30 \\
\hline 7 & $1.5-4.0$ & $1.5-4.5$ & 15 \\
\hline 8 & $1.0-3.0$ & $1.0-3.0$ & 15 \\
\hline 9 & $1.0-4.0$ & $1.0-4.0$ & 30 \\
\hline 10 & $0.5-1.0$ & $0.5-1.0$ & 15 \\
\hline 11 & $0.25-0.5$ & $0.25-0.5$ & 0 \\
\hline 12 & $0.25-0.5$ & $0.25-0.5$ & 30 \\
\hline 13 & No picture available & No picture available & - \\
\hline 14 & $2.0-5.0$ & $2.0-5.0$ & 0 \\
\hline 15 & 2.0 & 2.0 & 0 \\
\hline 16 & $1.0-3.0$ & $1.0-3.0$ & 0 \\
\hline 17 & No picture available & No picture available & - \\
\hline 18 & $0.5-2.0$ & $0.5-2.0$ & 0 \\
\hline 19 & $0.5-1.0$ & $0.5-1.2$ & 0 \\
\hline 20 & $0.25-2.0$ & $0.25-2.0$ & 0 \\
\hline 21 & No picture available & No picture available & - \\
\hline 22 & No picture available & No picture available & - \\
\hline 23 & No picture available & No picture available & - \\
\hline 24 & No picture available & No picture available & - \\
\hline 25 & $0.25-0.5$ & $0.25-0.5$ & 0 \\
\hline & & & \\
\hline
\end{tabular}

\subsection{Fire Perimeter and Fire Area}

After the creation of the fire line, the length of the fire line perimeter and the area of the fire were measured using the georectified photos in ArcGIS as detailed previously. The values are given in Table 17 and are graphed in Figure 33 (perimeter) and Figure 34 (area). The apparent reduction in fire area at 
minutes $11,13,17$, and 23 is due to the change of position of the helicopter, which changed the perspective of the video image.

Table 17 - Observed Fire Perimeter and Area at Each Minute

\begin{tabular}{|c|c|c|c|}
\hline Minute & $\begin{array}{c}\text { Fire Perimeter } \\
(\mathrm{m})\end{array}$ & Fire Area $\left(\mathrm{m}^{2}\right)$ & Comment \\
\hline 1 & 92 & - & Fire line creation \\
\hline 2 & 121 & - & Fire line creation \\
\hline 3 & 348 & 2874 & \\
\hline 4 & 386 & 5200 & Tower 1 \\
\hline 5 & 447 & 5524 & \\
\hline 6 & 571 & 8929 & Helicopter position \\
change
\end{tabular}




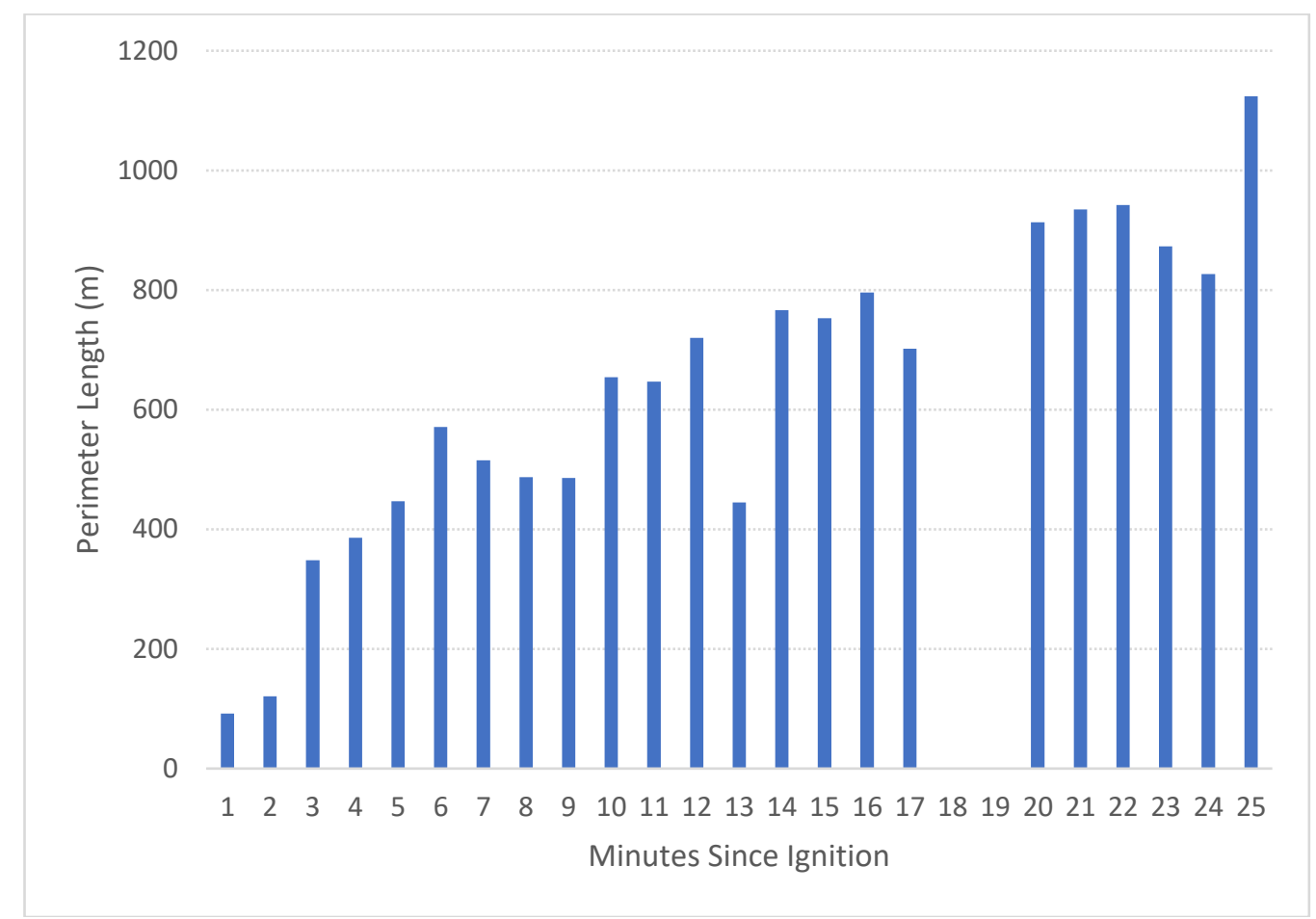

Figure 33 - Fire perimeter

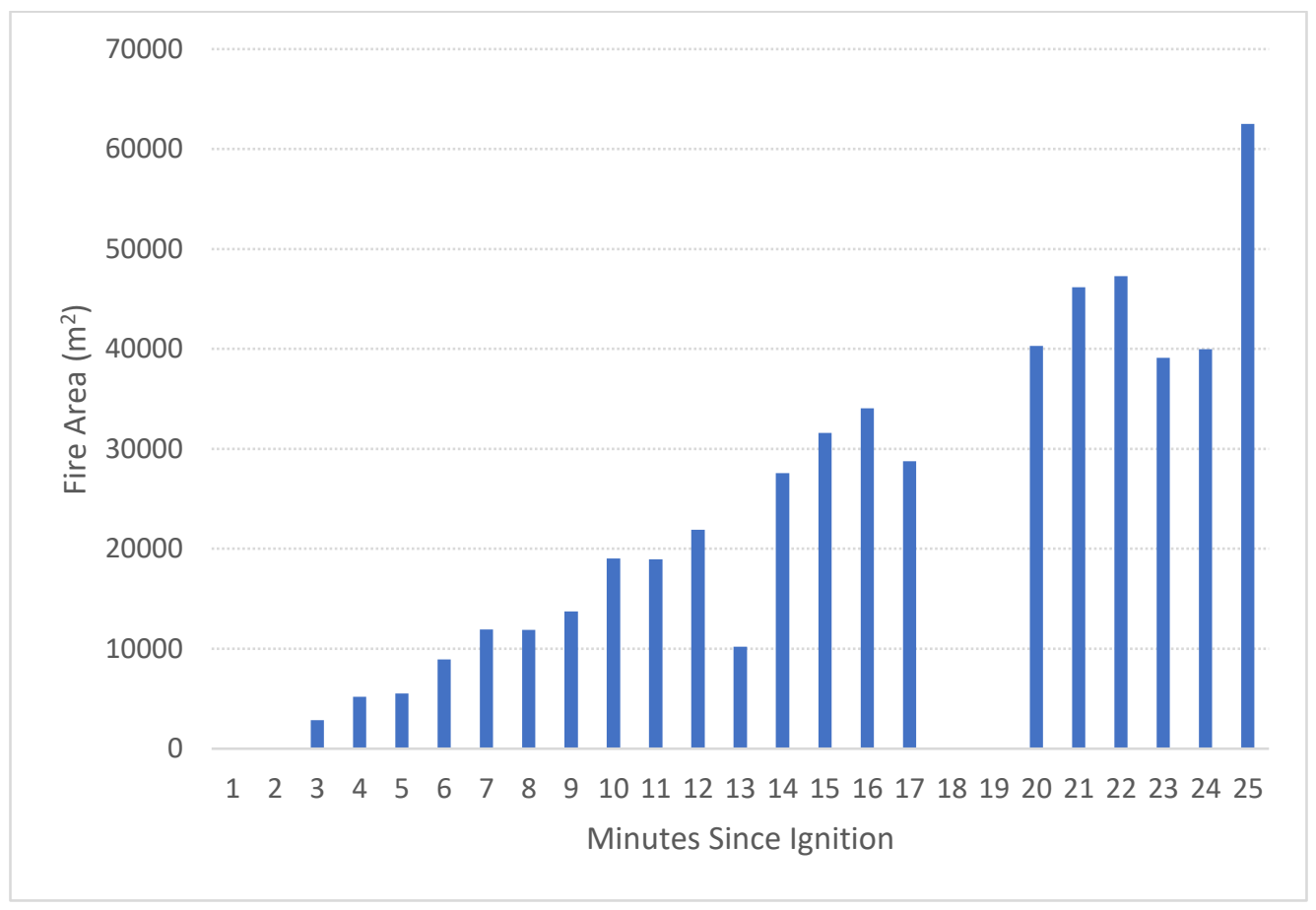

Figure 34 - Fire area 


\section{CHAPTER 4 \\ Analysis of Fire Behavior}

\subsection{Fire Behavior Prediction (BehavePlus)}

The software BehavePlus was used to predict the fire behavior as mentioned earlier. Due to the slope change from $15 \%\left(9^{\circ}\right)$ to $30 \%\left(17^{\circ}\right)$ at Tower 1 , the runs were separated into Ignition to Tower 1 and Tower 1 to Tower 3 . The input and output data of the BehavePlus runs from Ignition to Tower 1 are shown in Table 18 and for Tower 1 to Tower 3 in Table 19. The rate of spread and flame length predicted for this fire are classified as low (Scott and Burgan 2005).

Table 18 - BehavePlus Fire Prediction for Ignition to Tower 1

\begin{tabular}{|c|c|c|c|}
\hline Inputs & & & \\
\hline Fuel Model & GR4 & GR4 & 3 \\
\hline 1HR Moisture & $1.6 \%$ & $2.25 \%$ & $3 \%$ \\
\hline Midflame Wind Speed & $7.7 \mathrm{~km} \mathrm{hr}^{-1}$ & $7.7 \mathrm{~km} \mathrm{hr}^{-1}$ & $7.7 \mathrm{~km} \mathrm{hr}^{-1}$ \\
\hline Wind Direction (from N) & $128^{\circ}$ & $128^{\circ}$ & $128^{\circ}$ \\
\hline Air Temperature & $33.3^{\circ} \mathrm{C}$ & $33.3^{\circ} \mathrm{C}$ & $33.3^{\circ} \mathrm{C}$ \\
\hline Fuel Shading & $0 \%$ & $0 \%$ & $0 \%$ \\
\hline Slope & $15 \%$ & $15 \%$ & $15 \%$ \\
\hline Aspect & $225^{\circ}$ & $225^{\circ}$ & $225^{\circ}$ \\
\hline Spread Direction & $45^{\circ}$ & $45^{\circ}$ & $45^{\circ}$ \\
\hline Elapsed Time & $\begin{array}{c}0.133 \mathrm{hr} \\
\text { (7 minutes) }\end{array}$ & $\begin{array}{c}0.133 \mathrm{hr} \\
\text { (7 minutes) }\end{array}$ & $\begin{array}{c}0.133 \mathrm{hr} \\
\text { (7 minutes) }\end{array}$ \\
\hline Outputs & & & \\
\hline $\begin{array}{l}\text { Surface Rate of Spread } \\
\left(\mathrm{m} \mathrm{min}^{-1}\right)\end{array}$ & 0.9 & 0.8 & 5.1 \\
\hline $\begin{array}{c}\text { Fireline Intensity } \\
\left(\mathrm{kW} \mathrm{m}^{-1}\right)\end{array}$ & 66 & 48 & 878 \\
\hline Flame Length $(\mathrm{m})$ & 0.5 & 0.5 & 1.7 \\
\hline 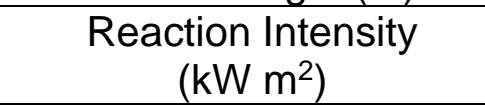 & 346 & 298 & 666 \\
\hline $\begin{array}{l}\text { Surface Spread Distance } \\
(\mathrm{m})\end{array}$ & 6.3 & 5.4 & 41.1 \\
\hline $\operatorname{Area}\left(\mathrm{m}^{2}\right)$ & 2,000 & 1,000 & 65,000 \\
\hline Perimeter $(\mathrm{m})$ & 155 & 56.2 & 1009 \\
\hline
\end{tabular}


Table 19 - BehavePlus Fire Prediction for Tower 1 to Tower 3

\begin{tabular}{|c|c|c|c|}
\hline Inputs & & & \\
\hline Fuel Model & GR4 & GR4 & 3 \\
\hline 1HR Moisture & $1.6 \%$ & $2.25 \%$ & 3 \\
\hline Midflame Wind Speed & $7.7 \mathrm{~km} \mathrm{hr}^{-1}$ & $7.7 \mathrm{~km} \mathrm{hr}^{-1}$ & $7.7 \mathrm{~km} \mathrm{hr}^{-1}$ \\
\hline Wind Direction (from N) & $128^{\circ}$ & $128^{\circ}$ & $128^{\circ}$ \\
\hline Air Temperature & $33.3^{\circ} \mathrm{C}$ & $33.3^{\circ} \mathrm{C}$ & $33.3^{\circ} \mathrm{C}$ \\
\hline Fuel Shading & $0 \%$ & $0 \%$ & $0 \%$ \\
\hline Slope & $30 \%$ & $30 \%$ & $30 \%$ \\
\hline Aspect & $225^{\circ}$ & $225^{\circ}$ & $225^{\circ}$ \\
\hline Spread Direction & $45^{\circ}$ & $45^{\circ}$ & $45^{\circ}$ \\
\hline Elapsed Time & $\begin{array}{c}0.28 \mathrm{hr} \\
\text { (17 minutes) }\end{array}$ & $\begin{array}{c}0.28 \mathrm{hr} \\
(17 \text { minutes })\end{array}$ & $\begin{array}{c}0.28 \mathrm{hr} \\
\text { (17 minutes) }\end{array}$ \\
\hline \multicolumn{4}{|l|}{ Outputs } \\
\hline $\begin{array}{l}\text { Surface Rate of Spread } \\
\left(\mathrm{m} \mathrm{min}^{-1}\right)\end{array}$ & 1.0 & 0.9 & 5.6 \\
\hline $\begin{array}{l}\text { Fireline Intensity } \\
\left(\mathrm{kW} \mathrm{m}^{-1}\right)\end{array}$ & 72 & 53 & 958 \\
\hline Flame Length $(\mathrm{m})$ & 0.6 & 0.5 & 1.8 \\
\hline $\begin{array}{l}\text { Reaction Intensity } \\
\left(\mathrm{kW} \mathrm{m}^{2}\right)\end{array}$ & 346 & 298 & 666 \\
\hline $\begin{array}{l}\text { Surface Spread } \\
\text { Distance }(\mathrm{m})\end{array}$ & 16.9 & 14.5 & 94.4 \\
\hline Area $\left(m^{2}\right)$ & ${ }^{*} 9,000$ & ${ }^{\star} 7,000$ & ${ }^{*} 287,000$ \\
\hline Perimeter (m) & ${ }^{*} 376$ & ${ }^{*} 322$ & ${ }^{\star} 2118$ \\
\hline
\end{tabular}

Note that the area and perimeter for the second run of the model, from Tower 1 to Tower 3 , assume a point source for the ignition at Tower 1 . Since this is not the case, the area and perimeter given at the end of the second BehavePlus run would not be the predicted area and perimeter of the entire fire, just the new section of the fire from Tower 1 to Tower 3 . The total perimeter can be estimated by adding the perimeters of the two runs, as can the total area be estimated by adding the areas of the two runs. 


\subsection{Observed vs. Predicted Fire Behavior}

The fire reached Tower 1 at minute seven of the fire, with an observed average rate of spread from ignition of $4.7 \mathrm{~m} \mathrm{~min}^{-1}$. This was far faster than the rate of $0.9 \mathrm{~m} \mathrm{~min}^{-1}$ predicted when using the GR4 fuel model at the lower fuel moisture. Fuel Model 3 more closely represented the taller grass observed in the initial part of the slope as shown in Figure 16. When using Fuel Model 3, the predicted rate of spread was $5.1 \mathrm{~m} \mathrm{~min}^{-1}$, and this more closely approximated the observed fire rate of spread.

Tower 3 was reached at minute 25 of the fire. Data were not available for minute 25, but at minute 24 the average rate of spread from Tower 1 to Tower 3 was $6.16 \mathrm{~m} \mathrm{~min}^{-1}$, which was slightly above the predicted $5.6 \mathrm{~m} \mathrm{~min}^{-1}$ (FM3), but far above the predicted $1 \mathrm{~m} \mathrm{~min}^{-1}$ (GR4). However, this average is skewed by the $31.9 \mathrm{~m} \mathrm{~min}^{-1}$ ROS observed at minute 16 . The rates of spread varied between $0.1 \mathrm{~m} \mathrm{~min}^{-1}$ and $6 \mathrm{~m} \mathrm{~min}^{-1}$, which on the lower end match the GR4 prediction, while on the higher end match the FM3 prediction.

The observed perimeter of the fire at minute seven was $515 \mathrm{~m}$, which was below the perimeter of 1009 m predicted by FM3, but above the $155 \mathrm{~m}$ predicted by GR4. The observed perimeter at minute 25 was $1124 \mathrm{~m}$, which was below the estimate value of $3127 \mathrm{~m}$ (FM3), but again above the estimate of $531 \mathrm{~m}$ (GR4).

The observed area of the fire at minute seven was $11933 \mathrm{~m}^{2}$, which was below the predicated area of $65,000 \mathrm{~m}^{2}$ (FM3), and well below the area predicted 
for GR4. The observed area of the fire at minute 25 was $62498 \mathrm{~m}^{2}$, which was well below the area predicted by both models.

The observed flame lengths were close to the predicted flame lengths of 0.6 m (GR4) and $1.8 \mathrm{~m}$ (FM3), except for minutes seven to nine when the observed flame lengths exceeded the predictions. The sonic anemometer on Tower 1 recorded an increase of wind speed at that time (Figure 26). The BehavePlus runs used a wind speed of $7.7 \mathrm{~km} \mathrm{hr}^{-1}\left(2 \mathrm{~m} \mathrm{~s}^{-1}\right)$ obtained from the AWS at the ignition line. However, the sonic anemometers show that the wind was not steady during the fire and wind speeds actually varied from 0 to $9 \mathrm{~m} \mathrm{~s}^{-1}$.

Flame heights and flame angles were not predicted by BehavePlus, so cannot be compared with the observations.

The experiment can be divided into 2 distinct sections. The first section was from ignition to Tower 1 . In this section, the slope was $15 \%$, the most appropriate fuel model was FM3, and the winds were at $45^{\circ}$ from upslope. During this portion of the experiment, the fire behavior was close to the predicted values. The second section was from Tower 1 to Tower 3 . In this section the slope increased to $30 \%$, the most appropriate fuel model was GR4, and the winds had become downslope. During this portion of the experiment, the fire behavior was much less than expected and occasional backing fire behavior was observed 


\section{CHAPTER 5 \\ Summary, Conclusions, Limitations of Study, Further Research}

\subsection{Summary}

A headfire burned up a grass slope that had been instrumented in situ and remotely. Both photographic and video images of the fire were captured. The data from the instruments and the images were analyzed to determine the fire behavior.

The original fuel model selected for the BehavePlus simulation was Fuel Model 3 (FM3). After the fuel beds were analyzed, Grass Group 4 (GR4) appeared to be the best selection. However, when both simulations were run and compared with observed fire behavior, FM3 predicted more intense fire behavior than was observed, while GR4 predicted less intense fire behavior.

The site selected for the fire was subject to prescribed burns each spring. The fire department even expressed surprise at the slow rate of burn for this fire. The original prediction was for a 12-minute burn duration from ignition to Tower

3. During the experiment the fire took almost 25 minutes to reach Tower 3 . The forward progression was slowed due to unexpected surfacing of the upper level winds during the experiment, as shown in Figure 24. The winds changed from upslope to downslope during this surfacing, and the fire became wind-driven rather than slope-driven. The head of the fire became a backing fire during this wind reversal. This resulted in a smaller perimeter and area for the fire than predicted by FM3. 
Since the wind was not in alignment with the slope, the fire burned across the slope. This meant that the ignition for the fire could not be a point, but had to be a line to ensure that the fire burned through the instrument towers. BehavePlus assumes a point of origin for fires so this may have affected our results.

The flame lengths and flame heights varied from 0.5 to $4 \mathrm{~m}$. This was within the expected fire behavior. The most intense fire burned when the fire reached Tower 1. This was when the wind reversal was occurring.

\subsection{Conclusions}

At the start of the experiment, the wind and slope were in alignment so that the forward rate of spread was upslope / upwind. Wind and slope were complementary contributors to the fire behavior. The fire burned upslope and exhibited expected fire behavior with respect to rates of spread and flame lengths. This behavior continued until Tower 1 was reached.

At Tower 1, the slope increased so an increase in the rate of spread was predicted. The fuel load decreased so the flame lengths were expected to decrease slightly. However, a wind reversal also occurred as the fire reached Tower 1.

After the wind reversal, the slope and wind were in opposition with the wind driving the fire downslope and the slope driving the fire upslope. The forward progression of the fire slowed between Tower 1 and Tower 3 , and the flame lengths were reduced to less than $1 \mathrm{~m}$. At times, backing fire behavior was observed when the force of the wind overcame the force of the slope. 
From this experiment, we can conclude that the wind speed and direction can overcome the influence of slope on fire behavior. This has implications for firefighter safety on wildland fires as fire is generally assumed to progress upslope. If the wind overcomes the influence of the slope, and the fire progression changes direction, then firefighters may find themselves in the path of the fire. It is important that the vertical wind profile on an incident be understood, not just the surface level winds, so that the potential for upper level winds to surface may be considered in firefighter response planning.

\subsection{Limitations of the Study}

There were several limitations to this study. The video camera used in the helicopter was not synced to a GPS clock, so exact ignition time was difficult to determine. The smoke from the fire obscured the fire line. It was difficult to determine precise fire boundary. The helicopter moved to different locations to try to observe the fire line through the smoke. This changed the georeferencing points for the photographs, so the fire perimeter estimation was not consistent. At times the fire boundary appeared to shrink as time progressed. The infrared camera that was supposed to be used in the helicopter malfunctioned, so the fire perimeters could not be obtained using that instrument. The laboratory oven malfunctioned when drying fuel moisture samples, destroying most of the samples, so the fuel moisture content was an estimate. The flame heights were difficult to measure as there were no height markers placed within the experiment plot. The rate of spread markers were difficult to see through the smoke and 
were not in line with the fire progression, so they could not be used to estimate the rate of spread.

Additionally, BehavePlus is generally used to predict fire behavior over longer periods of time, such as hours or days rather than minutes. It is also generally used for much larger geographic areas. BehavePlus assumes an average constant wind speed for making its predictions, which is appropriate for long durations, but there were several wind speed and direction changes during the 25-minute experiment run.

The planned ignition was for earlier in the day when conditions are generally calmer; however, there were several logistical delays on the day of the fire which pushed out the start. This meant dryer fuels and exposure to surfacing winds.

\subsection{Further Research / Next Steps}

Since the experiment site is subject to annual prescribed burns, it would be useful to collect information on subsequent burns. The fire behavior could be observed using Lidar and video only rather than the entire instrument suite used in this experiment. This would enable comparison of the fire behavior from this experiment with fire behavior when the winds do not surface.

To better understand the behavior of fire on slopes, a longer duration fire should be studied which would require a longer slope. Again, remote instruments such as Lidar and videographic recordings would gather much of the information needed to analyze the fire behavior. Once fire behavior on grass 
slopes is understood, then the same experiment should be run in different fuel types, such as California chaparral or brush.

\section{Acknowledgements}

The members of the Fire Weather Research Lab contributed greatly to this experiment. The following figures listed in Table 20 used in this thesis were created by other members of the Fire Weather Research Lab team as indicated and are used with permission. The Biomass fuel loading calculations were performed by a team from the US Forest Service Pacific Northwest Wildland Fire Science Laboratory and are used with permission.

Table 20 - Figures created by team members

\begin{tabular}{|l|l|}
\hline \multicolumn{1}{|c|}{ Figure/Table } & Created By \\
\hline Figure 22 - Sodar wind profile 20 June 2012 & Jon Contezac \\
\hline $\begin{array}{l}\text { Figure 23 - Lidar RHI profile 08:32 PDT (1532 } \\
\text { UTC) 20 June 2012 }\end{array}$ & Allison Charland Bagley \\
\hline $\begin{array}{l}\text { Figure 24 - Lidar at ignition 11:19 PDT (1919 } \\
\text { UTC) 20 June 2012 }\end{array}$ & Allison Charland Bagley \\
\hline GIS of the experiment plot and ArcGIS setup & Braniff Davis \\
\hline $\begin{array}{l}\text { Table 9 - Biomass Fuel Loading Fort Hunter } \\
\text { Liggett Site 1 }\end{array}$ & $\begin{array}{l}\text { US Forest Service Pacific } \\
\text { Northwest Research Station, } \\
\text { Pacific Wildland Fire } \\
\text { Sciences Laboratory }\end{array}$ \\
\hline
\end{tabular}




\section{References}

Albini, Frank A. 1976. Estimating wildfire behavior and effects. USDA For. Serv. Gen. Tech. Rep. INT-30, 92 pp, Inter-mountain Forest and Range Experiment Station, Ogden, Utah 84401. https://www.fs.fed.us/rm/pubs_int/int_gtr030.pdf

American Meteorological Society, cited 2019: "Weather". Glossary of Meteorology. [Available online at http://glossary.ametsoc.org/wiki/Weather]

Anderson, H., Brackebusch, A., Mutch, R., and Rothermel, R., 1966: Mechanisms of Fire Spread, Research Progress Report 2 - INT-28. 35pp, Ogden, Utah: USDA Forest Service, Intermountain Forest and Range Experiment Station.

https://www.fs.fed.us/rm/pubs_exp_for/priest_river/exp_for_priest_river_1966 _anderson.pdf

Anderson, Hal E.1982. Aids to determining fuel models for estimating fire behavior. USDA Forest Service General Technical Report INT-122, 22 pp, Intermountain. Forest and Range Experimental Station., Ogden,Utah 8440. https://www.fs.fed.us/rm/pubs_int/int_gtr122.pdf

Anderson, W., Pastor, E., Butler, C., Catchpole, E., Dupuy J-L, Fernandes, P., Ventura, J., 2006: Evaluating Models to estimate flame characteristics for free-burning fires using laboratory and field data. Forest Ecology and Management, 1-19.

Andrews, P.L., C.D. Bevins, and R.C. Seli. 2005: BehavePlus fire modeling system version 3.0 user's guide. 153 pp, USDA Forest Service General Technical Report RMRS-GTR-106.

https://www.frames.gov/documents/behaveplus/publications/Andrews_Bevins _Seli_2004_RMRS-GTR-DRAFT.pdf

Beer, T.,1993: The speed of a fire front and its dependence on wind speed. International Journal of Wildland Fire, 3, 193-202.

Bird, R. B., Stewart, W. E., and Lightfoot, E. N., 1960: Transport Phenomena. Wiley. 780 pp.

Butler, B. W., 2014: Wildland firefighter safety zones: a review of past science and summary of future needs. International Journal of Wildland Fire, 23, 295308

Byram, G. M., 1959: Chapter 3 - Combustion of Forest Fire Fuels, Forest Fire: Control and Use, K. P. Davis, McGraw-Hill, 61-89 
CA GOV. 2013: April 29. Retrieved from The State of California Geoportal: http://portal.gis.ca.gov/geoportal/catalog/main/home.page

Clements, C. B., 2006: In situ measurements of water vapor, heat, and CO2 fluxes within a prescribed grass fire. International Journal of Wildland Fire, 15, 299-306.

Clements, C. B., 2007: Observing the Dynamics of Wildland Grass Fires. FireFlux - A Field Validation Experiment. Bulletin of the American Meteorological Society, 1370-1382. https://doi.org/10.1175/BAMS-88-9-1369

Clements, C. B., 2008: First observations of turbulence generated by grass fires. Journal of Geophysical Research, 113, 1-13, https://doi.org/10.1029/2008JD010014

Clements, C.B. and Coauthors, 2014: Overview of the 2013 FireFlux II grass fire field experiment. In: Viegas, D.X., ed. Advances in Forest Fire Research. Coimbra, Portugal: Coimbra University Press: 392-400.

Clements, C. B. and A. Oliphant 2014: The California State University Mobile Atmospheric Profiling System: A facility for research and education in boundary-layer meteorology. Bulletin of the American Meteorological Society, 95, 1713-1724.

Clements, C. B., and Seto, D., 2015: Observations of Fire-Atmosphere Interactions and Near-Surface Heat Transport on a Slope. Boundary-Layer Meteorology, 154, 409-426.

Clements C. B., and Coauthors, 2019: The FireFlux II experiment: a modelguided field experiment to improve understanding of fire-atmosphere interactions and fire spread. International Journal of Wildland Fire 28 308326.

Contezac, J. M., 2018: Micrometeorological Observations of Fire-Atmosphere Interactions and Fire Behavior on a Simple Slope, Master's Thesis.

Covele, 2008: Wildland Toolkit. Peakview Software LLC https://apps.apple.com/us/app/wildland-toolkit/id318683999

Curry, J., and Fons, W., 1938: Rate of spread of surface fires in the ponderosa pine type of California. Journal of Agricultural Research, 57, 239-267.

Curry, J., and Fons, W., 1940: Forest-fire behavior studies. Mechanical Engineering, 62, 219-225. 
Dold, J., Simeoni, A., Zinoviev, A, and Weber, R, 2009:The Palasca Fire, September 2000: Eruption or Flashover?, Recent Forest Fire Related Accidents in Europe, Viegas D. X., 82 pp, Joint Research Centre, Institute for Environment and Sustainability EUR 24121 EN - 2009, 54-64. https://effis.jrc.ec.europa.eu/media/filer_public/6c/70/6c70555f-4b0c-47f7b649-4c3fa4e1e9f9/recent-forest-fire-related-accidents-ineurope_ec3ybmu.pdf

Dupuy, J. L., Maréchal, J., Portier, D. and Valette, J.-C., 2011: The effects of slope and fuel bed width on laboratory fire behaviour. International Journal of Wildland Fire, 20, 272-288. https://doi.org/10.1071/WF09075

Fons, W. L., 1946: Analysis of Fire Spread in Light Forest Fuels. Journal of Agricultural Research, 72, 93-121.

Frandsen, W. H., 1971: Fire Spread through Porous Fuels from the Conservation of Energy. Combustion and Flame, 16, 9-16.

Gray, L. G., 1933: Preliminary Report on Fire Hazard Rating Study. San Francisco: U. S. Weather Bureau.

Hardy, C.E., 1977: The Gisborne Era of Forest Fire Research. 6pp, Missoula, MT: University of Montana, Forest and Conservation Experiment Station Completion Report Contract No. 12-11-204-1. https://www.nifc.gov/safety/mann_gulch/long_term_impacts/documents/FS367_The_Gisborne_Era_of_Forest_Fire_Research_1949.pdf

Harvey, P., 2013, May 06: ExifTool by Phil Harvey. Retrieved from http://www.sno.phy.queensu.ca/ phil/exiftool/

IFSTA., 2013: Chapter 5 - Fire Behavior. Essentials of Firefighting, 6th Edition Fire Protection Publications. pp 1400

Keeley, J. E., 2009: Fire Intensity, fire severity and burn severity: a brief review and suggested usage. International Journal of Wildland Fire. 18, 116-126.

Linn, R. R., 2010: A numerical study of slope and fuel structure effects on coupled wildfire behaviour. International Journal of Wildland Fire. 19, 179201.

MacLean, N., 1992: Young Men and Fire. Chicago: University of Chicago Press. pp 301. 
McArthur, A. G., 1966: Weather and grassland fire behaviour. Canberra, Australia: Department of National Development, Forestry and Timber Bureau Leaflet No. 100.

McArthur, A. G., 1967: Fire behaviour in Eucalypt forests. Canberra, Commonwealth of Australia, Dept. of National Development, Forestry and Timber Bureau.

McArthur, A. G., 1969: The Tasmanian brushfires of 7th February, 1967 and associated fire behaviour characteristics. Mass Fire Symposium Proceedings. Maribyrnong, Victoria: Defense Standards Lab. p. 23

Mendes-Lopes, J. M., Ventura, J. M. P., and Amaral, J. M. P., 2003: Flame characteristics, temperature-time curves, and rate of spread in fires propagating in a bed of Pinus pinaster needles. International Journal of Wildland Fire, 12, 67-84.

Nelson, R. M. Jr, and Adkins, C. W., 1988: A dimensionless correlation for the spread of wind-driven fires. Canadian Journal of Forest Research, 18(4), 391397. https://doi.org/10.1139/x88-058

NWCG, 1996: S-190 - Introduction to Wildland Fire Behavior. National Wildfire Coordination Group (NWCG). Retrieved from National Wildfire Coordinating Group: http://www.nwcg.gov/?q=glossary

Ottmar, R. D., and Coauthors, 2016: Measurements, datasets and preliminary results from the RxCADRE project - 2008, 2011 and 2012. International Journal of Wildland Fire, 25, 1-9 DOI: https://doi.org/10.1071/WF14161

Papadopoulos, G. D., and Pavlidou, F.-N., 2011: A Comparative Review on Wildfire Simulators. IEEE Systems Journal, 5, 233-243.

Potter, B., 2012a: Atmospheric interactions with wildland fire behaviour - I. Basic surface interactions, vertical profiles and synoptic structures. International Journal of Wildland Fire, 21, 779-801.

Rothermel, R., and Anderson, H., 1966: Fire Spread Characteristics determined in the laboratory - INT-30, 41 pp, Ogden, Utah: USDA Forest Service Intermountain Forest and Range Experimental Station. https://www.fs.fed.us/rm/pubs_int/int_rp030.pdf

Rothermel, R. C., 1972: A Mathematical Model for Predicting Fire Spread in Wildland Fuels (INT-115). 48pp Ogden, Utah: USDA Forest Service, Intermountain Forest and Range Experiment Station. 
Schlobohm, P. B., 2002: Gaining an Understanding of the National Fire Danger Rating System (PMS 932 NFES 2665). National Wildfire Coordinating Group.

Scott, J. H., and Burgan, R. E., 2005: Standard Fire Behavior Fuel Models: A Comprehensive Set for Use with Rothermel's Surface Fire Spread Model. 80pp, United States Forest Service, United States Department of Agriculture. Fort Colins, CO: Rocky Mountain Research Station. https://www.fs.fed.us/rm/pubs/rmrs_gtr153.pdf

Show, S., 1919: Climate and Forest Fires in Northern California. Journal of Forestry, 17, 965 - 979. https://doi.org/10.1093/jof/17.8.965

Thomas, P., 1967: Some aspects of the growth and spread of fire in the open. Forestry, 40, 139-164.

Thomas, P., 1971: Rates of Spread of some wind-driven fires. Forestry, 44, 155175.

Weise, D. B., 1996: Effects of wind velocity and slope on flame properties. Can J. For. Res., 26, 1849-1858.

Weise, D. R., 1997: A Qualitative Comparison of Fire Spread Models Incorporating Wind and slope Effects. Forest Science, 43, 170-180.

Werth, P. A., and Coauthors, 2011: Synthesis of Knowledge of Extreme Fire Behavior: Volume 1 for Fire Managers., 144 pp, Gen. Tech. Rep. PNW-GTR854. Portland, Oregon: US Department of Agriculture, Forest Service, Pacific Northwest Research Station. DOI: https://doi.org/10.2737/PNW-GTR-854

Wilson, C. C., 1977: Fatal and near-fatal forest fires: the common denominators. The International Fire Chief, 43, 9-10, 12-15.

Wolff, M. F., 1991: Wind-aided firespread across arrays of discrete fuel elements. II. Experiment. Combustion Science and Technology, 77, 261-289.

Wu, Y., Xing, H., and Atkinson, G., 2000: Interaction of Fire Plume with inclined surface. Fire Safety Journal, 35, 391-403. https://doi.org/10.1016/S03797112(00)00032-1 


\section{Appendix A - Video Segment Metadata}

Video Segment Metadata summary
\begin{tabular}{|l|c|c|c|c|c|}
\hline \multicolumn{1}{|c|}{ Video File Name } & $\begin{array}{c}\text { Date and Starting Time } \\
\text { from meta data }\end{array}$ & $\begin{array}{c}\text { Start } \\
\text { Time }\end{array}$ & Duration & $\begin{array}{c}\text { Calculated } \\
\text { Ending } \\
\text { Time }\end{array}$ & $\begin{array}{c}\text { Gap Until } \\
\text { Next } \\
\text { Video }\end{array}$ \\
\hline 00005Ignition.MTS & $2012: 06: 2011: 17: 31-08: 00$ & $11: 17: 31$ & $0: 04: 53.00$ & $11: 22: 24.00$ & $0: 00: 06.00$ \\
\hline 00006Tower1.MTS & $2012: 06: 2011: 22: 30-08: 00$ & $11: 22: 30$ & $0: 06: 34.00$ & $11: 29: 04.00$ & $0: 00: 05.00$ \\
\hline 00007Tower1-2.MTS & $2012: 06: 2011: 29: 09-08: 00$ & $11: 29: 09$ & $0: 04: 15.00$ & $11: 33: 24.00$ & $0: 00: 03.00$ \\
\hline 00008Tower2.MTS & $2012: 06: 2011: 33: 27-08: 00$ & $11: 33: 27$ & $0: 01: 53.00$ & $11: 35: 20.00$ & $0: 02: 13.00$ \\
\hline 00009Tower2-3.MTS & $2012: 06: 2011: 37: 33-08: 00$ & $11: 37: 33$ & $0: 05: 29.00$ & $11: 43: 02.00$ & \\
\hline
\end{tabular}

Video Segment 1 Times

\begin{tabular}{|c|c|c|c|c|c|c|}
\hline GPS Time & o Time Stamp & Photoshop Time & Elapsed Time & Comment & Tiff File Name & Photoshop File Name \\
\hline 11:18:05 & 11:17:31 & 0:00:00 & & video start & & \\
\hline $11: 18: 10$ & 11:17:36 & 0:00:05 & 0:00:00 & ignition estimate & 0_00_05_00lgnition.tif & 0_00_05_00lgnition.psd \\
\hline $11: 18: 40$ & 11:18:06 & 0:00:35 & & & & 0_00_35_00.psd \\
\hline 11:19:10 & 11:18:36 & 0:01:05 & 0:01:00 & & 0_01_05_00.tif & 0_01_05_00.psd \\
\hline 11:19:40 & 11:19:06 & 0:01:35 & & & & 0_01_35_00.psd \\
\hline $11: 20: 10$ & 11:19:36 & 0:02:05 & 0:02:00 & & 0_02_05_00.tif & 0_02_05_00.psd \\
\hline $11: 20: 40$ & 11:20:06 & 0:02:35 & & & & 0_02_35_00.psd \\
\hline 11:21:10 & $11: 20: 36$ & 0:03:05 & 0:03:00 & & 0_03_05_00.tif & 0_03_05_00.psd \\
\hline $11: 21: 40$ & 11:21:06 & 0:03:35 & & & & 0_03_35_00.psd \\
\hline $11: 22: 10$ & $11: 21: 36$ & 0:04:05 & 0:04:00 & & 0_04_05_00.tif & 0_04_05_00.psd \\
\hline $11: 22: 40$ & $11: 22: 06$ & 0:04:35 & & & & 0_04_35_00.psd \\
\hline 11:22:58 & $11: 22: 24$ & 0:04:53 & & video end & & \\
\hline $11: 23: 10$ & $11: 22: 36$ & & & target next image & & \\
\hline
\end{tabular}

Video Segment 2 Times

\begin{tabular}{|c|c|c|c|c|c|c|}
\hline GPS Time & Video Time Stamp & Photoshop Time & Elapsed Time & Comment & Tiff File Name & Photoshop File Name \\
\hline $11: 23: 04$ & $11: 22: 30$ & 0:00:00 & & video start after $6 \mathrm{sec}$ pause & & \\
\hline $11: 23: 10$ & $11: 22: 36$ & 0:00:06 & 0:05:00 & target image time & 6-0_00_06_00.tif & 6-0_00_06_00.psd \\
\hline $11: 23: 40$ & $11: 23: 06$ & 0:00:36 & & & 6-0_00_36_00.tif & 6-0_00_36_00.psd \\
\hline $11: 24: 10$ & $11: 23: 36$ & 0:01:06 & 0:06:00 & & 6-0_01_06_00.tif & 6-0_01_06_00.psd \\
\hline $11: 24: 40$ & $11: 24: 06$ & 0:01:36 & & & 6-0_01_36_00.tif & 6-0_01_36_00.psd \\
\hline $11: 25: 10$ & $11: 24: 36$ & 0:02:06 & $0: 07: 00$ & & 6-0_02_06_00.tif & 6-0_02_06_00.psd \\
\hline $11: 25: 40$ & $11: 25: 06$ & 0:02:36 & & & 6-0_02_36_00.tif & 6-0_02_36_00.psd \\
\hline $11: 26: 10$ & $11: 25: 36$ & 0:03:06 & 0:08:00 & & 6-0_03_06_00.tif & 6-0_03_06_00.psd \\
\hline $11: 26: 40$ & $11: 26: 06$ & $0: 03: 36$ & & & 6-0_03_36_00.tif & 6-0_03_36_00.psd \\
\hline $11: 27: 10$ & $11: 26: 36$ & 0:04:06 & 0:09:00 & & 6-0_04_06_00.tif & 6-0_04_06_00.psd \\
\hline $11: 27: 40$ & $11: 27: 06$ & $0: 04: 36$ & & & 6-0_04_36_00.tif & 6-0_04_36_00.psd \\
\hline $11: 28: 10$ & $11: 27: 36$ & 0:05:06 & 0:10:00 & & 6-0_05_06_00.tif & 6-0_05_06_00.psd \\
\hline $11: 28: 40$ & $11: 28: 06$ & $0: 05: 36$ & & & 6-0_05_36_00.tif & 6-0_05_36_00.psd \\
\hline $11: 29: 10$ & $11: 28: 36$ & 0:06:06 & $0: 11: 00$ & & 6-0_06_06_00.tif & 6-0_06_06_00.psd \\
\hline $11: 29: 38$ & 11:29:04 & $0: 06: 34$ & & video end & 6-0_06_34_11.tif & 6-0_06_34_11.psd \\
\hline $11: 29: 40$ & $11: 29: 06$ & & $0: 11: 30$ & target next image & & \\
\hline
\end{tabular}


Video Segment 3 Times

\begin{tabular}{|c|c|c|c|c|c|c|}
\hline GPS Time & Video Time Stamp & Photoshop Time & Elapsed Time & Comment & TIFF File name & Photoshop File Name \\
\hline 11:29:43 & 11:29:09 & 0:00:00 & & video start after 5 sec pause & & \\
\hline 11:30:10 & $11: 29: 36$ & $0: 00: 27$ & $0: 12: 00$ & target image time & 7-0_00_27_00.tif & 7-0_00_27_00.psd \\
\hline 11:30:40 & 11:30:06 & 0:00:57 & & & 7-0_00_57_00.tif & 7-0_00_57_00.psd \\
\hline 11:31:10 & 11:30:36 & 0:01:27 & 0:13:00 & & 7-0_01_27_00.tif & 7-0_01_27_00.psd \\
\hline 11:31:40 & 11:31:06 & 0:01:57 & & & 7-0_01_57_00.tif & 7-0_01_57_00.psd \\
\hline $11: 32: 10$ & $11: 31: 36$ & 0:02:27 & $0: 14: 00$ & & 7-0_02_27_00.tif & 7-0_02_27_00.psd \\
\hline $11: 32: 40$ & 11:32:06 & 0:02:57 & & & 7-0_02_57_00.tif & 7-0_02_57_00.psd \\
\hline 11:33:10 & $11: 32: 36$ & 0:03:27 & 0:15:00 & & 7-0_03_27_00.tif & 7-0_03_27_00.psd \\
\hline 11:33:40 & 11:33:06 & 0:03:57 & & & 7-0_03_57_00.tif & 7-0_03_57_00.psd \\
\hline 11:33:58 & 11:33:24 & 0:04:15 & & end of video & & \\
\hline 11:34:10 & 11:33:36 & & 0:16:00 & target next image & & \\
\hline
\end{tabular}

\section{Video Segment 4 Times}

\begin{tabular}{|r|c|c|c|l|l|}
\hline GPS Time & Video Time Stamp & Photoshop Time & Elapsed Time & Comment & TIFF File name \\
\hline $11: 34: 01$ & $11: 33: 27$ & $0: 00: 00$ & & video start after 3 sec pause & \\
\hline $11: 34: 10$ & $11: 33: 36$ & $0: 00: 09$ & $0: 16: 00$ & target image time & 8-0_00_09_00.tif 8-0_00_09_00.psd \\
\hline 11:34:40 & $11: 34: 06$ & $0: 00: 39$ & & & 8-0_00_39_00.tif 8-0_00_39_00.psd \\
\hline $11: 35: 10$ & $11: 34: 36$ & $0: 01: 09$ & $0: 17: 00$ & & 8-0_01_09_00.tif 8-0_01_09_00.psd \\
\hline $11: 35: 40$ & $11: 35: 06$ & $0: 01: 39$ & & & 8-0_01_39_00.tif 8-0_01_39_00.psd \\
\hline $11: 35: 54$ & $11: 35: 20$ & $0: 02: 09$ & & end of video & \\
\hline $11: 36: 10$ & $11: 35: 36$ & & $0: 18: 00$ & target image time & \\
\hline
\end{tabular}

\section{Video Segment 5 Times}

\begin{tabular}{|c|c|c|c|c|c|c|c|}
\hline GPS Time & Video Time Stamp & Photoshop Time & Elapsed Time & & Comment & TIFF File name & Photoshop File Name \\
\hline $11: 36: 10$ & $11: 35: 36$ & & 0:18:00 & missed image & video camera not running & & \\
\hline $11: 36: 40$ & 11:36:06 & & & missed image & video camera not running & & \\
\hline 11:37:10 & 11:36:36 & & 0:19:00 & missed image & video camera not running & & \\
\hline $11: 37: 40$ & 11:37:06 & & & missed image & video camera not running & & \\
\hline 11:38:07 & $11: 37: 33$ & 0:00:00 & & start of video & & & \\
\hline $11: 38: 10$ & $11: 37: 36$ & 0:00:03 & $0: 20: 00$ & target image & & 9-0_00_03_00.tif & 9-0_00_03_00.psd \\
\hline $11: 38: 40$ & 11:38:06 & $0: 00: 33$ & & & & & \\
\hline 11:39:10 & 11:38:36 & $0: 01: 03$ & $0: 21: 00$ & & & 9-0_01_03_00.tif & 9-0_01_03_00.psd \\
\hline $11: 39: 40$ & 11:39:06 & $0: 01: 33$ & & & & & \\
\hline $11: 40: 10$ & 11:39:36 & 0:02:03 & $0: 22: 00$ & & & 9-0_02_03_00.tif & 9-0_02_03_00.psd \\
\hline $11: 40: 40$ & 11:40:06 & $0: 02: 33$ & & & & & \\
\hline $11: 41: 10$ & 11:40:36 & 0:03:03 & $0: 23: 00$ & & & 9-0_03_03_00.tif & 9-0_03_03_00.psd \\
\hline $11: 41: 40$ & 11:41:06 & $0: 03: 33$ & & & & & \\
\hline $11: 42: 10$ & $11: 41: 36$ & 0:04:03 & $0: 24: 00$ & & & 9-0_04_03_00.tif & 9-0_04_03_00.psd \\
\hline $11: 42: 40$ & $11: 42: 06$ & 0:04:33 & & & & & \\
\hline $11: 43: 10$ & $11: 42: 36$ & 0:05:03 & $0: 25: 00$ & & & 9-0_05_03_00.tif & 9-0_05_03_00.psd \\
\hline $11: 43: 36$ & $11: 43: 02$ & 0:05:29 & & end of video & end of video segments & & \\
\hline
\end{tabular}


Appendix B - Photograph / Georeferenced Photo / Fire Line Boundary

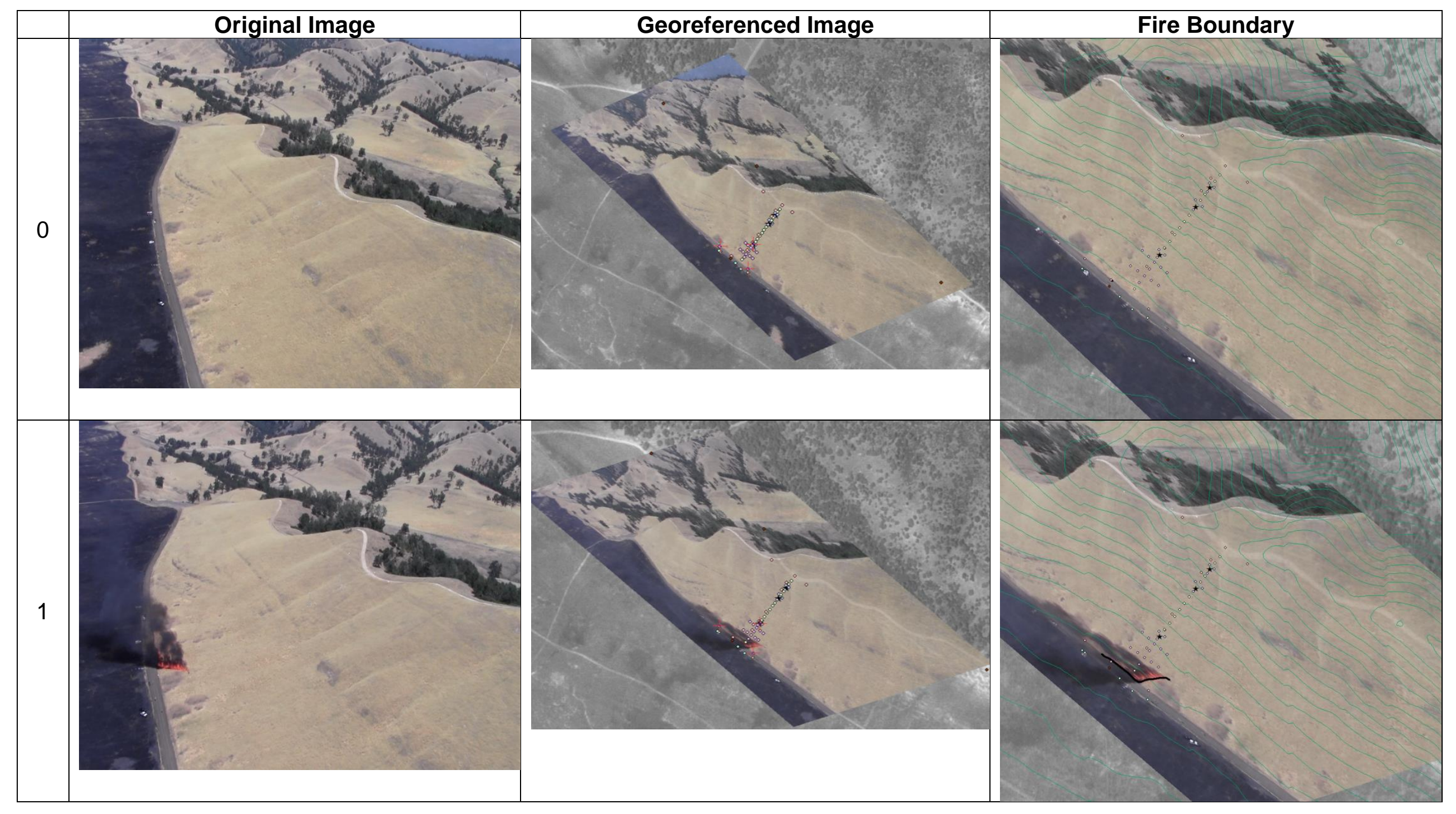




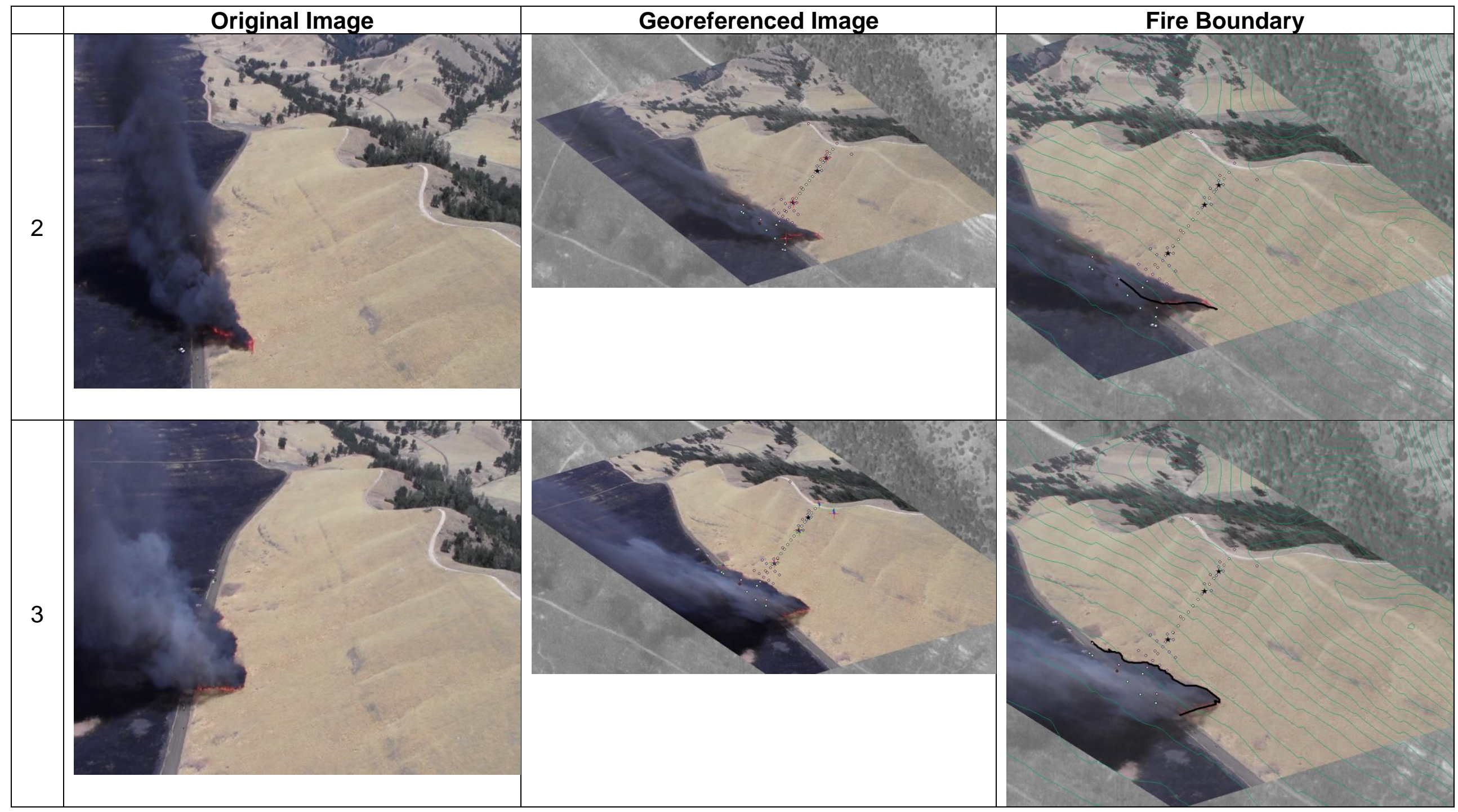




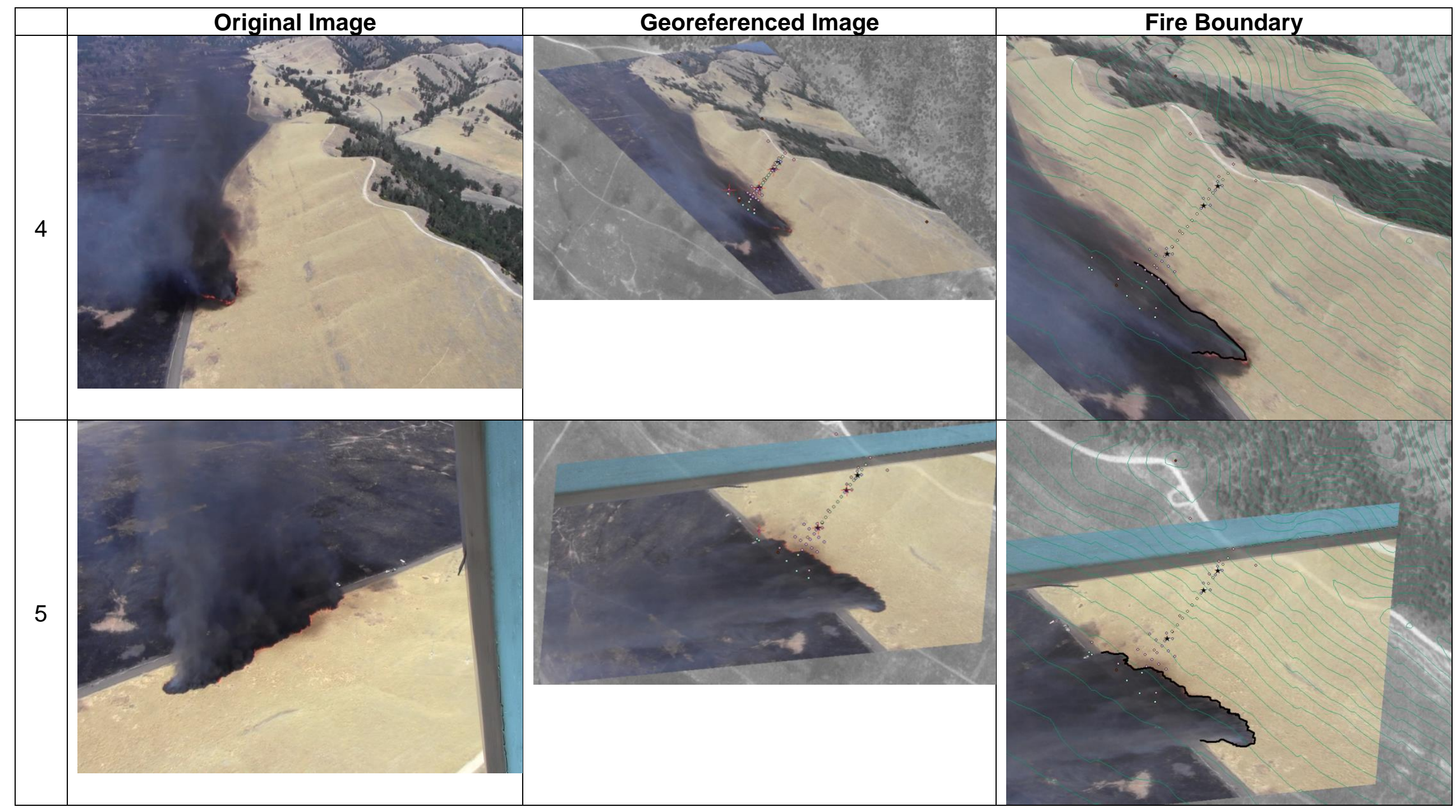




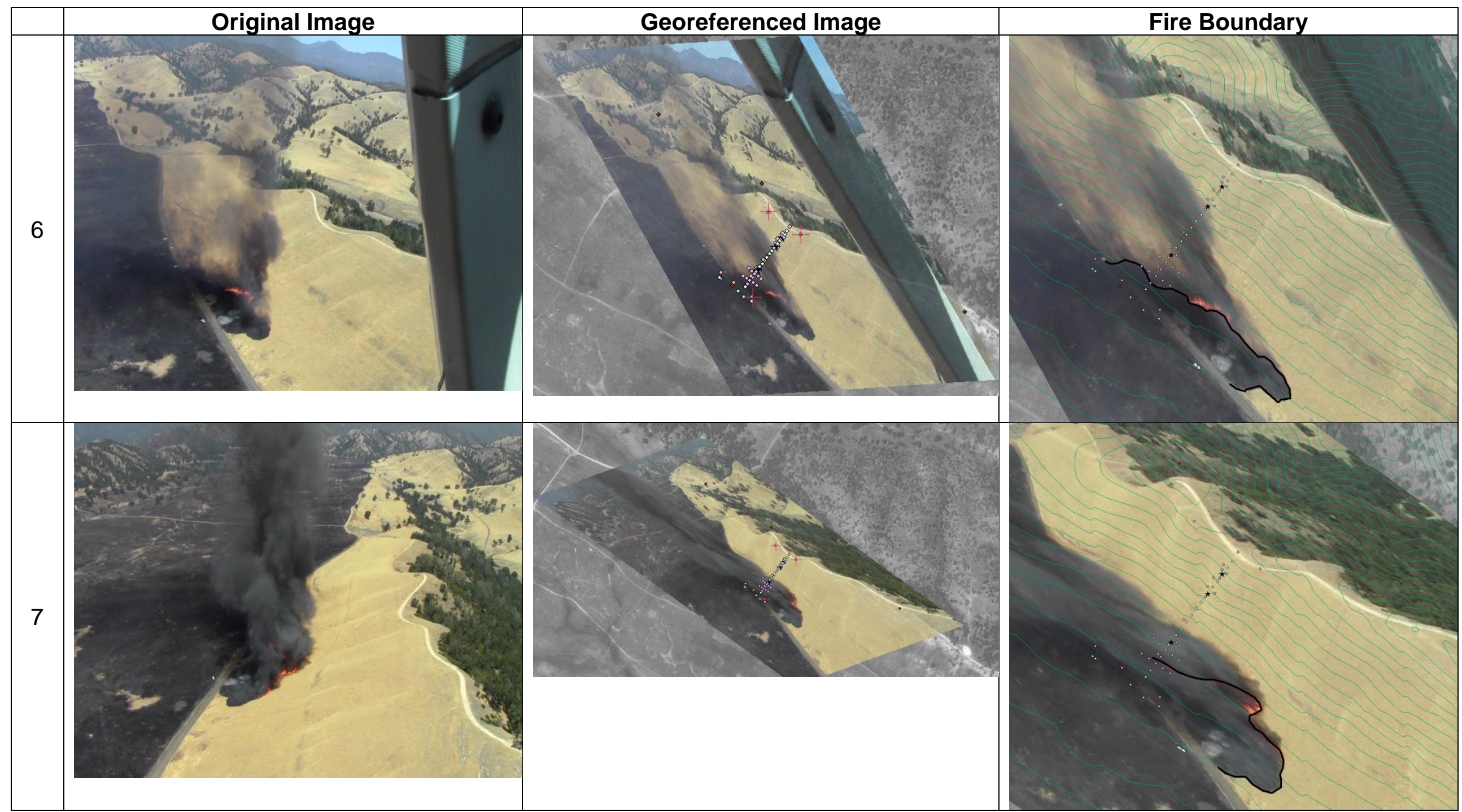




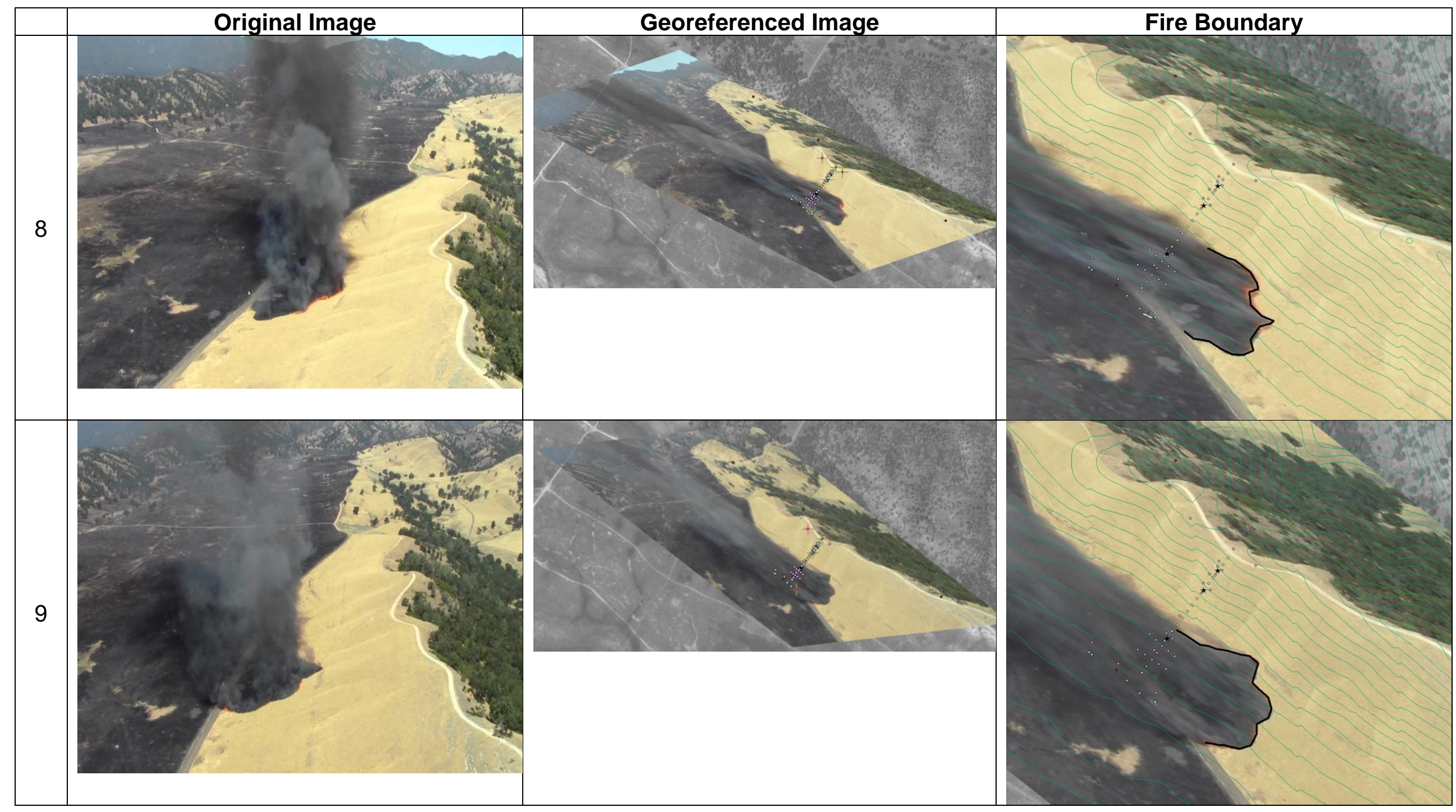




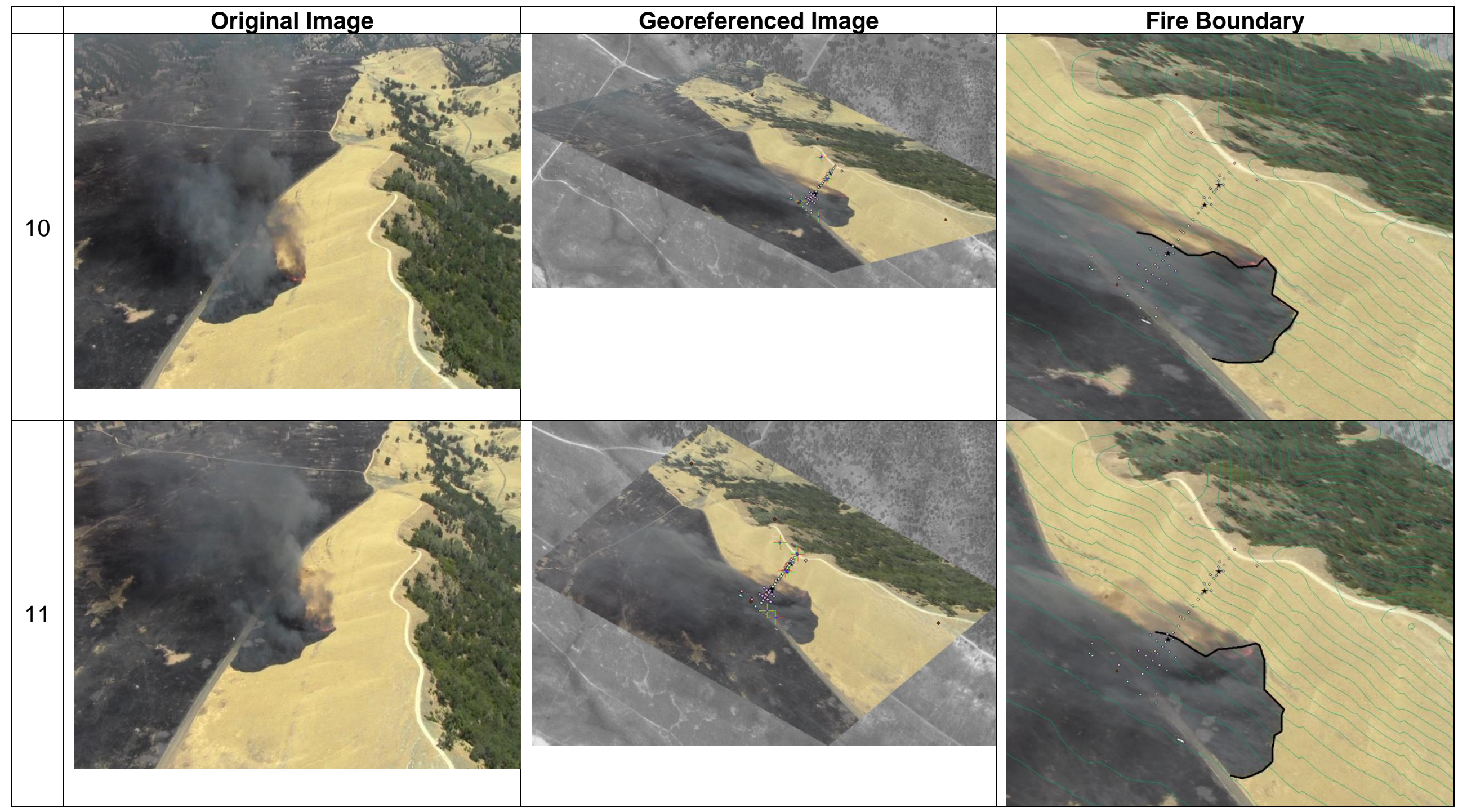




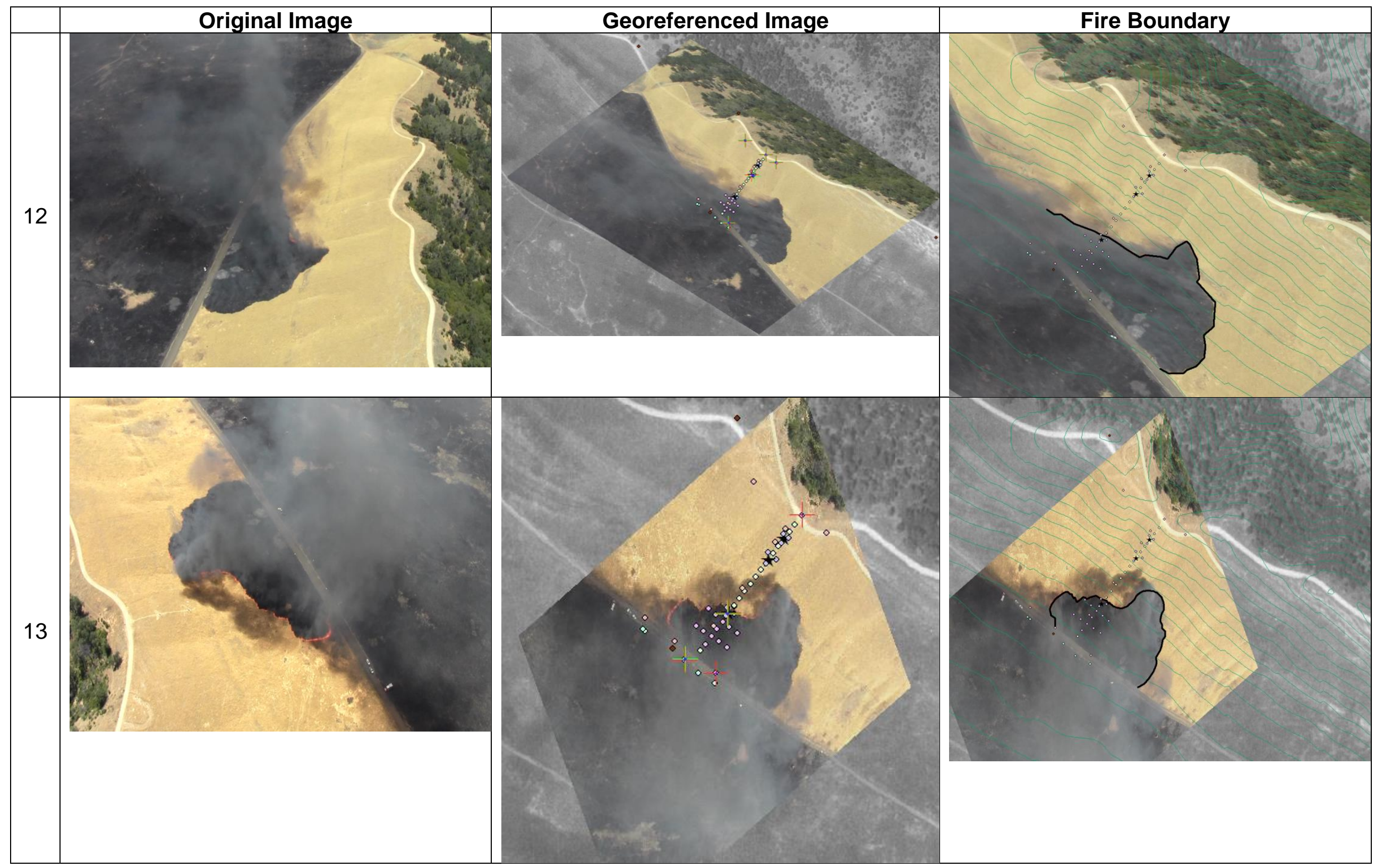




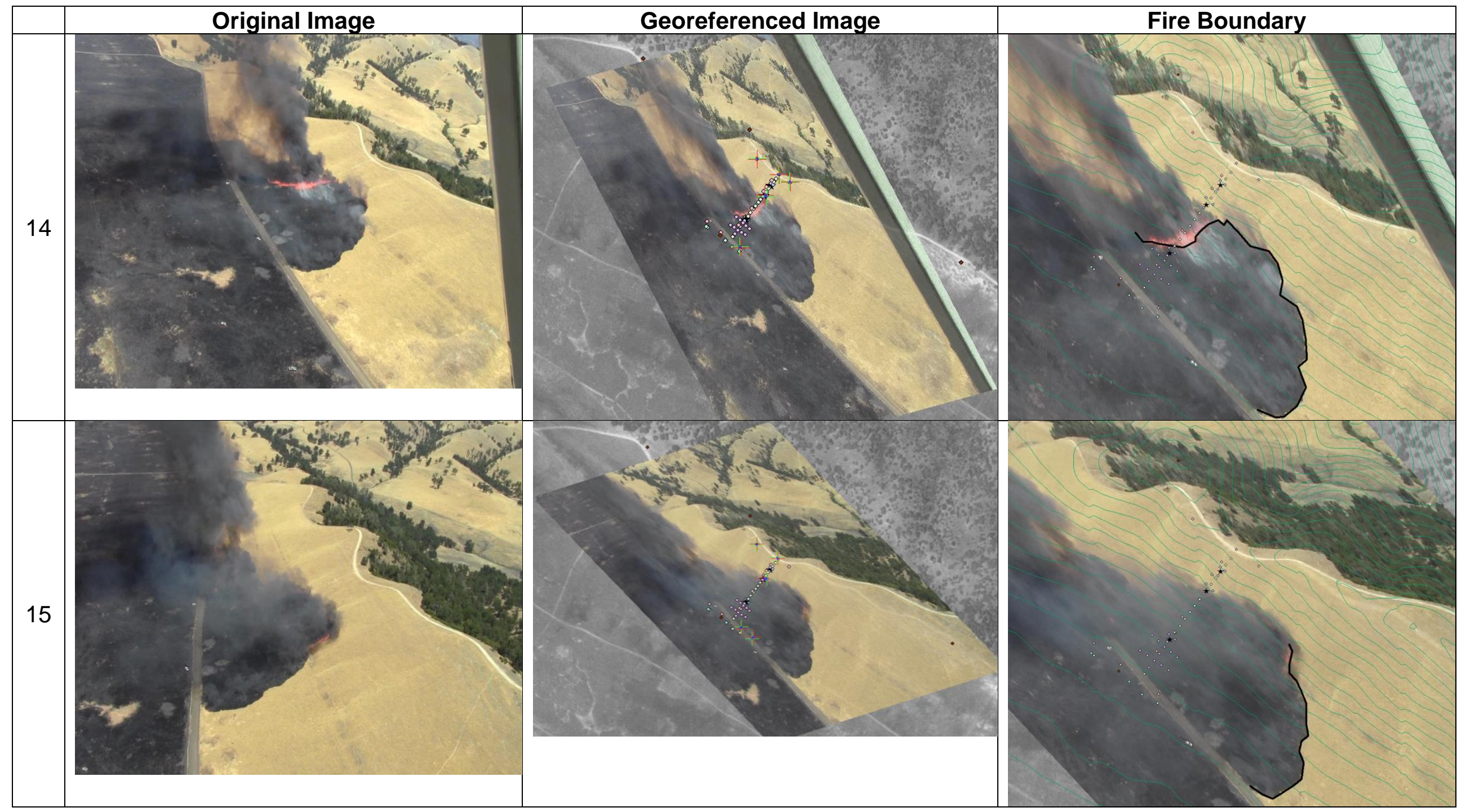




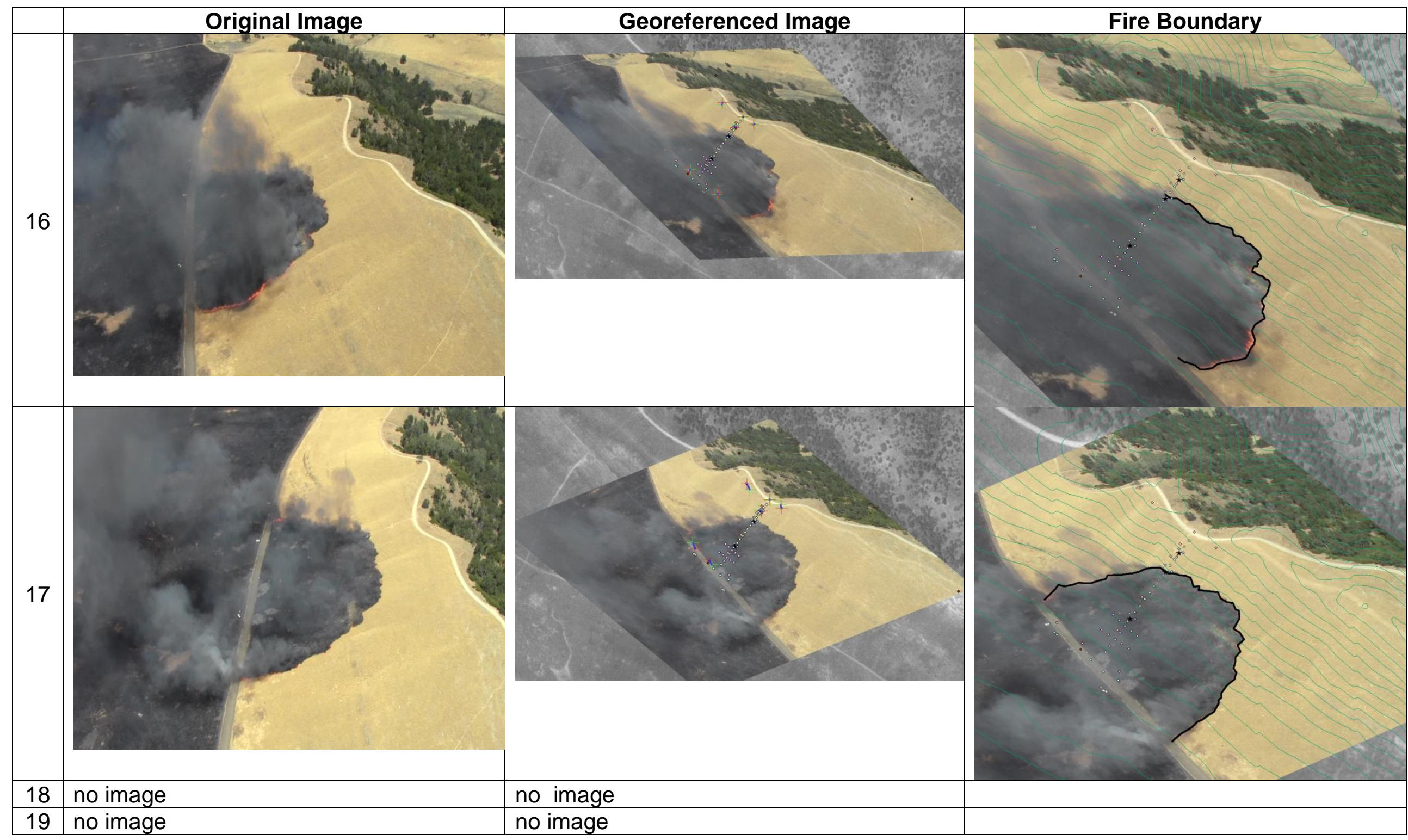




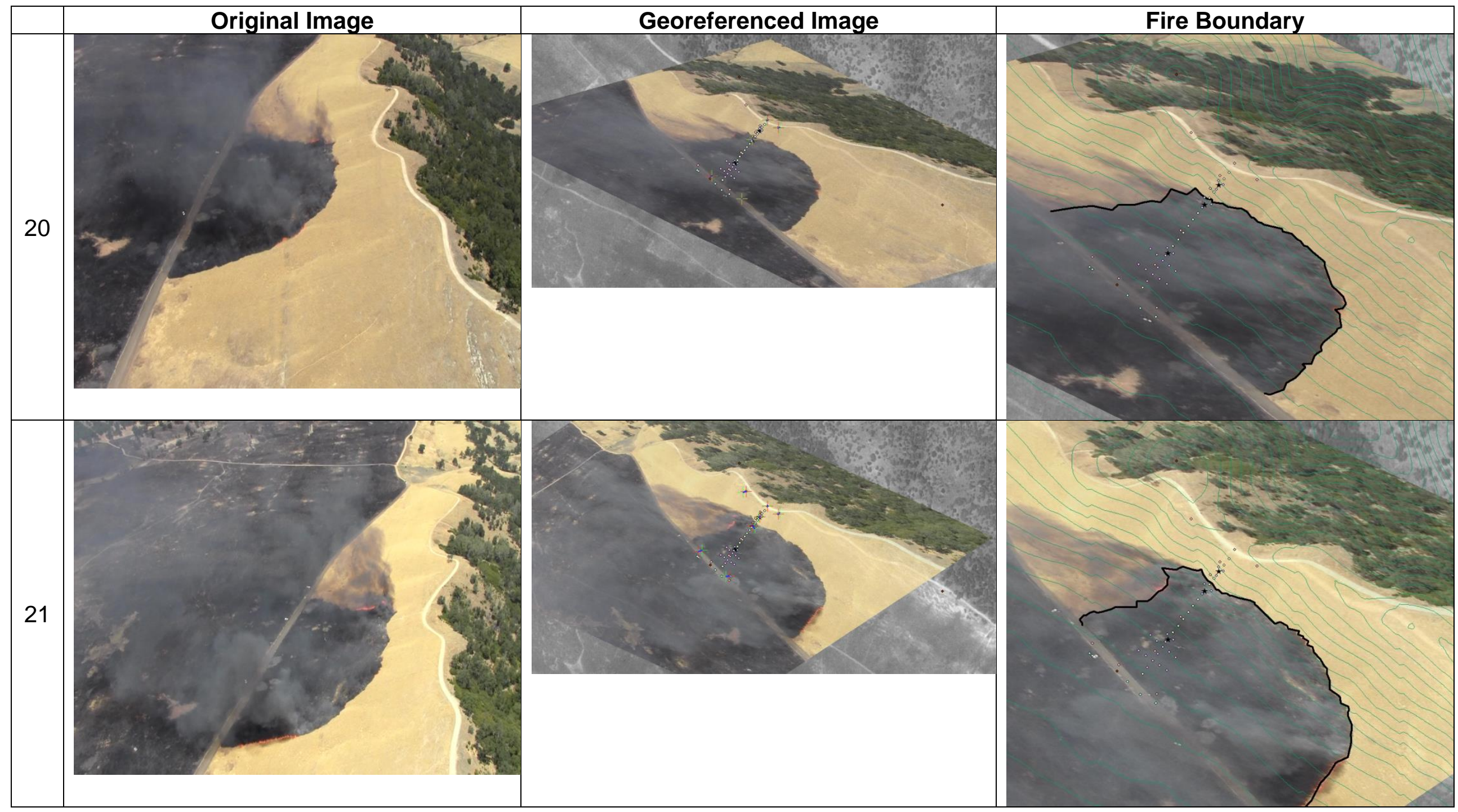




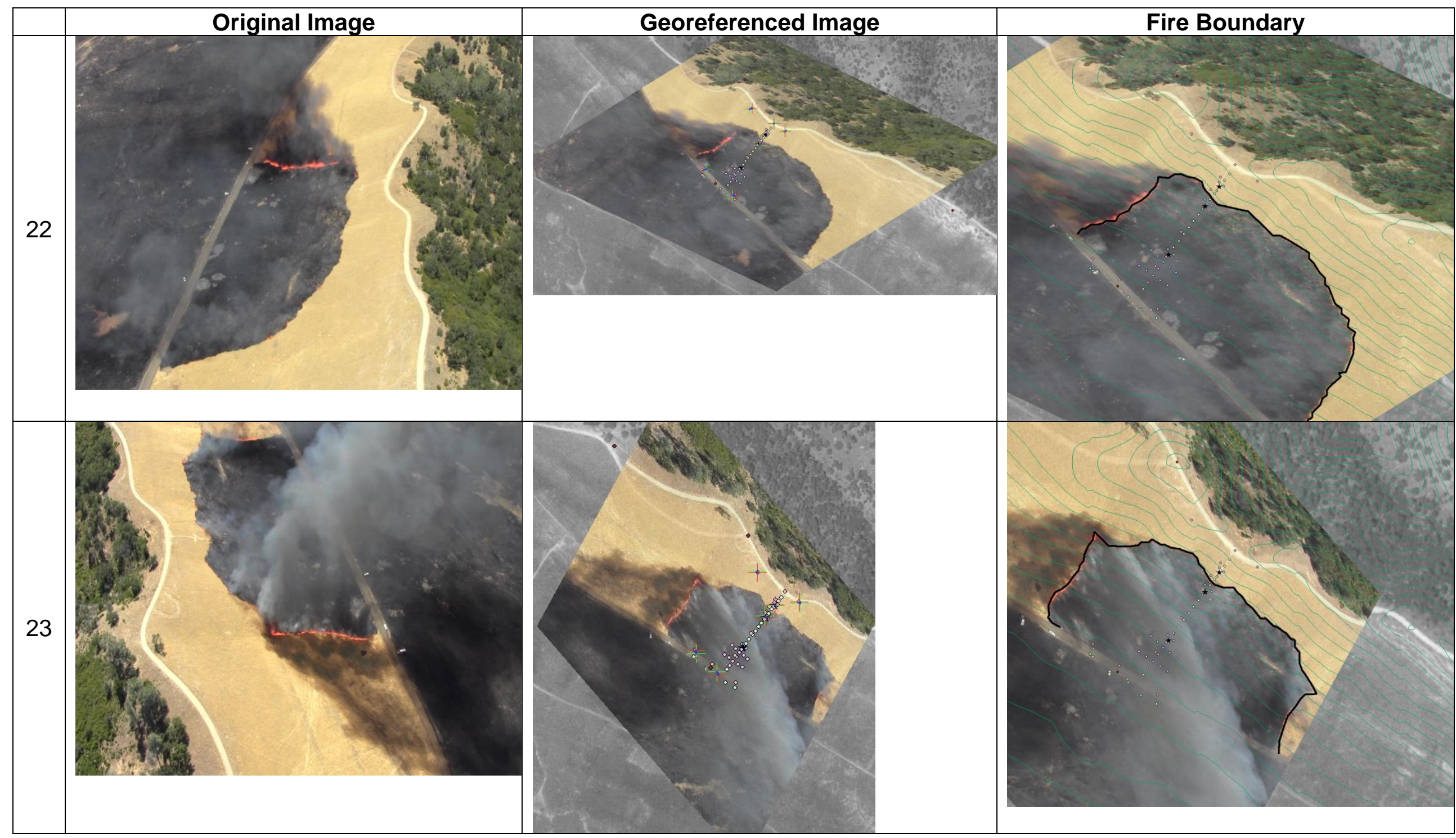




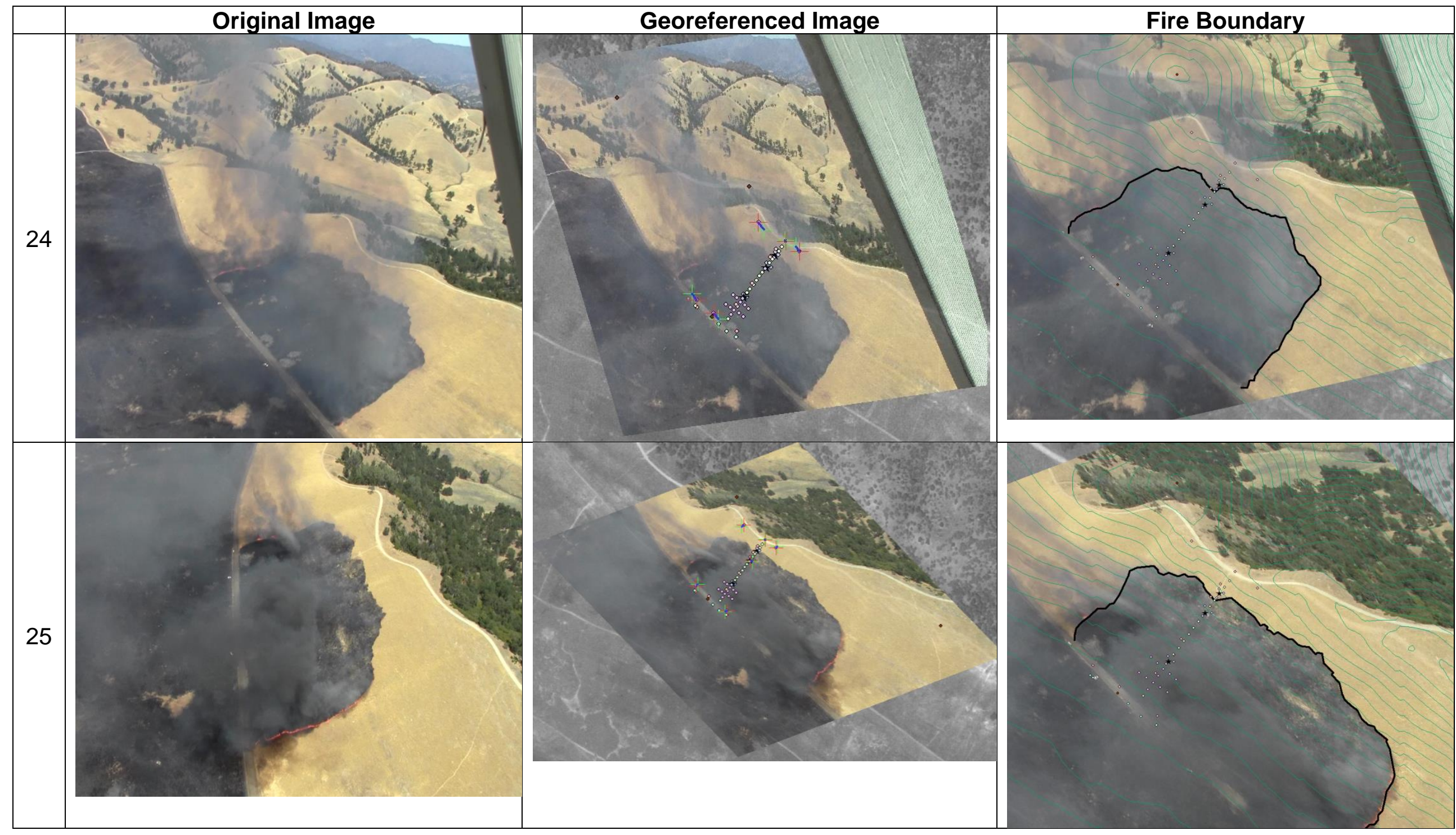


Appendix C - Georeference Points FHL Site 1

\begin{tabular}{|c|c|c|c|c|c|c|c|}
\hline & Photo & Point \#1/layer & Point \#2/layer & Point \#3/layer & Point \#4/layer & Point \#5/layer & $\begin{array}{l}\text { RMS } \\
\text { Error }\end{array}$ \\
\hline 0 & $\begin{array}{c}\text { 0_00_05_00 } \\
\text { Ignition }\end{array}$ & $\begin{array}{c}\text { FID50 LoNRefPost } \\
\text { hl field_instruments }\end{array}$ & $\begin{array}{c}\text { FID48 LoSRefPost } \\
\text { / } \\
\text { hl_field_instruments }\end{array}$ & $\begin{array}{l}\text { FID2 Tower 1/ } \\
\text { hl_field_instruments }\end{array}$ & - & - & 0.00 \\
\hline 1 & 0_01_05_00 & $\begin{array}{l}\text { FID50 LoNRefPost } \\
\text { hl_field_instruments }\end{array}$ & $\begin{array}{c}\text { FID48 LoSRefPost } \\
\text { / } \\
\text { hl_field_instruments }\end{array}$ & $\begin{array}{c}\text { FID2 Tower 1 / } \\
\text { hl_field_instruments }\end{array}$ & - & - & 0.00 \\
\hline 2 & 0_02_05_00 & $\begin{array}{c}\text { FID48 / } \\
\text { LoSRefPost } \\
\text { hl_field_instruments }\end{array}$ & $\begin{array}{l}\text { FID2 Tower 1 / } \\
\text { hl_field_instruments }\end{array}$ & $\begin{array}{l}\text { FID12 Tower } 3 \text { / } \\
\text { hl_field_instruments }\end{array}$ & - & - & 0.00 \\
\hline 3 & 0_03_05_00 & $\begin{array}{l}\text { FID50 LoNRefPost } \\
\text { hl_field_instruments }\end{array}$ & $\begin{array}{l}\text { FID2 Tower1 / } \\
\text { hl_field_instruments }\end{array}$ & $\begin{array}{l}\text { FID5 Tower2 / } \\
\text { hl_field_instruments }\end{array}$ & $\begin{array}{l}\text { FID45 UpRAWS / } \\
\text { hl_field_instruments }\end{array}$ & $\begin{array}{c}\text { FID47 } \\
\text { UpSRefPost / } \\
\text { hl_field_instruments }\end{array}$ & $\begin{array}{c}4.123 \\
93\end{array}$ \\
\hline 4 & 0_04_05_00 & $\begin{array}{c}\text { FID50 LoNRefPost } \\
\text { / } \\
\text { hl_field_instruments }\end{array}$ & $\begin{array}{l}\text { FID2 Tower1 / } \\
\text { hl_field_instruments }\end{array}$ & $\begin{array}{l}\text { FID5 Tower2 / } \\
\text { hl_field_instruments }\end{array}$ & - & 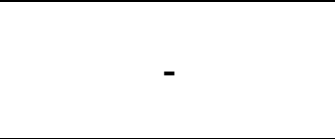 & 0.00 \\
\hline 5 & 0_00_06_00 & $\begin{array}{c}\text { FID50 LoNRefPost } \\
\text { hl field_instruments }\end{array}$ & $\begin{array}{l}\text { FID2 Tower1 / } \\
\text { hl_field_instruments }\end{array}$ & $\begin{array}{l}\text { FID5 Tower2 / } \\
\text { hl_field_instruments }\end{array}$ & - & - & 0.00 \\
\hline 6 & 0_01_06_00 & $\begin{array}{c}\text { FID46 } \\
\text { UpNRefPost / } \\
\text { hl_field_instruments }\end{array}$ & $\begin{array}{c}\text { FID47 } \\
\text { UpSRefPost / } \\
\text { hl_field_instruments }\end{array}$ & $\begin{array}{c}\text { FID48 / } \\
\text { LoSRefPost } \\
\text { hl_field_instruments }\end{array}$ & - & - & 0.00 \\
\hline 7 & 0_02_06_00 & $\begin{array}{c}\text { FID46 } \\
\text { UpNRefPost / } \\
\text { hl_field_instruments }\end{array}$ & $\begin{array}{c}\text { FID47 } \\
\text { UpSRefPost / } \\
\text { hl_field_instruments }\end{array}$ & $\begin{array}{c}\text { FID48 / } \\
\text { LoSRefPost } \\
\text { hl_field_instruments }\end{array}$ & - & - & 0.00 \\
\hline 8 & 0_03_06_00 & $\begin{array}{c}\text { FID46 } \\
\text { UpNRefPost / } \\
\text { hl_field_instruments }\end{array}$ & $\begin{array}{c}\text { FID47 } \\
\text { UpSRefPost / } \\
\text { hl_field_instruments }\end{array}$ & $\begin{array}{l}\text { FID45 UpRAWS / } \\
\text { hl_field_instruments }\end{array}$ & $\begin{array}{l}\text { FID5 Tower2 / } \\
\text { hl_field_instruments }\end{array}$ & $\begin{array}{l}\text { FID1 Mustard / } \\
\text { hl_veg_poly }\end{array}$ & $\begin{array}{c}5.226 \\
58\end{array}$ \\
\hline & Photo & Point \#1/layer & Point \#2/layer & Point \#3/layer & Point \#4/layer & Point \#5/layer & $\begin{array}{l}\text { RMS } \\
\text { Error }\end{array}$ \\
\hline
\end{tabular}




\begin{tabular}{|c|c|c|c|c|c|c|c|}
\hline 9 & 0_04_06_00 & $\begin{array}{c}\text { FID46 } \\
\text { UpNRefPost / } \\
\text { hl_field_instruments }\end{array}$ & $\begin{array}{l}\text { FID45 UpRAWS / } \\
\text { hl_field_instruments }\end{array}$ & $\begin{array}{l}\text { FID5 Tower2 / } \\
\text { hl_field_instruments }\end{array}$ & $?$ & - & $\begin{array}{c}2.945 \\
63\end{array}$ \\
\hline 10 & 0_05_06_00 & $\begin{array}{c}\text { FID46 } \\
\text { UpNRefPost / } \\
\text { hl_field_instruments }\end{array}$ & $\begin{array}{l}\text { FID5 Tower2 / } \\
\text { hl_field_instruments }\end{array}$ & $\begin{array}{c}\text { FID49 LoCRefPost } \\
\text { / } \\
\text { hl_field_instruments }\end{array}$ & $\begin{array}{l}\text { FID1 Mustard / } \\
\text { hl_veg_poly }\end{array}$ & - & $\begin{array}{c}6.813 \\
17\end{array}$ \\
\hline 11 & 0_06_06_00 & $\begin{array}{c}\text { FID46 } \\
\text { UpNRefPost / } \\
\text { hl_field_instruments }\end{array}$ & $\begin{array}{l}\text { FID45 UpRAWS / } \\
\text { hl_field_instruments }\end{array}$ & $\begin{array}{l}\text { FID5 Tower2 / } \\
\text { hl_field_instruments }\end{array}$ & $\begin{array}{l}\text { FID1 Mustard / } \\
\text { hl_veg_poly }\end{array}$ & $?$ & $\begin{array}{c}5.647 \\
31\end{array}$ \\
\hline 12 & 0_00_27_00 & $\begin{array}{c}\text { FID46 } \\
\text { UpNRefPost / } \\
\text { hl_field_instruments }\end{array}$ & $\begin{array}{l}\text { FID45 UpRAWS / } \\
\text { hl_field_instruments }\end{array}$ & $\begin{array}{c}\text { FID47 } \\
\text { UpSRefPost / } \\
\text { hl_field_instruments }\end{array}$ & $\begin{array}{l}\text { FID5 Tower2 / } \\
\text { hl_field_instruments }\end{array}$ & $\begin{array}{c}\text { FID48 / } \\
\text { LoSRefPost } \\
\text { hl_field_instruments }\end{array}$ & $\begin{array}{c}3.918 \\
66\end{array}$ \\
\hline 13 & 0_01_27_00 & $\begin{array}{l}\text { FID45 UpRAWS / } \\
\text { hl_field_instruments }\end{array}$ & $\begin{array}{l}\text { FID2 Tower1 / } \\
\text { hl_field_instruments }\end{array}$ & $\begin{array}{l}\text { FID50 Camera / } \\
\text { hl_field_instruments }\end{array}$ & $\begin{array}{c}\text { FID48 / } \\
\text { LoSRefPost } \\
\text { hl_field_instruments }\end{array}$ & 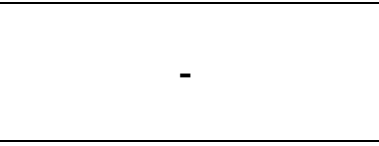 & $\begin{array}{c}1.296 \\
30\end{array}$ \\
\hline 14 & 0_02_27_00 & $\begin{array}{c}\text { FID46 } \\
\text { UpNRefPost / } \\
\text { hl_field_instruments }\end{array}$ & $\begin{array}{l}\text { FID45 UpRAWS / } \\
\text { hl_field_instruments }\end{array}$ & $\begin{array}{c}\text { FID47 } \\
\text { UpSRefPost / } \\
\text { hl_field_instruments }\end{array}$ & $\begin{array}{l}\text { FID5 Tower2 / } \\
\text { hl_field_instruments }\end{array}$ & $\begin{array}{c}\text { FID48 / } \\
\text { LoSRefPost } \\
\text { hl_field_instruments }\end{array}$ & $\begin{array}{c}3.191 \\
41\end{array}$ \\
\hline 15 & 0_03_27_00 & $\begin{array}{c}\text { FID46 } \\
\text { UpNRefPost / } \\
\text { hl_field_instruments }\end{array}$ & $\begin{array}{l}\text { FID45 UpRAWS / } \\
\text { hl_field_instruments }\end{array}$ & $\begin{array}{l}\text { FID5 Tower2 / } \\
\text { hl_field_instruments }\end{array}$ & $\begin{array}{c}\text { FID48 / } \\
\text { LoSRefPost } \\
\text { hl_field_instruments }\end{array}$ & $\begin{array}{l}\text { FID1 Mustard / } \\
\text { hl_veg_poly }\end{array}$ & $\begin{array}{l}4.530 \\
64\end{array}$ \\
\hline 16 & 0_00_09_00 & $\begin{array}{c}\text { FID46 } \\
\text { UpNRefPost / } \\
\text { hl_field_instruments }\end{array}$ & $\begin{array}{l}\text { FID45 UpRAWS / } \\
\text { hl_field_instruments }\end{array}$ & $\begin{array}{c}\text { FID47 } \\
\text { UpSRefPost / } \\
\text { hl_field_instruments }\end{array}$ & $\begin{array}{l}\text { FID5 Tower2 / } \\
\text { hl_field_instruments }\end{array}$ & $\begin{array}{c}\text { FID49 LoCRefPost } \\
\text { / } \\
\text { hl_field_instruments } \\
\text { FID1 Mustard / } \\
\text { hl_veg_poly }\end{array}$ & $\begin{array}{c}4.821 \\
24\end{array}$ \\
\hline 17 & 0_01_09_00 & $\begin{array}{c}\text { FID46 } \\
\text { UpNRefPost / } \\
\text { hl_field_instruments }\end{array}$ & $\begin{array}{l}\text { FID45 UpRAWS / } \\
\text { hl_field_instruments }\end{array}$ & $\begin{array}{c}\text { FID47 } \\
\text { UpSRefPost / } \\
\text { hl_field_instruments }\end{array}$ & $\begin{array}{l}\text { FID12 Tower3 / } \\
\text { hl_field_instruments }\end{array}$ & $\begin{array}{c}\text { FID50 Camera / } \\
\text { hl_field_instruments } \\
\text { FID49 LoCRefPost } \\
\text { / } \\
\text { hl_field_instruments }\end{array}$ & $\begin{array}{c}10.30 \\
053\end{array}$ \\
\hline & Photo & Point \#1/layer & Point \#2/layer & Point \#3/layer & Point \#4/layer & Point \#5/layer & $\begin{array}{l}\text { RMS } \\
\text { Error }\end{array}$ \\
\hline 18 & no image & - & - & - & - & - & - \\
\hline
\end{tabular}




\begin{tabular}{|c|c|c|c|c|c|c|c|}
\hline 19 & no image & - & - & - & - & - & - \\
\hline 20 & 0_00_03_00 & $\begin{array}{l}\text { FID45 UpRAWS / } \\
\text { hl_field_instruments }\end{array}$ & $\begin{array}{c}\text { FID47 } \\
\text { UpSRefPost / } \\
\text { hl_field_instruments }\end{array}$ & $\begin{array}{c}\text { FID5 Tower2 / } \\
\text { hl_field_instruments }\end{array}$ & $\begin{array}{c}\text { FID49 LoCRefPost } \\
\text { / } \\
\text { hl_field_instruments }\end{array}$ & $\begin{array}{l}\text { FID1 Mustard / } \\
\text { hl_veg_poly }\end{array}$ & $\begin{array}{c}2.568 \\
76\end{array}$ \\
\hline 21 & 0_01_03_00 & $\begin{array}{c}\text { FID46 } \\
\text { UpNRefPost / } \\
\text { hl_field_instruments }\end{array}$ & $\begin{array}{l}\text { FID45 UpRAWS / } \\
\text { hl_field_instruments }\end{array}$ & $\begin{array}{c}\text { FID47 } \\
\text { UpSRefPost / } \\
\text { hl_field_instruments }\end{array}$ & $\begin{array}{l}\text { FID12 Tower3 / } \\
\text { hl_field_instruments }\end{array}$ & $\begin{array}{c}\text { FID5 Tower2 / } \\
\text { hl_field_instruments } \\
\text { FID50 Camera / } \\
\text { hl_field_instruments } \\
\text { FID48 / } \\
\text { LoSRefPost } \\
\text { hl_field_instruments }\end{array}$ & $\begin{array}{c}6.321 \\
17\end{array}$ \\
\hline 22 & 0_02_03_00 & $\begin{array}{c}\text { FID46 } \\
\text { UpNRefPost / } \\
\text { hl_field_instruments }\end{array}$ & $\begin{array}{l}\text { FID45 UpRAWS / } \\
\text { hl_field_instruments }\end{array}$ & $\begin{array}{c}\text { FID47 } \\
\text { UpSRefPost / } \\
\text { hl_field_instruments }\end{array}$ & $\begin{array}{l}\text { FID5 Tower2 / } \\
\text { hl_field_instruments }\end{array}$ & $\begin{array}{c}\text { FID50 Camera / } \\
\text { hl_field_instruments } \\
\text { FID48 / } \\
\text { LoSRefPost } \\
\text { hl_field_instruments }\end{array}$ & $\begin{array}{c}5.642 \\
12\end{array}$ \\
\hline 23 & 0_03_03_00 & $\begin{array}{c}\text { FID46 } \\
\text { UpNRefPost / } \\
\text { hl_field_instruments }\end{array}$ & $\begin{array}{c}\text { FID47 } \\
\text { UpSRefPost / } \\
\text { hl_field_instruments }\end{array}$ & $\begin{array}{l}\text { FID12 Tower3 / } \\
\text { hl_field_instruments }\end{array}$ & $\begin{array}{l}\text { FID5 Tower2 / } \\
\text { hl_field_instruments }\end{array}$ & $\begin{array}{l}\text { FID50 Camera / } \\
\text { hl_field_instruments } \\
\text { FID51_Camera / } \\
\text { hl_field_instruments }\end{array}$ & $\begin{array}{c}3.922 \\
65\end{array}$ \\
\hline 24 & 0_04_03_00 & $\begin{array}{c}\text { FID46 } \\
\text { UpNRefPost / } \\
\text { hl_field_instruments }\end{array}$ & $\begin{array}{l}\text { FID45 UpRAWS / } \\
\text { hl_field_instruments }\end{array}$ & $\begin{array}{c}\text { FID47 } \\
\text { UpSRefPost / } \\
\text { hl_field_instruments }\end{array}$ & $\begin{array}{l}\text { FID50 Camera / } \\
\text { hl_field_instruments }\end{array}$ & $\begin{array}{l}\text { FID49 LoCRefPost } \\
\text { hl_field_instruments }\end{array}$ & $\begin{array}{c}12.95 \\
230\end{array}$ \\
\hline 25 & 0_ $\stackrel{9-}{0} \_03 \_00$ & $\begin{array}{c}\text { FID46 } \\
\text { UpNRefPost / } \\
\text { hl_field_instruments }\end{array}$ & $\begin{array}{l}\text { FID45 UpRAWS / } \\
\text { hl_field_instruments }\end{array}$ & $\begin{array}{c}\text { FID47 } \\
\text { UpSRefPost / } \\
\text { hl_field_instruments }\end{array}$ & $\begin{array}{l}\text { FID5 Tower2 / } \\
\text { hl_field_instruments }\end{array}$ & $\begin{array}{c}\text { FID50 Camera / } \\
\text { hl_field_instruments } \\
\text { FID48 / } \\
\text { LoSRefPost } \\
\text { hl_field_instruments }\end{array}$ & $\begin{array}{c}4.971 \\
49\end{array}$ \\
\hline
\end{tabular}

